\title{
AN EVALUATION OF THREE ALTERNATIVE FORMATS FOR PROBATION VIOLATOR HEARINGS
}

by

Rickey L. Williams and Roger E. Hagen

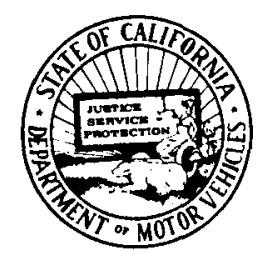

December 1981

Report \#77

Research \& Development Office Ronald S. Coppin, Chief
State of California

Business, Transportation \& Housing Agency

Department of Motor Vehicles Doris Alexis, Director 


\section{PREFACE}

This report is the final product of the project entitled "Optimization of the Probation Violator Hearing Format." The project was funded by the National Highway Traffic Safety Administration through a grant administered by the California Office of Traffic Safety (Grant \#057702). The report was prepared by staff of the Alcohol Traffic Safety/Driver Improvement Study, a special study unit within the Research \& Development Office, California Department of Motor Vehicles. Project activities were conducted under the administrative direction of Ronald S. Coppin, Chief, Research \& Development office.

Several other documents were prepared during the course of the study. The most significant was an interim report, "Driver Improvement: A survey of per sonnel, procedures, and work climate" (Hagen, R. E., and Williams, R. L., Report 72, CAL-DMV-RSS-79-72). Detailed operations and training manuals were also produced (Williams \& Hagen, 1978; and Tosti, Hagen \& Williams, 1978, respectively).

The opinions, findings and conclusions expressed in this publication are those of the authors and not necessarily those of the State of California, the National Highway Traffic Safety Administration, or the Federal Highway Administration. 
ACKNOWLEDGMENTS

The authors wish to express their appreciation and gratitude to all who contributed to completion of the project. Elmer Brown, formerly Chief, Division of Drivers Licenses, deserves special mention. The project effort could not have taken place without his support and enthusiasm. Likewise the authors wish to acknowledge the Project Task Force, and the numerous driver improvement managers, analysts and clerical staff who contributed so much to the development, implementation and completion of the project tasks. The project-related computer programming was undertaken by Programming Team III, Software Applications Unit, Division of Electronic Data Processing. The management information system which they developed contributed to our ability to identify project-assigned drivers, and allowed us to identify several strengths and weaknesses of the caseload approach.

Raymond C. Peck, Research Program Specialist, was responsible for conception of the initial project idea and design. Subsequent project design and manuscript review activities were performed by Ronald Coppin, Raymond Peck, and Edward McConnel1. While final responsibility for the contents of the report rests with the authors, we wish to acknowledge the contributions of each of our reviewers and the assistance of Edward McConnell and Jensen Kuan in the analysis and interpretation of the data.

We would also like to acknowledge the assistance of Don Tosti, and Tosti Associates, in developing the project training course, and to express our appreciation for his guidance during the initial training session.

Finally we would like to thank those who coded the project data, prepared the tables and figures, and typed the many report drafts. Pamela Daugherty, Doris Johnson and Debra Shortino accomplished the first task with remarkable energy and consistency. Linda Moeckley prepared the draft figures and tables and typed the initial report drafts. The final report was completed by Bonnie Grippen, Judy Gunter and Debra Shortino and proofread by Louie Wong. The quality of the final report testifies to the effort and skill of the production staff. 
TABLE OF CONTENTS

PAGE

PREFACE ..............................

ACKNOWLEDGMENTS ............................... i

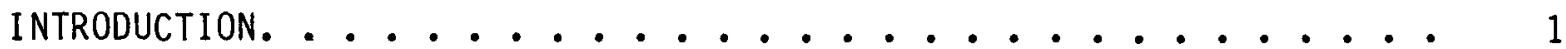

Project Scope and objectives . . . . . . . . . . . . 2

Background ..................... 3

METHODS ........................... . 11

Operational Procedures ................... . . 11

Evaluation Methodology ................. 23

RESULTS • . . . . . . . . . . . . . . . . . . 31

Driver Descriptions. . . . . . . . . . . . . 31

Process Analysis........................ 35

Recidivist Licensing Actions.................. 39

Traffic Safety Impact. .................. 42

Probation Success. .................. 60

Cost-Benefit Analyses. . ................ 61

Procedure and Forms Survey ................ 65

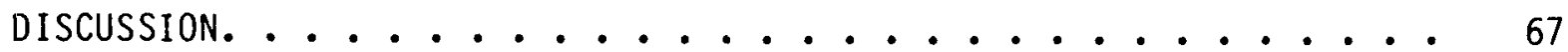

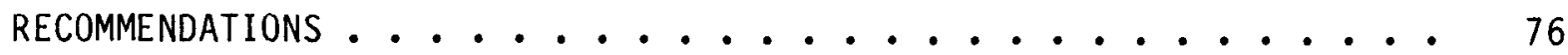

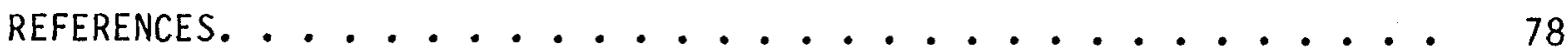

LIST OF TABLES

NUMBER

PAGE

1 Key Features of Three Probation Violator Hearing Formats at Project Entry, and Follow-up Contacts, by Hearing Format .

2 Probation Violator Incidence Rates of Accidents, Convictions Per 100 Drivers (2-Year Prior History)........

3 Probation Violator Incidence Rates of Legal Actions Per 100 Drivers, (2-Year Prior History).......... 33

4 Licensing Actions at Project Entry (Standard Hearing Format).

5 Percentages of Drivers by Number of Hours Allowed Within Daily Time Blocks................. 
LIST OF TABLES (Continued)

NUMBER

PAGE

$6 \quad$ License Restriction Profiles.............. 38

7 Observed and Expected Recidivist Action by Hearing Format . .

40

8 Statistical Tests of the Differences Between Number of Drivers Receiving Licensing Actions and Those Retained on Probation for 14 Months, by Hearing Format. . . . .

9 Number of Drivers by Treatment. . . . . . . . . .

10 Prior Driving Record Variables Discriminating Between Drivers with Varying Subsequent Records of Accidents

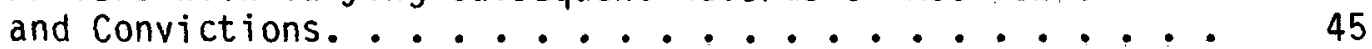

11 Variables Tested for Homogeneity of Regression. . . . . . 46

12 Comparison of Differences in Unadjusted and Adjusted Fatal and Injury Accident Means, by Hearing Format and Regression Assumption. . . . . . . . . . . .

13 Subsequent One-year Traffic Accident and Conviction Means, and Standard Deviations, by Hearing Format . . . . . .

14 Pairwise Comparisons of Hearing Formats on Fatal and Injury Accident Adjusted Means..............

15 Standardized Discriminant Function Weights and Correlations Between the Canonical Variable and Accident Variables, by Accident Type .................

16 Pairwise Comparisons of Hearing Formats on Zero-Point Conviction Adjusted Means...............

17 Canonical Variable Centroids for Accidents and Convictions, by Hearing Format. .................

18 Standardized Discriminant Function Weights and Correlations Between the Canonical Variables and Accident and Conviction Variables, by Type.............

19 Proportions of Drivers Free of Accidents by Follow-up Interval by Hearing Format ...............

Pairwise Group Comparisons of Accident Survival Patterns over One Year.................... 


\section{LIST OF TABLES (Continued)}

\section{NUMBER}

PAGE

21 Proportion of Drivers Free of Convictions by Follow-up Interval by Hearing Format. . . . . . . . . . .

22 Proportions of Drivers Free of Licensing Actions by Time Interval by Hearing Format ............

23 Pairwise Comparisons of Legal Action Survival During the One Year Follow-up................

24 Pairwise Test of Conviction Survival by Project Entry Action--Standard Hearing. . . . . . . . . . . .

Variables Predictive of Driver Accidents, Convictions and Failures to Appear Following Probation Violator Hearings, by Order of Entry in the Discriminant Function Equations and Hearing Format. .................

26 Hearing Unit Cost Estimates 1979 - 1980 . . . . . . .

27 Estimated Accident Costs and Proportions, by Accident Type and Cost Data Source. ...............

28 Numbers and Percentages of PDO Accidents by Reporting Source and Hearing Format . . . . . . . . . . . .

29 Annual Financial Impact Estimates for Fixed Restriction Hearings.....................

\section{LIST OF FIGURES}

NUMBER

1 Macro flowchart of entry scheduling criteria. . . . . . 14

2 Illustration of PV assignment and hearing formats . . . . 15

3 Canonical variable centroids by hearing format--accident discriminant analysis ..............

4. Canonical variable centroids by hearing format--accident and conviction discriminant analysis..........

5 Proportion of drivers remaining accident-free by hearing format--1-year follow-up.............. 


\section{LIST OF FIGURES (Continued)}

NUMBER

PAGE

6 Proportion of drivers remaining free of convictions by hearing format--1-year follow-up...........

7 Proportion of drivers remaining free of licensing actions, by hearing format--1-year follow-up ..........

8 Proportion of drivers in standard hearing format remaining. conviction-free, by project entry licensing action--

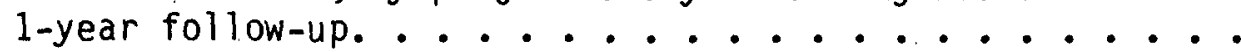

\section{LIST OF APPENDICES}

PAGE

A Exhibits........................

Exhibit A - Order Modifying Probation (Standard Hearing Format) .................

Exhibit B - Probationary Drivers License. . . . . . . .

Exhibit C - Order Modifying Probation. (Restriction Hearing Formats).

Exhibit D - Pre-Hearing Questionnaire.........

Exhibit E - Probation Agreement . . . . . . . . 88

B Probation Violator Evaluation Data Base . . . . . . 89

C Driver Descriptive Data . . . . . . . . . . 93

D Bias Tests. . . . . . . . . . . . . . 98

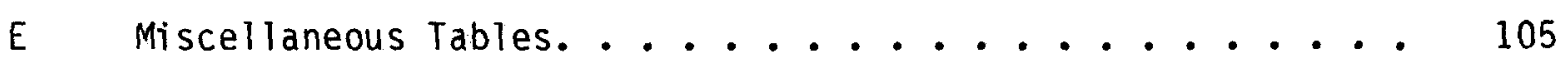

F Overview of PV Project Survey Responses and General Comments. 107

\section{LIST OF APPENDICES TABLES}

A Observed Distributions of Three Unique Treatments in Driver Prior Histories, by Hearing Format.......... 99

B Two-year Prior History Means by Variable and Hearing Format . 100 


\section{LIST OF APPENDICES TABLES (Continued)}

$\underline{\text { NUMBER }}$

PAGE

C Significance of Chi-square Tests in the Log-linear Analysis for Total Accidents.............. 102

D One Year Unadjusted Means, Subsequent Traffic Accidents by Hearing Format, With Wrong or Incomplete Treatments Included ............... 104

E Proportions of Drivers in Standard Hearing Format Remaining Conviction-Free, by Project Licensing Action (1-year

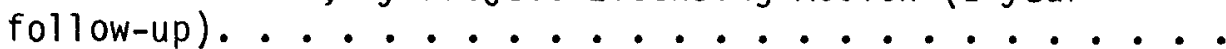

F Subsequent One-Year Traffic Accident and Conviction Adjusted Means. ................. 


\section{INTRODUCTION}

The California Vehicle Code (CVC) categorizes drivers who accrue repeated moving traffic safety convictions as negligent operators. Drivers with repeated major offenses (e.g., driving under the influence, reckless driving, hit and run) in specified time frames face mandatory suspension or revocation of their driving privilege. Such offenses are also assigned two negligent operator points on the driver record. Minor convictions (e.g., speeding, failure to obey traffic control devices, some safety-related equipment defects) receive one point. Other convictions (e.g., failure to register vehicle, no license in possession) appear on the driver record, but receive a point count of zero. The point count associated with an abstract is administratively assigned by the Department of Motor Vehicles (DMV).

In conjunction with the mandatory suspension and revocation program mentioned above, the DMV operates a discretionary driver improvement program, one component of which focuses on the negligent operator. The goal of this program is to reduce the incidence of traffic accidents and convictions. The four basic treatment levels of the negligent operator program are: (1) the warning letter (WL), (2) group educational meeting (GEM), (3) individual hearing (IH) or probation-by-mail, and (4) the probation violator (PV) hearing.

A WL is issued the first time a driver accrues three negligent operator points in 12 months. However, a driver who accrues four points in 1 year, six points in 2 years, or eight points in 3 years is defined as a negligent operator. Drivers certifying under penalty of perjury that they drive more than 25,000 miles per year are allowed two additional points; i.e., 6,8 , or 10 points to qualify them as negligent operators. These screening criteria are chaptered in CVC $\$ 12810$.

Drivers marginally meeting the negligent operator point criteria are usually first assigned to a GEM. GEM subjects who continue to accrue points are placed on departmental probation for 12 months either by mail, or following an IH. Drivers perceived as high accident risks during an IH may receive a license suspension (normally 30-90 days) as an additional condition of probation. The principal requirement of negligent operator probation is that 
the driver not receive a traffic conviction during the 12-month probationary period. Should there be additional convictions, the department may issue a $W L$, extend probation, or schedule a PV hearing. Historically, most PV hearings result in a license suspension (normally 3-6 months), or revocation for 1 year.

The PV hearing follows sequentially as a necessary activity for those who fail to improve their driving while on probation. The primary goal of these hearings, as with all the driver improvement activities described above, is to reduce traffic accidents. Actions selected by the driver improvement analyst (DIA) following a hearing are presumably chosen with accident and violation reduction, rather than punishment, in mind.

Analyses of driver records (Kadel1, Peck, Howe, \& Epperson, 1977; Kade11, Peck, \& Howe, 1978; Kade11 \& Peck, 1979) indicate that 57\% to $75 \%$ of probation violators who receive hearings remain conviction-free for 6 months following the hearing. The reduction is statistically significant when compared to a similar driver group that was untreated. The PV hearing also reduces accidents, at least marginally. Estimates of accident reduction range up to 9.16 accidents saved per 1,000 treated drivers. Finally, the monetary savings to the public (in reduced accidents) have not always exceeded the cost of conducting the probation violator hearing program.

\section{Project Scope and Objectives}

Funding was obtained from the California office of Traffic Safety (0TS 057702) to conduct the project titled "Optimization of the Probation Violator Hearing Format." The project scope, as stated in the grant application, is "...to develop and evaluate new strategies for the probation violator hearing." Major project objectives are to:

- "Develop a behavior modification strategy (including contingency contract methodologies) for use by the DIA in the probation violator hearing setting."

- "Develop a caseload scheduling procedure for the probation violator hearing setting."

- "Train selected DIA staff in the use of the behavior modification and contingency contracting methodologies."

- "Implement and evaluate probation violator hearing formats in selected pilot field offices." 
The first three objectives have been met by prior publications (Tosti, Hagen, \& Williams, 1978; Williams \& Hagen, 1978) and by training more than 100 driver improvement personnel. An interim report (Hagen \& Williams, 1979) was prepared. The interim report contributed to the creation of a divisional task force which explored several issues relating to driver improvement performance and work climate. The present report overviews the completed objectives and fully documents project implementation and evaluation activities.

\section{Background}

The understanding and control of behavior have received great emphasis in psychology in the 20th century. In fact, "behavior modification" has moved from the experimental laboratory to widespread application in the past 30 years. Bandura (1969) provides an excellent exposition on behavior modification theory and practice. Behavior modification has been used to control drug abuse (Callner, 1975; Boudin, 1972), to teach controlled drinking to alcoholics (Sobell \& Sobell, 1972), and to control juvenile delinquency and other problem behavior in children (Zeilberger, Sampen, \& Sloane, 1968; Stuart, 1971; Davidson \& Seidman, 1974; 0'De11, 1974). Franks (1969) reviewed the use of behavior modification to treat an even wider variety of problem human behaviors.

Based upon a limited amount of research, it appears appropriate to apply behavior modification principles and procedures in a driver improvement setting. Ames and Micas (1972) considered the feasibility of such an approach while McGuire and Peck (1977) described a theoretical paradigm whereby such principles could be operationalized. Both of these reports addressed technical issues in applying such principles in a driver improvement setting. Further, Goldiamond (1974) addressed the legal and ethical considerations of purposely applying behavior modification principles in any "real world" setting. Public concerns regarding social control or the purposeful manipulation of behavior must be acknowledged.

The effectiveness of employing various behavior modification principles, specifically reward and incentive, has been addressed in a number of driver improvement evaluations. Harano and Hubert (1974) attempted to influence subsequent driving records of both good and bad drivers through the use of an opportunity to receive a 12-month license extension should they maintain a 
clean driving record for 1 year. Specifically, drivers who were free of collisions and convictions over a 1 year prior period were sent a letter notifying them of a 12-month license extension issued as a "reward" for this accomplishment. They were also told that at the end of the following year, should their records again be clean, they would be recontacted and given a second extension. The results of this reward program indicated no reliable influence on subsequent collisions compared to uncontacted controls.

In the second portion of the study, drivers having one or more prior entries were involved in an incentive program. These drivers were sent a letter describing their eligibility for a 12-month license extension which would be granted provided their records remained free of collisions and convictions over the subsequent year. The results of this incentive program indicated no significant effects on subsequent convictions, but various beneficial effects on subsequent collisions compared to controls.

It was recommended that a driver improvement program be established on an experimental basis wherein drivers with prior entries be involved in an ongoing incentive program in conjunction with a group educational meeting. At the meeting, appropriate behaviors could be identified and rehearsed. The incentive (be it an extension, a reduction in point count, or some other predetermined reinforcer) should then increase the future likelihood of the newly learned behaviors. A program of this kind, concentrating on the marginally deviant drivers mentioned above, would have the advantage of reaching a much larger number of drivers than the driver improvement methods applied to the relatively small number of drivers who meet the vehicle code definition of a prima facie negligent operator.

Marsh (1978) randomly assigned 17,662 negligent operators to one of six programs or a control group. One treatment was the present group educational meeting (GEM), three were modifications of the GEM, and two treatments were programmed-learning homework tasks. One of the nonclassroom programs provided an incentive for return of the homework and maintenance of a clean driving record. Driving records were inspected for accidents and convictions during the 1 year after treatment. Onily the nonclassroom homework with incentive program showed significantly fewer accidents than the control, and that reduction was restricted to the second 6 months after treatment. When data 
from additional GEM and control samples were combined with the original data, the GEM's accident rate was significantly below the control during the first 6 months, indicating that it was effective as an accident countermeasure. None of the experimental classroom programs were significantly (or even directionally) superior to the GEM in reducing accidents or convictions during the first 6 months. All treatments except the nonclassroom homework without incentive were effective in reducing subsequent convictions.

Kleinknecht (1969) used a combination of negative reinforcement ${ }^{1}$ and punishment $^{2}$ in a driver improvement project. A group of drivers who maintained conviction-free records after being identified as problem drivers were reinforced by having restrictions on their driving privilege decreased at 2-week intervals. Drivers who received a further conviction during a 24-week period were punished by a suspension and/or return to an earlier, more severe restriction stage.

Kleinknecht's procedures did not allow the drivers any say in the schedule of restrictions and suspensions. This schedule of restrictions and suspensions nonetheless approximated a contingency contract, since drivers were informed of the expected behavior and resulting consequences. Such contracts are a very effective method of establishing the mutual responsibilities and benefits to be received by two or more parties (Kazdin, 1975). Kazdin emphasizes the importance of negotiation in using contingency contracts. The importance of negotiation in human social exchange has also been stressed by social psychologists. Rubin and Brown (1975) reviewed many aspects of negotiation behavior. Differences in outcome with varying bargaining strategies (e.g., winner-take-all or cooperative strategies) and the importance of intangible issues such as the perceived status of the bargaining opponent were reported. The models presented support Kazdin's views on contingency contracts.

The design of the Kleinknecht study included a total of four groups. The first group has already been described. The second group received noncontin-

\footnotetext{
INegative reinforcement-removal of adversive stimulus to Increase the likellhood the behavior that preceded it will reoccur in the future.

2punishment--introduction of an adversive stimulus to decrease the likelihood the behavior that preceded it will reoccur in the future.
} 
gent restriction removal. In other words, drivers in group two received progressive removal of restrictions (and no punishment) regardless of their driving record. Both groups also attended five evenings of group discussion concerning traffic safety. A third group was contacted, and received only the traffic safety discussion. Finally, a fourth group received the standard probationary procedures employed in the State of Washington; i.e., an extended probationary period, or a license suspension.

All drivers were males, aged 18 to 35, with at least 2 years of driving experience. They had accrued either five convictions (or more) in 24 months, four convictions and an accident in 24 months, or had been placed on probation and then received an additional conviction.

Drivers with performance-contingent restriction removal did not have better traffic records throughout the entire 9-month follow-up period, compared to the other three groups. The evidence did suggest, however, that some control over driving behavior was achieved during the first 3 months. Drivers with performance-contingent restriction removal performed better than both the noncontingent restriction removal group and the education group on mean time to first conviction or accident (during the first 3 months) and on mean number of convictions and accidents per driver (during the first month).

There are at least two potential explanations of these results. First, Kleinknecht (1969) made no attempt to customize restrictions to driver needs, nor were the restrictions negotiated with the driver. These are the very activities that Kazdin (1975) cites as the greatest strengths of contingency contracting. The actual writing out of the agreement, with signatures by both parties, serves to maximize the impact of the contingency contract. The fact that contracts may be negotiated for mutual benefit and modified to suit changing circumstances certainly adds to their appeal and effectiveness. Secondly, the short follow-up period and small sample size (286 drivers di-. vided among four groups) resulted in low statistical power, especially for the analysis of accident impact. Such circumstances could easily result in a failure to detect a real difference in treatment effects. Current practice in California DMV negligent operator studies calls for sample sizes of several thousand, particularly when accidents are included as a dependent variable. 
Individual expectations also appear to modify the likelihood that problem driving behavior will continue following a hearing. Schuster (1970, 1971) hypothesized that drivers' evaluation of their own performance is based at least partially on feedback from the licensing agency. Manipulation of licensing actions produced correlational evidence that severe actions (e.g., license suspension for marginal offenders), or moderate actions for drivers with aggravated records were associated with increased convictions following the hearing.

Even when licensing action severity is not manipulated, suspension or revocation of the driving privilege fails to deter many negligent operators from driving. At least $33 \%$ of suspended drivers and $68 \%$ of revoked drivers continue to operate a motor vehicle, as evidenced by violations and accidents during the period of licensing action (Coppin \& van 0ldenbeek, 1965). This estimate must be considered conservative, since it is based upon drivers who had some type of driver record entry. It does not reflect the incidence of driving that did not result in a reported accident or conviction.

There are several apparent reasons for continued driving while under licensing action. First, the risk of detection and conviction is 1ow. Coppin \& van 01 denbeek (1965) found that only about $33 \%$ of the convictions obtained by suspended or revoked negligent operators in California during the period of licensing action were specifically for violating the licensing action. A more recent estimate (NHTSA, 1979) suggests that only $25 \%$ of suspended or revoked drivers who receive a moving violation during a period of licensing action are adjudicated for violating their license suspension. Such low conviction rates are partially explained by the courts' concern with proof-ofservice of the action. The courts are reluctant to prescribe the mandatory penalty for driving while suspended or revoked unless there is a signed statement on file with DMV indicating that the driver was informed of the licensing action. Further, in California a conviction often does not result because the courts do not contact DMV and are not aware a suspension or revocation exists (Finkelstein \& McGuire, 1971).

Anecdotal evidence suggests that some suspended or revoked negligent operators will continue to drive in order to protect or continue their livelihood while curtailing other driving. The difference between the driver who 
who ignores the licensing action entirely and the driver who simply wishes to maintain employment sometimes emerges in statements by drivers in the hearing; e.g., "I'm going to drive no matter what you do" as compared to "I've got to get to work." This is substantiated by a similar finding for drivers who lost their driving privilege for multiple drunk driving convictions (Hagen, McConnell, \& Williams, 1980).

While suspension or revocation is an all-or-none sanction, restrictions may be varied along three dimensions-time, vehicle, and place (or purpose). Thus, license restriction offers a greater opportunity to select a licensing action which will deter unsafe driving, while allowing the driver to meet basic transportation needs. Negotiation of the restriction conditions removes a major shortcoming of the procedures used by Klejnknecht, and addresses driver transportation needs. A signed contract maximizes the impact of the hearing process, and if necessary, may be used by the courts to establish proof-of-service.

Thus far, we have discussed techniques which focus on the actions taken to improve driving behavior. Inherent in these techniques is the presumption that increased knowledge of the driver is required in order to negotiate a meaningful contingency contract and to oversee performance during the specified follow-up period. ${ }^{3}$ It also seems likely that the very process of negotiating a mutually satisfactory contract will lead to some degree of rapport between the driver and the Driver Improvement Analyst (DIA). These gains in knowledge and rapport are valuable and should be maintained to extend treatment impact throughout the probationary period.

Social welfare workers and probation officers also require knowledge of and rapport with people in order to bring about changes in behavior. These professions have traditionally relied upon caseload assignment strategies to meet such requirements. Clients or probationers are assigned to a specific caseworker or probation officer who performs an evalution of needs, plans a

\footnotetext{
We anticlpated that a formal, mutually negotiated contingency contract in a driver improvement setting should increase a driver's commitment. to safe driving. This is of particular importance because of the observation that "...risk taking and negligent driving is often reinforced by nonoccurrence of accidents and citations and may result in varlous sociopsychological rewards..." (Peck, 1976).
} 
program of activities or actions, and monitors performance. Such work tasks bear a great similarity to those of driver improvement personnel.

It seemed to us that certain case management techniques could be used to maximize and preserve both knowledge of drivers and rapport with drivers gained through face-to-face contacts. These techniques are:

- case assignment of probationary drivers to a specific DIA,

- systematic monitoring of driver performance by the assigned DIA, and

- periodic communication and feedback on performance between the DIA and the driver during the period of probation subsequent to a hearing.

Since the purpose of the present project was to maximize the impact of the probationary process on driving performance, rather than to separately measure the relative contributions of contingency contracting or caseload management, we chose to adopt and integrate both techniques. The design of the present study, then, is based on the following concepts:

- The present PV hearing and PV licensing actions have not resulted in the desired degree of accident reduction.

- Negligent operators expect to lose the driving privilege if they violate probation. A negotiated license restriction offers the driver a desirable alternative to loss of the driving privilege.

- License restrictions may be designed to meet transportation needs expressed by the driver, while also controlling and eliminating unsafe driving. Thus, the legitimate traffic safety responsibilities of the department and the driver may be met without removing the driving privilege altogether.

- A negotiated contingency contract is the preferred means of describing licensing sanctions, conditions of probation, and the respective obligations of the department and the probation violator. The process of signing the contract serves to formalize the driver's commitment to behavior change.

- Case assignment allows the DIA to develop in-depth knowledge of probation violators with whom repeated hearings are conducted. Secondly, in-depth knowledge could result in more appropriate actions after a hearing, thereby producing changes in driver behavior leading to decreased traffic accident involvement.

- Case assignment fosters increased mutual knowledge and rapport between the driver and the DIA. 
- Periodic performance review and follow-up contacts between the DIA and the probationary driver provide the driver with the reinforcement required to shape and maintain responsible driving behavior.

- Case monitoring provides DIAs with feedback on the outcome of their driver improvement activities.

- Making the avoidance of responsible accidents an explicit condition of probation will serve to emphasize the true traffic safety goal of the PV hearing. 
METHODS

Operational Procedures

The following section of the report describes scheduling criteria and procedures for conducting PV hearings as they existed prior to the PV project, as well as the three hearing formats used during the course of the project. The two new hearing formats incorporated major changes in scheduling criteria and hearing tasks. They also required additional follow-up contacts with drivers. The selection of project personnel and hearing points and the specialized training which project personnel received are also described.

The development of project procedures was a joint undertaking between the project staff, a driver improvement task force, and driver improvement management. Driver improvement trainers also provided their expertise during the project developmental phase. Research staff took the lead role in developing procedures, while driver improvement staff made innumerable contributions, both in these developmental decisions and through contribution from their wealth of driver improvement knowledge. Driver improvement management reviewed all products of the developmental phase including an operational procedures manual and a training manual.

Research staff conducted a needs analysis prior to procedure development. Activities undertaken included screening taped probation violator hearings, sitting in on hearings and discussing these monitoring activities and our impressions with those who conducted the hearings which were monitored in person. Project forms were reviewed by the driver improvement task force and distributed for field testing prior to project implementation.

Scheduling Procedures Prior to Study. Drivers are scheduled for PV hearings following a review of the driver record. Prior to the project, this review process was conducted exclusively at DMV headquarters. A copy of the record was generated for manual review upon receipt of a traffic conviction by a probationary driver. Major convictions were screened for possible mandatory actions necessitated by multiple offenses. Probationary drivers receiving a major conviction, but not qualifying for a mandatory suspension or revocation, were usually scheduled for a hearing. 
Guidelines for scheduling PV hearings on the grounds of minor convictions were based on the following accumulation of convictions after the effective date of probation:

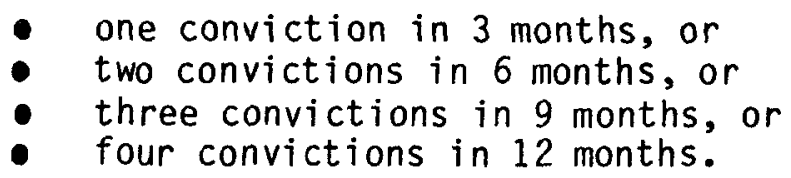

However, drivers whose records satisfied these criteria were not necessarily scheduled for a hearing since the ultimate decision to schedule was entirely at the discretion of the reviewing DIA. In all cases probation was extended 12 months from the date of the last conviction, but drivers were not always informed of the extension. Drivers whose records did not meet these time criteria, but perhaps included accidents, violation of a suspension or revocation, failures to appear (FTA) in court, or lack of liability insurance at the time of an accident usually were scheduled for a PV hearing. Finally, it was apparent that little standardization existed in the operational application of the scheduling procedures.

Scheduling Procedures During Study. Scheduling procedures and criteria for PV hearings were changed statewide during the PV project. First, all criteria were automated, eliminating discretionary review by headquarters DIAs. Secondly, criteria for the first hearing under the new system (entry hearing) and subsesquent (recidivist) hearings ${ }^{4}$ were different. Finally, drivers receiving countable convictions while on probation, but not qualifying for a hearing, began receiving a letter from the department either informing them that DMV was aware of the conviction or was actually extending probation by 4 months because of the conviction.

A hearing was scheduled upon receipt of a major conviction (two points). Driving during a suspension resulted in a hearing only if there were less than 60 days remaining in the duration of the suspension. A one-point conviction within 4 months of the probation effective date, or two one-point convictions within 9 months, also resulted in a hearing being scheduled. $A$ single one-point conviction 4-8 months from the probation effective date resulted in a 4-month probation extension letter, while a single one-point

${ }^{4}$ Recidivist criterlal are described on page 19. 
conviction after the eighth month resulted in a WL. Accidents were not used in the entry criteria since there was some question as to whether such action was legally permissible without specific notification to the driver. The order of probation (previously issued) required only that the driver remain conviction-free for 12 months from the effective date of probation. A macro flowchart of these scheduling criteria is displayed in Figure 1.

The intent of the scheduling criteria changes was to increase consistency in the scheduling process. At the same time, the types of convictions which always resulted in a hearing were expanded to reflect the perceived traffic safety hazard of the violation. Drivers who remained conviction-free for months at a time were given more lenient treatment upon receipt of the first one-point conviction. Furthermore, whenever probation was extended, the driver was informed of the reason for, and the duration of the extension.

Three hearing formats were used in the project. Probation violators were assigned to one of the three treatments in accordance with the randomily assigned terminal digit of their drivers license. Figure 2 illustrates this assignment process and overviews the basic structure of each format.

Hearing Formats. The standard hearing, the format orginally in use, served as the comparison condition against which two new formats were assessed. While some changes in scheduling criteria were made, procedures for conducting the standard hearings remained virtually unchanged. The major distinctions in procedures between hearing formats are shown in Table 1 . There are differences between the standard hearing format and the caseload hearing formats on each of these parameters. The two caseload formats differ at project entry only in the number of stages specified in the contingency contract. These differences are reflected in the number of contacts during the followup period. Finally, the use of restriction as a recidivism countermeasure was discouraged for the fixed restriction hearing format and encouraged in the sequential hearing format.

Standard hearings were scheduled for 30 minutes. The DIA typically advised the driver of legal rights, explained the hearing notice, reviewed the driver record, and asked the driver to describe any accidents. Drivers were also allowed to present evidence regarding their driving records. Additional communication from the analyst could include: defensive driving tips, a lecture 


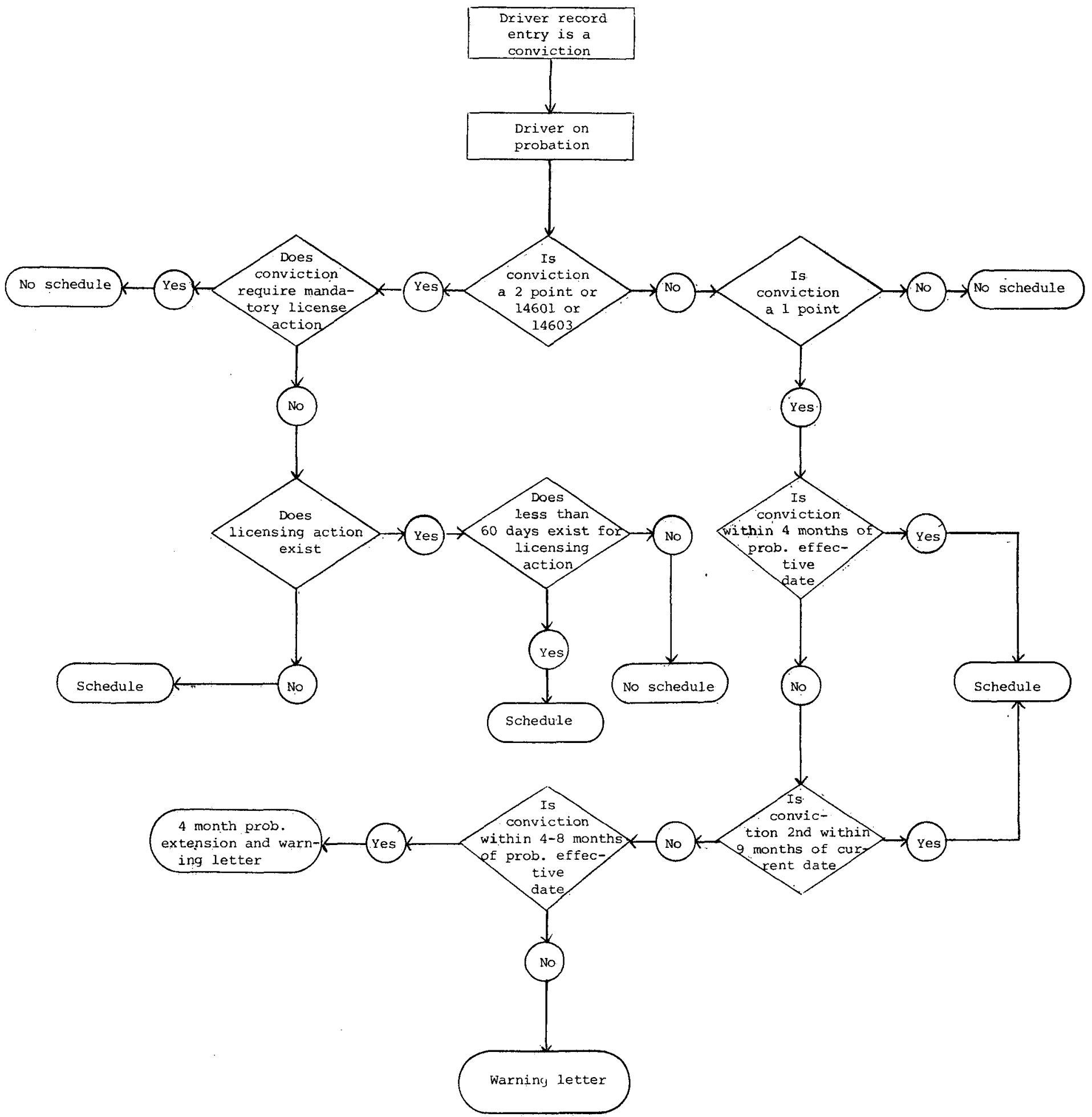

Figure 1. Macro flowchart of entry scheduling criteria. 


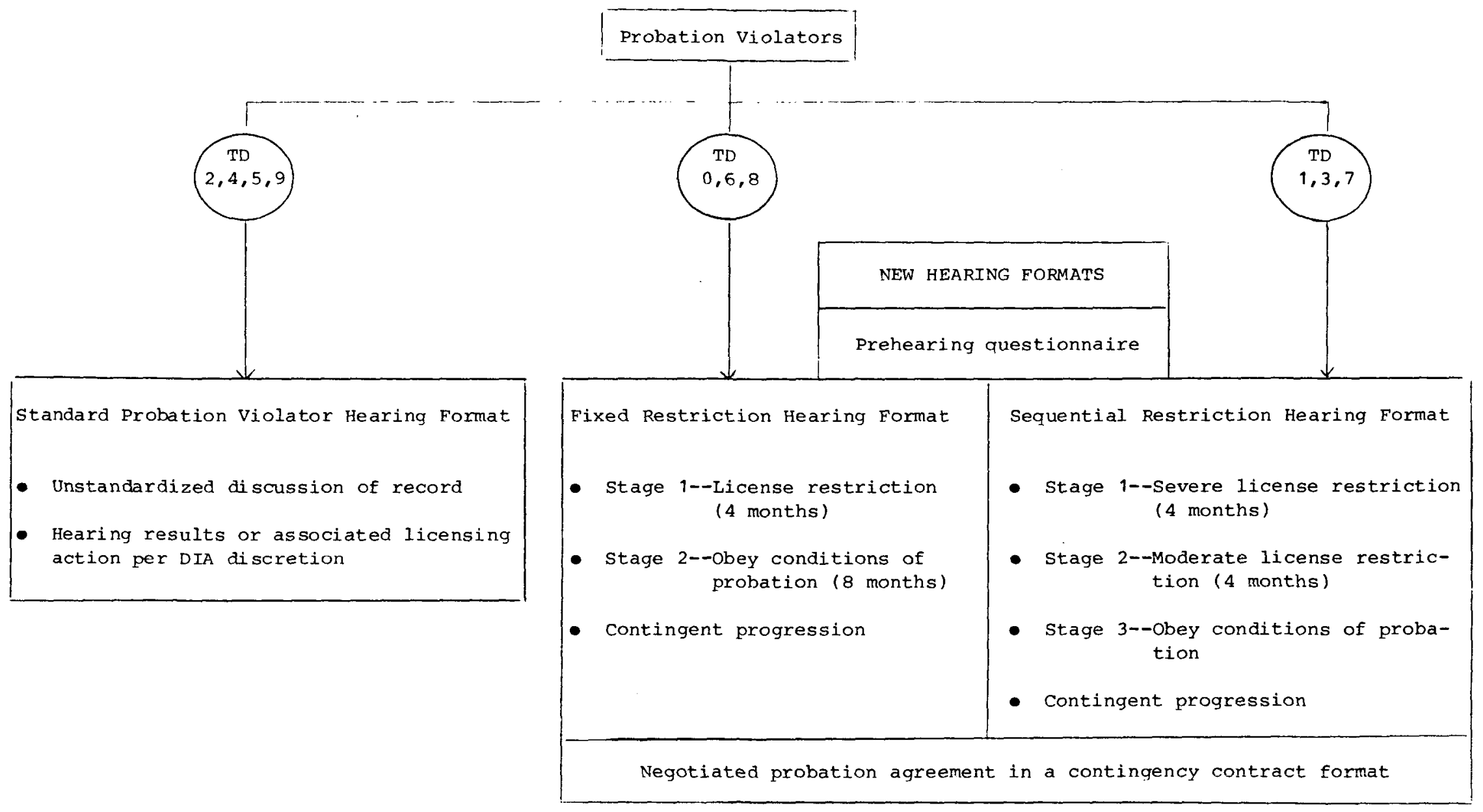

Figure 2. Illustration of PV assignment and hearing formats. 
Table 1

Key Features of Three Probation Violator Hearing Formats at

Project Entry and Follow-up Contacts, by Hearing Format

\begin{tabular}{l|l|l|l}
\hline Hearing format components & \multicolumn{3}{|c|}{ Hearing tormat } \\
\cline { 2 - 4 } & $\begin{array}{l}\text { Standard } \\
\text { hearing }\end{array}$ & $\begin{array}{l}\text { Fequential } \\
\text { restriction } \\
\text { restriction }\end{array}$ \\
\hline
\end{tabular}

PROJECT ENTRY

\begin{tabular}{|c|c|c|c|}
\hline $\begin{array}{l}\text { Hearing duration (mi nutes) ........................ } \\
\text { Licensing actions available }\end{array}$ & 30 & 60 & 60 \\
\hline 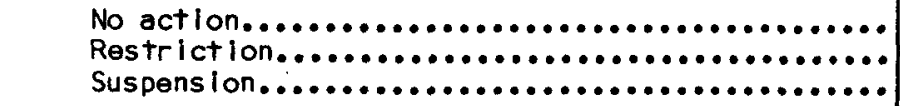 & $\begin{array}{l}\text { Yes } \\
\text { Rare } \\
\text { Yes }\end{array}$ & $\begin{array}{l}\text { No } \\
\text { Always } \\
\text { No }\end{array}$ & $\begin{array}{l}\text { No } \\
\text { Always } \\
\text { No }\end{array}$ \\
\hline Revocation $\ldots \ldots \ldots \ldots \ldots \ldots \ldots \ldots \ldots \ldots \ldots \ldots \ldots \ldots \ldots$ & Yes & No & No \\
\hline 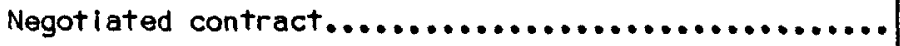 & No & Yes & Yes \\
\hline
\end{tabular}

SCHEDULED FOLLOW-UP ACTIVITIES

\begin{tabular}{|c|c|c|c|}
\hline 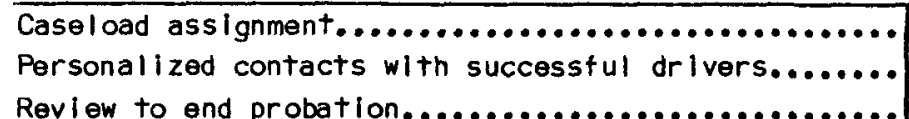 & $\begin{array}{l}\text { No } \\
\text { Headquarters }\end{array}$ & $\begin{array}{l}\text { Yes } \\
2 \\
\text { Fleld DIA }\end{array}$ & $\begin{array}{l}\text { Yes } \\
3 \\
\text { Field DIA }\end{array}$ \\
\hline
\end{tabular}

UNSCHEDULED FOLLOW-UP ACTIONS

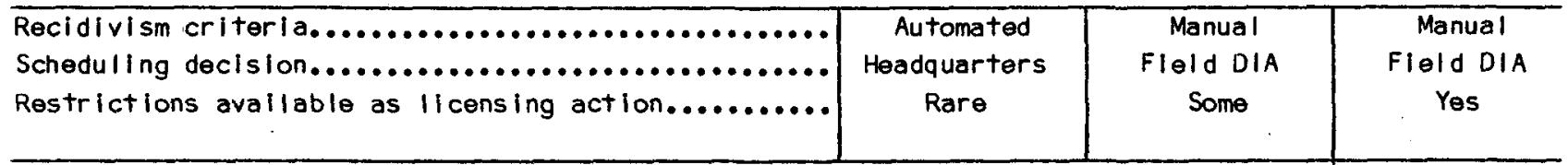

on increased accident likelihood, an analysis of the high cost of traffic fines and other expenses resulting from a poor driving record, or a general discussion of the value of the driving privilege.

The major change from past practice was to inform drivers that accident responsibility (but not mere accident involvement) was to become a valid reason for future record review and possible suspension or revocation. The driver was issued a form (DL-202A) describing the modification of probation (see Appendix A, Exhibit A). The license was collected and stamped "PRoBATION" on the face and "License valid only subject to the conditions of probation shown on a current form DL-202A" on the reverse side (see Exhibit B). This form was identical, except for wording, to those used in the two new hearing formats to specify restrictions on the driving privilege. 
Following the hearing, the DIA reviewed the evidence presented, wrote a summary report, and made recommendations. Driver attitude and "insight" into the problem were often mentioned in the case evaluation. Such insight can best be described as individual admission of wrongdoing, acceptance of responsibility for past actions, and an ostensibly sincere promise of future improvement. Drivers exhibiting these behaviors were less likely to be perceived as future accident risks. Licensing actions taken following the hearing could range from an extension of probation (with or without license suspension for 30-180 days) through revocation of the license for 1 year. Most drivers received a license suspension (and extended probation) or revocation. As mentioned above, the conditions of probation were modified to include accident responsibility. Actions recommended by the DIA were reviewed by senior DIA staff. The reviewer had the authority to impose a licensing action in the name of the department. Thus the reviewer, not the analyst, had the final say in the outcome of the hearing.

The two new hearing formats made use of driving restrictions, negotiated with the driver in the form of a contingency contract. The number of restriction stages was fixed by project procedures, while the duration of actual restriction stages could vary from 2-4 months. The severity of restrictions and the type of restrictions chosen were left to the discretion of the DIA, although some examples of reasonable restrictions were provided.

The fixed restriction hearing made use of a restricted driving privilege during the first 2-4 months from project entry. Only necessary driving, or minimal risk exposure was allowed during this time. Unrestricted driving was allowed during months 5-12.

The third format, the sequential restriction hearing, was the most complex and also made use of the restricted driving privilege. This format required three stages of driver control during the 12-month probation period. During Stage I (usually months 1-4), only necessary driving, or minimal risk exposure was allowed. During Stage II (usually months 5-8), some recreational driving, or moderate risk exposure was allowed. Finally, Stage III (months 9-12) allowed unrestricted driving.

Drivers in the fixed or sequential restriction hearing formats were also 
informed of the possibility of an additional hearing, should they be responsible for a future traffic accident. Their licenses were also stamped (Exhibit B), and they were instructed to carry the form DL-202A. This form contained the restriction(s) on their driving privilege (Exhibit $C$ ). Drivers in the sequential restriction hearing format received three forms, as illustrated. Only the first and third forms (designated first and second) were used with drivers in the fixed restriction hearing format. Like all probationary drivers, they were required to obey the provisions of the vehicle code and all traffic regulations. Additionally, these drivers agreed to report any traffic convictions, traffic accidents, or address changes to the caseload DIA within 10 days.

Both of the restriction hearing formats were scheduled in 60-minute time blocks, as opposed to 30 minutes for the standard hearings. During the first 15 minutes, the driver was to complete a questionnaire (Exhibit D) describing demographic information (name, address, employer, occupation, and marital status), driving exposure (vehicles, annual mileage, and years of experince), driving needs (purpose and time), and transportation alternatives. The DIA had this time to complete a previous hearing report or to review the current driver record before the scheduled hearing.

The new restriction hearing formats not only changed the focus of the hearing (i.e., from attitude change to behavior change), they also required that the DIA perform a greater number of specific tasks during the hearing than was true in the standard hearing. These tasks were:

- Confirm the driver's understanding of the hearing notice and legal rights.

- Briefly discuss the driver's background, career, or interests in order to indicate interest and put the driver at ease. Use information from the questionnaire as a starting point.

- Briefly review the recent additions to the record to confirm the violation of probation.

- Secure agreement from the driver to working towards positive goals in the hearing; i.e., maintaining the driving privilege and finding behavior changes that will eliminate future convictions and accidents.

- Prompt drivers themselves to come up with behavioral solutions to the problem. Record solutions (behavior) and ask the drivers for an appraisal of their utility. 
- Explore transportation needs and priorities, using information from the prehearing questionnaire information to guide the discussion.

- Propose a license restriction as a means of meeting the driver's needs and the mutual traffic safety responsibility of the driver and the department. Whenever possible, incorporate into the restrictions the behavioral change suggestions proposed by the driver.

- Discuss restrictions with the driver and determine a mutually acceptable probation agreement (a contingency contract).

- Write out the agreed upon restrictions on the preprinted probation agreement (see Exhibit E). Explain the printed conditions of probation. Obtain driver's initials, next to the preprinted conditions, and signature on the form. Sign form as representative of department. close the hearing.

As in the standard hearing format, DIAs conducting the new hearings were responsible for writing a summary report for the driver's legal file. The restrictions on the driving privilege, negotiated between the DIA and the driver, were reviewed only to the extent necessary to preserve legal safeguards. Changes in recommended actions from those mutually negotiated were rare and usually were merely clarifications of word choice regarding restrictions.

Recidivist Scheduling Criteria. Recidivist criteria for all three formats were similar, in that accident responsibility was made grounds for scheduling a recidivist hearing. (The driver was informed of this condition of probation at the entry hearing.) Mere accident involvement was not necessarily equated with accident responsibility. In the standard hearing format, the following types of accidents (when reported by law enforcement) were deemed responsible accidents and resulted in hearing scheduling when they occurred within 4 months of the PV entry hearing:

1. driver cited or held responsible by the reporting officer;

2. driver ran off the road, hit a pedestrian, or hit a fixed object; or

3. driver was reported to be under the influence of alcohol or other drugs.

If there was also a conviction on the record since the last hearing, a hearing was scheduled in response to such accidents, regardless of when the accident occurred after the entry hearing. Any two accidents after the entry 
hearing, regardless of type or reporting source, resulted in a hearing being scheduled.

The conviction criteria used in scheduling entry hearings were also used to define conviction recidivism, except that the date of the last PV hearing, rather than the probation effective date, was used in all time-based criteria. This change in scheduling criteria was predicated on the assumption that discretionary actions taken following a hearing are in response to all violations that have occurred up to that time. Printouts generated by accidents or convictions were routed directly to the scheduling unit. They were not routinely reviewed prior to hearing scheduling.

For the fixed restriction and sequential hearing formats, any conviction or accident addition following the entry hearing generated a driver record printout, and required a scheduling decision by the assigned caseload DIA. While DIAs were given the standard hearing scheduling criteria as a guideline, complete discretion and responsibility for the decision was theirs. Options included no action, sending a WL, extension of probation with driver notification, and scheduling a recidivist hearing. The recidivist hearing provided the opportunity (in addition to the above options): to impose or extend restrictions, to suspend the driving privilege for 30-180 days, or to revoke the driving privilege for 1 year. Use of restrictions at a recidivist hearing was discouraged in the fixed restriction hearing format, but cases where this occurred were retained in the evaluation.

The rationale for giving the caseload DIA complete scheduling discretion (while denying such authority to the headquarters review analyst) was three-fold:

1. The caseload DIA would be familiar with the record and, having conducted the prior hearing and follow-up contacts, would know more about the driver than could be contained in the legal file.

2. In cases where the driver had made a self-report of the accident or conviction, as required in the probation agreement, the caseload DIA would know any extenuating circumstances regarding the incident in question.

3. Caseload DIAs were to be given a greater sense of personal responsibility for the outcome of their actions than were analysts conducting standard hearings. 
Follow-up Contacts. No systematic follow-up contacts were made in the standard hearing format. Instead, record review and hearing scheduling activities for this group were conducted at headquarters. Field DIAs therefore had little information concerning whether or not drivers they had seen in the past successfully completed probation.

The fixed and sequential restriction formats included systematic contacts at the end of each restriction stage and upon successful completion of probation. The DIA reviewed the driver record, congratulated the driver either by telephone or by letter and advanced the driver to the next (more lenient) probation stage by issuing a new DL-202A (Exhibit C).

Unscheduled contacts (WL, probation extension letter, and recidivist hearing) were also made by the field DIA in response to any convictions or responsible accidents which were accrued after project entry. Drivers who reported such involvement to their assigned DIAs had the opportunity to influence them in making their scheduling decisions by presenting any extenuating circumstances.

Project Hearing Points and Personnel. The new hearing procedures were introduced in 18 of the department's 23 driver improvement districts. In all, this involved 44 (out of 150) hearing points statewide. The project hearing points conduct approximately two-thirds of all PV hearings. Selected hearing points were those where two or more DIAs normally conducted hearings, and which also had an estimated volume of at least two PV hearings per week.

Approximately 2 months into the project, it became apparent that the number of drivers assigned to the caseload hearing formats would exceed DIA availability (or did not justify use of the hearing point) at four project locations. These hearing points were therefore dropped from the project to the extent that no additional drivers entered the project from those hearing points. Drivers entering the project prior to removal of the hearing point from the project were retained in the evaluation data base. Retention was based on the fact that project follow-up procedures were maintained for drivers who had already entered the project at the time the decision to delete the hearing point was made.

DIAs who normally covered the selected hearing points were alternately divi- 
ded into two groups. One group continued to conduct the standard hearings; the second received special training and conducted the new restriction-format PV hearings at assigned project hearing points. The second group was categorized as project DIAs. AIl DIAs continued to perform their other assignments (i.e., group educational meetings, reexaminations, and individual hearings):

Three DIAs were removed from the project (or given 1 imited caseloads); when it was discovered that they were having difficulties with project procedures and demands. Drivers assigned to these caseloads were not used in the evaluation. One analyst was dropped from the project prior to implementation after voicing strong personal objections to project procedures.

A number of analysts and managers rotated to new assignments, were promoted, or retired during the course of the project. Specific caseload transfer procedures were provided to handle such circumstances.

Training. Project DIAs and managers of districts containing project hearing points received extensive training in interviewing skills, negotiation skills, proactive diagnosis, contingency contracting, and all project procedures. Upper management also participated in training. Participation in small group discussions and role-playing exercises was emphasized and required of all trainees. All of the role-playing exercises and most of the small group discussions took place in three-member groups (triads). Video and audio tapes provided models demonstrating interviewing and negotiation skills, as well as the major hearing procedures.

A training consultant with expertise in contingency contracting participated in designing the training course, the production of a draft of training materials (finalized in Tosti et al., 1978), and conduct of the first training course. Project staff performed the final edit of the training manual and produced the video and audio models (from scripts written by the consultant) in cooperation with driver improvement training staff.

Remaining training sessions prior to project implementation were conducted by the Research \& Development staff, supported by driver improvement trainers. The five initial training sessions lasted 24 hours and ranged from 13-16 in class size. Seventy-five driver improvement managers and analysts were 
trained initially. Further, clerical staff from each project district received training relative to their duties and responsibilities.

The project pilot phase began with project training and continued through the first 6 weeks of implementation. During the pilot, project staff answered procedural questions posed by driver improvement personnel, as did the ODL Quality Control and Driver Improvement Control units. Answers to questions regarding specific cases or individual concerns were provided to all requesters. Questions which raised issues of general concern or resulted in procedural changes (usually concerning paperwork, discretionary decisions, or clarification of responsibilities) were addressed in two revisions to the operations and procedures manual during the pilot period (Williams \& Hagen, 1978) and in a series of memos circulated to all project personnel throughout the project.

Project staff screened audio tapes of hearings conducted during the 6-week pilot period. Audits of required paperwork, such as the probation agreements, were performed throughout the project. Project staff visited seven district offices to conduct additional training and to discuss procedures. clarity of language in specifying restrictions is an example of a problem necessitating additional training. In other instances, telephone communication between project staff and a DIA or manager was sufficient to clarify project needs. Telephone contacts were maintained with driver improvement personnel by the Research \& Development staff throughout the course of the project.

Staff hiring and rotation resulted in 17 analysts and managers joining the project after operations began. These personnel also received the project training. Four such sessions were conducted, with class size ranging from 2-9. Training was typically conducted in 2 days (16 hours).

\section{Evaluation Methodology}

This section of the report describes the selection of drivers for the project, available data, and five evaluation components. These components are defined as follows. (1) Driver descriptions summarize data obtained from the driver record, the prehearing questionnaire and the probation agreement (where the latter documents were available). Summaries include demographic 
information and driving history. (2) The process analyses focused on the licensing actions recommended by driver improvement analysts at the project entry hearing and the licensing actions taken in response to further driver recidivism. In addition, the process of ending probation was also examined. (3) The traffic safety impact analyses were designed to detect differences in traffic accident and conviction means which might be attributed to different treatment modes and to describe and test the duration of treatment impact. (4) The driver success analyses were designed to assess the impact of variables other than hearing format on driver success in completing probation within 1 year following the project entry hearing. (5) Finally, the costbenefit analyses was performed in order to compare the accident reduction (societal monetary savings) achieved by each hearing format with the associated cost of conducting such hearings.

Briver Descriptions. Drivers entered the project upon receipt of a traffic conviction during negligent operator probation. Drivers varied in their prior history of negligent operator hearings. For some, the project entry hearing was perhaps the first one-on-one meeting with a DIA. At the other extreme, some drivers had received one or more prior PV hearings and had past records of suspension or revocation. Thus, drivers entering the project represented the entire mix of probation violators in the department's ongoing post-licensing control program.

Existing procedures for selecting hearing points were maintained during the project. Drivers who qualified for a PV hearing were scheduled at the hearing point which normally would be assigned, based upon the latest home address of record. No special effort was made to schedule PV hearings to project hearing points.

Drivers were assigned to one of the three evaluation groups on the basis of the last digit of the drivers license number. This terminal digit (TD) may be considered a random number. Some drivers, however, failed to attend the scheduled hearing and thus did not receive the treatment contained in the assigned hearing format. In other instances, drivers received an incorrect treatment--one other than that based on random assignment--or an incomplete treatment. The Research \& Development staff chose to exclude these drivers from the data analysis. A full discussion of the rationale for this decision 
and the implications regarding potential introduction of bias in the statistical results are discussed in Appendix $D$.

Detailed demographic data were available for drivers in the experimental treatments, while only age, sex, and hearing point were available for the standard treatment group. Driver accident, conviction, and licensing action histories were available for all drivers for the 2 years prior to project entry and 1 year afterwards. A complete listing of variables contained in the data base is contained in Appendix $B$.

Examples of demographic variables are occupation, exposure to high-risk driving situations, and driving needs. Departmental action histories include past warning letters, GEMs and hearings scheduled, hearing attendance, restrictions, and suspensions or revocations based on a wide variety of legal grounds (e.g., repeated major convictions, prior negligent operator hearings, lack of liability insurance, or failures to appear in court as promised).

Process Analyses. The licensing actions taken by DIAs following both project entry hearings and hearings resulting from later recidivism were examined. Differences between hearing formats which were due to discretionary choices by DIAs were noted. The number of drivers receiving licensing actions due to recidivism was compared to the number of drivers completing probation within one year. Again, differences between the hearing formats were noted.

Traffic Safety Impact Analyses. The major null hypotheses in the traffic safety impact analyses were:

- There is no difference in driving performance between drivers assigned to the three hearing formats, whether measured by traffic accidents or traffic accidents and convictions combined.

- There is no difference in the survival rate following treatment for drivers in the three groups, whether measured by time to first accident or time to first traffic violation with conviction.

A series of secondary analyses were designed to probe for possible explanations of traffic safety differences between treatment groups. They address potential experimental biases, as well as process differences across hearing formats. The null hypotheses were: 
- No differences in prior history variables existed between drivers assigned to the three hearing formats.

- No driver characteristics or prior history variables will exert differential effects across hearing formats on the measure of traffic safety impact.

Discussion of several technical issues is in order prior to further description of the traffic safety analyses. The first issue concerns the criteria for statistical significance. Unless otherwise stated, this criteria (alpha) was set at $p<.10$. Secondly, all $t$ tests were two-tailed. The third technical issue is the basis for covariate selection. Prior studies conducted by the Research \& Development office indicate that driver age, sex, and driving history should be considered as covariates. Total convictions and FTAs, total accidents, and total suspensions and revocations represent the typical driver history covariates used in past studies. These variables were selected as potential covariates in the present project prior to examining the data. A stepwise discriminant analysis was used to probe prior driver history data for other appropriate covariates. The following variables were analyzed, in addition to those listed above: major convic-tions, fatal and injury accidents, total days suspended or revoked, and number of mandatory suspensions and revocations. In addition, contingency table analysis was used to explore the relationships between prior history variables, hearing format and subsequent accidents and convictions.

Traffic safety impact was analyzed using multivariate analysis of covariance (MANCOVA). A series of MANCOVAs were performed using accident and conviction histories. Both types of outcome measures were of interest. Furthermore, these measures were known to be intercorrelated (Kwong, Kuan, \& Peck, 1976; Peck \& Kuan, 1979). Thus, univariate tests alone would not have shown the very patterns of results that were of interest. At the same time, the planned analysis could have resulted in misinterpretation of certain patterns of effects. For example, it is not unusual for the driver at fault in a serious accident to receive a traffic conviction. Other drivers committing a similar violation, but remaining accident-free, may avoid a conviction or be convicted of a lesser charge. By first examining traffic accidents separately, we insured that this critical impact measure would not be obscured by the possible circular effects described above. 
Tests of slope differences were conducted to test whether the data met an important MANCOVA assumption (i.e., homogeneity of regression slopes). Since MANCOVA results are sometimes difficult to interpret when prior history interacts with treatment outcomes, contingency tables analysis was used to model the data. Log-linear analysis techniques, when applied to contingency tables, are not subject to the same interpretation problems. The log-linear results therefore were useful in determining whether to proceed with MANCOVA in the presence of significant slope differences.

Several statistics are available for testing the significance of the multivariate analysis of variance. The most common of these are Roy's largest root criteria, Wilk's Lambda, Hotelling's $T$ statistic, and Pillai's criterion. Debates continue among statisticians regarding the situations under which each is appropriate: e.g., Harris (1975), pp. 109-113; Overall \& Klett (1972), pp. 317-319; Bock (1975), pp. 154-155; 01son (1976, 1979); and Stevens (1979). The guideline used in the present study was based upon the number of dimensions in the data which were significant at $p=.15$, the default value in the computer program. Where only one characteristic root was significant, Roy's largest characteristic root statistic was used. Significance levels of this statistic are tabled in Harris (1975). Where two or more characteristic roots were significant, Wilk's Lambda was used.

A number of follow-up techniques were used to interpret significant multivariate statistical tests. The rationale for the research strategy used is contained in Borgen \& Seling (1978). First, a series of one-way ANOVAs were conducted to assess the individual contribution of each dependent variable to hearing format differences. When significant differences were obtained using ANOVA, futher pairwise tests were conducted using the least significant difference method (LSD), in order to isolate the actual group means producing the statistically significant ANOVA. The above strategy serves to isolate sources of group separation, but does not take correlations between the dependent variables into account. A limitation of the LSD method is that it results in nominal significance levels that exceed the true experiment-wise significance levels (Carmer \& Swanson, 1973; Keselman, Games \& Rogan, 1979). However, the inflationary effect on significance levels would be modest because of the small number of contrasts and requirement of a significant ANOVA. 
The data structure was analyzed using discriminant analysis. This technique is described in nonmathematical terminology in Nie, et al. (1975). Such an analysis yields several products which describe the data structure. Each discriminant function corresponds to independent sources of variance in the data. Group positions are described by centroids, or averages, on a canonical variable. As Nie et al. explain, each discriminant function is produced by weighting scores on the dependent variables originally collected (e.g., fatal and injury accidents, property damage accidents) in such a way as to maximize the distance between the centroids for each discriminant function. The centroids thus describe the relative positions of the hearing formats on the canonical variable (i.e., the composite variable obtained for each dimension in the data). The contribution of the orginal variables (e.g., accidents) to the canonical variable is shown by discriminant function weights. When these weights are standardized, so that they range from -1 to +1 , they show the unique contributions of each dependent variable to the separation between groups.

Direct interpretation of the discriminant function weights, however, does not present a complete picture of the data structure of the dependent variables, which are seldom uncorrelated. The formulas used in calculating the discriminant functions make use of the variance unique to each dependent variable and largely ignore the overlapping or common variance between variables (i.e., the covariance). Treatments (in this case, hearing formats) may exert changes in the relationships between the dependent variables, i.e., their covariance. Thus, covariance should not be ignored if data structure is of interest. Only when the dependent variables are uncorrelated--which is uncommon when several related data measures are collected from the same person--may the standardized discriminant function weights be directly interpreted. The structure matrix, on the other hand, shows the correlation of each dependent variable to the canonical variable for each dimension in the data. These correlations, in most instances, are more meaningful interpreting he relative importance of the dependent variables which yield a significant MANCOVA than are the standardized discriminant function weights or the one-way ANOVA tests (Borgen \& Seling, 1978).

The duration of treatment impact (changes in treatment impact over time) was also of interest. These changes were documented through survival rate 
analyses. The proportion of drivers in each treatment group who remained accident- and conviction-free was tested at 4-month intervals. A third survival rate analysis was based on probation failure, defined as: any extension of probation, any increased restriction, and any suspension or revocation.

Driver Success Analyses. The null hypotheses tested in this section were that no driver characteristics or prior history variables will correlate with driver success or failure within each hearing format.

Discriminant analysis was used to explore the relationship between the prior history and entry-action variables, and driver success or failure to complete probation. These analyses were conducted within each hearing format.

Cost-Benefit Analyses. Program costs were documented by the departmental Management and Operations Analysis unit and concurred in by DDL prior to their use in the PV hearing evaluation. Accident costs and the proportions of various accident types among negligent operators were taken from Kadell and Peck (1979).

The basis for the cost-benefit analysis was differences between the three hearing formats in total accident means. In interpreting mean differences, one must take into account the variability and sampling error in the data. Unless the difference between two means is statistically significant, these differences may be ascribed to chance or sampling error. Under such circumstances, one may state that by definition there is no real difference between the two means. Nevertheless, these means represent a best estimate of real population values and have some utility in decision making, particularly when no additional data regarding the population values are available. The latter argument has been presented earlier in Garretson \& Peck (1979). These two theoretical positions, both of which are valid within the area of decision theory, are in conflict with each other. This conflict produces a dilemma regarding cost-benefit analysis.

The pivotal question concerns the validity of carrying out a benefit-cost analysis based on sample means which do not exhibit a statistically significant difference. The DMV Research \& Development office has chosen to take the 
position that sample means, whether significantly different or not, may be used as the basis for a cost-benefit analysis. Of course, variance in the data (and sampling error) must also be taken into account in the program implementation decision. In recognition of these issues, expected benefits to be derived from implementing alternative programs are stated as $90 \%$ confidence intervals. In addition, the probability of a net loss, based on the sample means and variability, is also calculated. 
RESULTS

The analyses of questionnaire and driver record data are presented in this section of the report. Results are organized into: driver descriptions, process analyses; traffic safety impact analyses; driver success analyses; and cost-benefit analyses.

Driver Descriptions

The descriptions of probation violators are based upon both driver records and the prehearing questionnaire. Questionnaire responses were solicited from drivers in the fixed restriction and sequential restriction hearing formats. Recall that drivers were assigned to hearing formats by a random process. Since $99 \%$ of those drivers questioned filled out the questionnaire, these data may be considered representative of all probation violators who attended hearings at project hearing points. A more detailed description of driver responses is contained in Appendix $C$.

Probation violators were predominantly males $(97 \%)$, aged $20-25$ (53.8\%, mode = 22 , mean $=26.69)$. By way of comparison only $8.81 \%$ of all licensed California drivers are males between 20-25 years of age. The mean age of all licensees is 39.7 for males and 39.3 for females (DMV, 1981). It appears that young males are thus overrepresented in the probation violator population. Fifty-nine percent of probation violators were single, $27.7 \%$ were married, and the remainder were separated, divorced or widowed. The most commonly reported occupations were craftsmen and foremen (31\%), professional drivers (13.4\%), and salespersons (7.6\%). It appears that craftsman and foreman, as well as professional drivers, are overrepresented among probation violators in comparison to negligent operators in general (Coppin \& Samuels, 1961; Marsh \& Hubert, 1974).

Most drivers identified their primary driving need as going to and from work $(66.7 \%)$ or driving on the job $(25 \%)$. More than $73 \%$ reported that their primary need occurred sometime between 0600 - 1200, Monday through Friday and $65 \%$ reported a like need between 1201-1800 on these days. Further, their primary vehicle was 5-7 years 0ld, typically a passenger car (56.8\%), or, 
less commonly, a pickup or jeep (17.8\%). Only $7.6 \%$ reported a motorcycle as their primary vehicle.

Just over $70 \%$ of those surveyed reported driving over 15,000 miles per year (median $=15,000-20,000 ;$ mode $=$ over 30,000$)$. Most had been driving less than 10 years (mean $=9.43$; median $=6.76$ ). Driving after 10:00 p.m. during the last month was frequently reported; the average number of nights was 12.9. The most common response, however, was 20 nights. Furthermore, $8.5 \%$ reported driving "to let off steam," while $11.5 \%$ admitted driving after consuming three or more drinks during the last month.

Examination of driving records for all 3,295 drivers produced the following profiles of reported driving incidents during the 2 years prior to project entry (see Table 2). The accident rates reported indicate that probation violators are approximately five times as likely to have had an accident as the average California driver and more than three times as likely as all 20-24 year old males to have been involved in a traffic accident (DMV, 1981). The percentages of fatal, injury, and property damage accidents reported are consistent with earlier data obtained from PLCRES (Kadell \& Peck, 1979).

The conviction rates of probation violators are extremely high (3.8 convictions per driver annually). Less than $1 \%$ of all California drivers perform this poorly (DMV, 1981). A comparison of the proportion of major convictions to total convictions reveals, however, that the conviction pattern of probation violators is nearly identical to that for all California drivers.

The legal histories indicate that only about $25 \%$ of probation violators had received a license suspension or revocation at any time in the prior 2 years. It was possible for a driver to have received either mandatory or discretionary actions, or both simultaneously. Prior hearing attendance rates reflect only scheduled hearings; drivers receiving probation-by-mail were tallied separately. Further, the reported rates obscure multiple hearings and drivers whose probation periods had been extended (because of traffic convictions) without a hearing being scheduled. These rates perhaps best reflect the likelihood of recent prior face-to-face contact. Most drivers (91.47\%) had attended an individual hearing, rather than receiving probation- 
Table 2

Probation Violator Incidence Rates of

Accidents, Convictions Per 100 Drivers

(2-Year Prior History)

\begin{tabular}{|c|c|c|}
\hline Incident by type & $\begin{array}{l}\text { Events per } \\
100 \text { drlvers }\end{array}$ & $\begin{array}{c}\text { Percent of } \\
\text { total }\end{array}$ \\
\hline Total accidents.............. & 63.13 & 100.00 \\
\hline $\begin{array}{l}\text { Fatal .................. } \\
\text { Injury................... } \\
\text { Property damage.......... }\end{array}$ & $\begin{array}{r}.30 \\
22.40 \\
40.43\end{array}$ & $\begin{array}{l}.48 \\
35.50 \\
64.00\end{array}$ \\
\hline Total convictions............. & 760.86 & 100.00 \\
\hline $\begin{array}{l}\text { Two-point............... } \\
\text { One-point................ } \\
\text { Zero-point............. }\end{array}$ & $\begin{array}{r}42.40 \\
615.36 \\
103.10\end{array}$ & $\begin{array}{r}5.57 \\
80.88 \\
13.55\end{array}$ \\
\hline
\end{tabular}

Table 3

Probation Violator Incldence Rates of Legal Actions Per 100 Drivers (2-Year Prlor History)

\begin{tabular}{|c|c|}
\hline Incident by type & $\begin{array}{l}\text { Events per } \\
100 \text { drivers }\end{array}$ \\
\hline Legal HIstory & \\
\hline $\begin{array}{l}\text { Mandatory II cense S\&R*.... } \\
\text { DIscretionary II cense S\&R. } \\
\text { Prior hearlings attended... } \\
\text { Prior hearlings** not } \\
\text { attended.................. }\end{array}$ & $\begin{array}{r}6.49 \\
26.07 \\
77.63 \\
16.93\end{array}$ \\
\hline
\end{tabular}

*S\&R is suspension or revocation.

**Driver scheduled for hearing, but did not attend.

by-mail. The average duration of probation at project entry was 14.85 months.

The average recency of the last violation prior to the project entry hearing was 96.3 days. The time lags between violation and conviction dates, the time required for the courts to forward the conviction abstract to DMV, the time required for DMV to update the driver record files and the availability of a DIA to conduct the hearing all contribute to the lag between the violation date and the probation violatior hearing. By comparison, Finkelstein \& McGuire (1971) reported that the average lag between a violation and a negli- 
gent operator hearing was 152 days. Visual inspection of many driver record files left us with the impression that, for most probation violators, the most recent conviction of record was that which triggered the scheduled hearing. Even if this impression is untrue (i.e., an additional conviction was accrued between the event triggering hearing scheduling and the actual hearing), it is evident that the PV hearing does not immediately follow the act of violating probation.

A number of drivers had unique prior histories in that driver improvement contacts and, in some cases, licensing actions had been either modified or withheld. More specifically, $8.53 \%$ had received probation-by-mail rather than probation following an individual hearing, $1.03 \%$ had probation withheld following a hearing, and $8.29 \%$ had at least one departmental contact delayed by assignment to a hands-off control group for the ongoing post-licensing control reporting and evaluation study (PLCRES). Probation-by-mail was first implemented as an experimental alternative to the individual hearing in 1977. Under this procedure, a hearing was held only when requested by the driver upon receipt of an order of probation from DMV (Sherman \& Ratz, 1979). Less than $10 \%$ of all drivers receiving probation by this process between 1977-78 requested an individual hearing. Thus, for most drivers who received probation-by-mail, the PV hearing was probably the first one-on-one meeting with a DIA. The no action project compared the department's individual hearing, which usually results in probation, to a treatment consisting of a hearing followed by no licensing action (Garretson \& Peck, 1979). Drivers in the latter group, by definition, had received an individual hearing or probationby-mail in addition to their no action treatment and had subsequently violated probation. Drivers assigned to a PLCRES control group had all discretionary treatments withheld for 18-36 months unless they accrued more than five convictions in 1 year. The treatment previously delayed or withheld could have been at any of four treatment levels: warning letter, group educational meeting, individual hearing, or probation violator hearing. See Carpenter \& Peck (1980) for the most recent PLCRES status report. Again, a driver had to have achieved probationary status to become a probation violator.

Operational limitations. A number of drivers were not included in the project evaluation. For the most part, circumstances beyond the control of 
driver improvement or research personnel led to the decision to exclude drivers from the project data base. For example, legal constraints prevented limiting the driving privilege of a probation violator on the basis of a traffic accident until such time as the driver was informed face-to-face of this change in the conditions of probation. Similarly, departmental policy defines a discretionary license suspension or restriction as an idle act if the affected driver is already under a mandatory suspension or revocation of like or greater duration. It was possible for such a mandatory action to be imposed (e.g., for failure to maintain accident liability insurance) in the interim between hearing scheduling and hearing attendance. In such instances, drivers were removed from the project data base.

While no exact tally of drivers who failed to appear for the project entry hearing was maintained, it is estimated that several hundred drivers were excluded until such time as they attended a hearing. It is not uncommon for 20-30\% of all scheduled PV hearings to result in driver nonattendance. In the present study, the no-show rate for the three hearings would be expected to be the same; hence, with exclusion of no shows, it did not introduce a bias.

Other reasons for excluding drivers from the project data base were: invalid probations and other hearings cancelled by the department (52 cases); (2) drivers who incurred a mandatory licensing action between the time the driver qualified for treatment and the hearing date. (85 cases); (3) wrong treatment or incomplete treatment (213 cases)--many of these were the result of the driver appearing for the hearing at a time or place other than that originally scheduled; (4) drivers with no California drivers licenses (15 cases); and (5) drivers whose records were not available at the end of the follow-up period, or who were deceased (8 cases).

\section{Process Analysis}

Described in the portion of the Results section are the licensing actions received by drivers at the project entry hearing, recidivist licensing actions and procedures for ending probation.

Licensing actions. The standard hearing incorporated the most commonly used licensing actions; i.e., "no action" (a 12-month extension of probation with- 
out concurrent suspension of the driving privilege), suspension (ranging from $30-180$ days) in conjunction with 12 months of probation, or revocation (complete withdrawal of the driving privilege for 1 year). Licensing actions resulting from the entry hearing for the standard group are shown in Table 4 . Nearly half (49\%) of these drivers received no suspension or revocation. The most common suspensions (41.5\%) ranged from 30-90 days. Less than $10 \%$ received the maximum suspension ( 6 months) or revocation.

Table 4

Licensing Actions at Project Entry (Standard hearling format)

\begin{tabular}{c|c|c}
\hline Action & $\begin{array}{c}\text { Number } \\
\text { of } \\
\text { drivers }\end{array}$ & $\begin{array}{c}\text { Percentage } \\
\text { of } \\
\text { drivers }\end{array}$ \\
\hline No action............. & 669 & 48.65 \\
30 day suspension.... & 203 & 14.76 \\
60 day suspension.... & 257 & 18.69 \\
90 day suspension.... & 111 & 8.07 \\
120 day suspension... & 9 & .65 \\
6 month suspension... & 57 & 4.15 \\
Revocation............. & 69 & 5.02 \\
\hline
\end{tabular}

Orivers in the fixed restriction and sequential restriction groups received time, vehicle, or geographic restrictions on their driving privilege, or some combination thereof. Ninety-eight percent of all drivers signed the probation agreement. Additionally, .5\% failed to initial the pre-printed conditions of probation, although they did sign the document. Only 10 drivers (.3\%) completely refused to negotiate restrictions. In those cases, restrictions were imposed by the department. It appears that DIAs were almost entirely successful in establishing a contingency contract in the PV hearing.

The duration of the first restriction (which was the only restriction for the fixed restriction group) averaged 116 days for all restricted drivers combined. Only 5\% of all restricted drivers received an action of shorter duration. Restricted drivers, on the average, were allowed to drive 86.33 hours per week (range 2-168) during the first restriction stage. If drivers 
who received only vehicle, purpose or geographic restrictions are eliminated, the average number of hours allowed per week was 75.75. By way of comparison, the driving hours allowed per week during the first 4 months were also computed for the standard hearing group. The average number of hours allowed for this group was 120 (range $0-168$ ).

The average-hours-allowed estimates should not be interpreted as an absolute measure of driving exposure. They describe potential driving hours rather than the number of hours actually driven. As such, the variable is a means of comparing licensing actions which at first glance have no common measurement scale. It serves to quantify the observation that many drivers in the standard hearing received no driving limitations at project entry while all drivers in the remaining formats received a driving restriction.

Driving needs were reflected in the time restrictions which were ultimately ordered by the department for drivers in the two restriction hearing formats. Recall that $65 \%$ of all drivers responding to the prehearing questionnaire said they needed most to drive Monday through Friday between 0600-1800. Inspection of Table 5 indicates that over $70 \%$ of all restricted drivers were allowed to drive at all hours between 1200-1800, Monday through Friday. Nearly 50\% were allowed all hours between 0600-1200 on these days. The table columns show three hourly totals (out of seven possible for each six-hour time block) which clearly account for most of the restrictions used. Note that while some weekend driving was allowed, this option was less commonly used than allowing driving during weekdays. The use of " 3 hours allowed" during the 0600-1800 time blocks (the middle column) was noticeably more prevalent on the weekends.

Examination of the total number of hours of driving allowed per week (see Table 6) revealed that seven profiles accounted for fully $40 \%$ of all time restrictions. Five of these totals were interpreted in terms of needs expressed by drivers and the data describing commonly used time blocks (Table $3)$. These interpretations represent the five most commonly used restriction patterns. The sixth and seventh totals may be interpreted in more than one way. They are essentially variations on other restrictions. 
Table 5

Percentages of Drlvers by Number of Hours Allowed Within Dally TIme Blocks

\begin{tabular}{|c|c|c|c|c|}
\hline \multirow{2}{*}{ Time block } & \multicolumn{3}{|c|}{$\begin{array}{l}\text { Number of } \\
\text { hours al lowed' }\end{array}$} & \multirow{2}{*}{$\begin{array}{l}\text { Cumulat Ive } \\
\text { percentages }\end{array}$} \\
\hline & 6 & 3 & 0 & \\
\hline \multicolumn{5}{|l|}{ Monday - Friday } \\
\hline $\begin{array}{l}0001-0600 \ldots \ldots \\
0601-1200 \ldots \ldots \\
1201-1800 \ldots \ldots \\
1801-2400 \ldots \ldots\end{array}$ & $\begin{array}{l}22.5 \\
49.5 \\
71.2 \\
26.8\end{array}$ & $\begin{array}{l}.5 \\
2.2 \\
1.7 \\
3.6\end{array}$ & $\begin{array}{r}59.1 \\
6.5 \\
2.8 \\
30.7\end{array}$ & $\begin{array}{l}82.1 \\
58.2 \\
75.7 \\
61.1\end{array}$ \\
\hline Saturday - Sunday & & & & \\
\hline $\begin{array}{l}0001-0600 \ldots \ldots \\
0601-1200 \ldots \ldots \\
1201-1800 \ldots \ldots \\
1801-2400 \ldots \ldots\end{array}$ & $\begin{array}{l}15.1 \\
21.0 \\
25.6 \\
17.0\end{array}$ & $\begin{array}{r}8.1 \\
19.2 \\
25.6 \\
10.0\end{array}$ & $\begin{array}{l}66.1 \\
39.3 \\
37.7 \\
51.5\end{array}$ & $\begin{array}{l}89.3 \\
79.5 \\
88.9 \\
78.5\end{array}$ \\
\hline
\end{tabular}

IOther total hours allowed (e.9., 1-2, 4-5) are excluded.

Táble 6

License Restriction Profiles

\begin{tabular}{c|c}
\hline $\begin{array}{c}\text { Percentage } \\
\text { of restricted } \\
\text { drivers }\end{array}$ & $\begin{array}{c}\text { Hours al lowed } \\
\text { per wék } \\
N=1,920\end{array}$ \\
\hline 11.5 & 168 \\
7.1 & 60 \\
5.3 & 144 \\
4.6 & 72 \\
4.5 & 120 \\
4.3 & 84 \\
3.0 & 78 \\
\hline 40.3 & \\
\hline
\end{tabular}

The most commonly used pattern (168 hours allowed) represents the maximum number of hours in a week. These cases therefore represent geographic, purpose or vehicle restrictions. All cases analyzed for the fixed and sequential restriction did contain a restriction in some form. The second 
most common hourly total (60 hours) was most likely to have allowed driving from 0601-1800, five days per week. Monday through Friday were most likely to have been the five days.

The next hourly total (144 hours) suggests a more complex restriction pattern, namely driving at all hours six days per week, or driving at all hours five days per week, with an additional 12 hours on each of the remaining days. The fourth hourly total (72 hours) suggests that 12 hours of driving were allowed on each of six days. The six days were probably Monday through Friday and either Saturday or Sunday. The pattern of 120 hours allowed per week probably represents driving at all hours, five days per week. The five days were most commonly Monday through Friday. It should be noted that no attempt has been made here to describe the relationship of time restrictions to other restriction types. Thus, for example, a driver who was limited to a maximum of 60 hours per week may also have received purpose, geographic or vehicle restrictions.

Only $33.2 \%$ of the restricted drivers received geographic or destination restrictions. The most common were: to and from work $(36.7 \%)$; to, from, and during work (34.6\%); and during work only (15.7\%). Vehicle restrictions were used even less commonly (14.6\%). Most common were: employer's vehicle (or class 1 vehicle) only (31\%), no motorcycles (26.8\%), some combination of vehicle time or destination $(21 \%)$, and owner's vehicle only $(18.6 \%)$.

\section{Recidivist Licensing Actions}

An examination of the licensing actions used as a result of recidivism (i.e., either convictions, accidents, or both) is in order at this point. Licensing actions, of course, are not predicated entirely upon convictions or accidents occurring after project entry. Differences in operational procedures existed between hearing formats; hence, the placement of these results in the process analysis rather than with the traffic safety impact analyses. The major differences in procedure between the standard hearing and the two restriction hearing formats are centralized, automated review for the standard hearing and manual review of driver records by the caseload DIA. It is also likely that, upon holding a hearing, any DIA would react differently to identical conviction or accident histories for drivers whose prior histories of licensing actions differed. 
The mean number of suspensions and revocations, exclusive of those received at project entry was .278, .256, and .245 for the standard hearing, fixed restriction hearing and sequential restriction hearing formats, respectively. The statistical test indicated that these mean differences were not significantly different, $\underline{F}(2,3288)=1.60$. This is not to say that there were no differences between the hearing formats in the licensing actions chosen. Chi-square goodness-of-fit tests indicated that use of warning letters and extensions of probation was not the same across hearing formats. The $x^{2}$ for warning letters and probations were 75.81 and 10.24 , respectively, both $p$ $<.001$ at $\underline{\mathrm{df}}=2$. Visual inspection of Table 7 suggests that use of warning letters was less likely than expected in the standard hearing format and more likely than expected in the two restriction hearing formats. Extensions of probation, on the other hand, were used more than anticipated in the standard hearing format and less than expected in the other hearing formats. A similiar test of suspensions and revocations indicated no significant differences between hearing formats, $x^{2}=2.55, \underline{\mathrm{df}}=2$, NS.

Table 7

Observed and Expected Recidivist Action by Hearing Format

\begin{tabular}{|c|c|c|c|}
\hline \multirow{2}{*}{ Hearing format } & \multicolumn{3}{|c|}{ Type of licensing action } \\
\hline & $\begin{array}{l}\text { Warning } \\
\text { lotter }\end{array}$ & $\begin{array}{l}\text { Extension } q^{f} \\
\text { probation }\end{array}$ & $\begin{array}{l}\text { Suspension } \\
\text { or revocation } 3\end{array}$ \\
\hline \multirow[t]{2}{*}{ Standard hearing........ } & 73 & 235 & 382 \\
\hline & 156.07 & 196.97 & 360.13 \\
\hline \multirow{2}{*}{ Fixed restriction........ } & 151 & 110 & 245 \\
\hline & 108.51 & 136.94 & 250.39 \\
\hline \multirow[t]{2}{*}{ Sequential restriction... } & 150 & 1.27 & 236 \\
\hline & 109.42 & 138.09 & 252.48 \\
\hline
\end{tabular}

Note: Observed Expected

$1^{2}=75.81, \underline{d f}=2, \underline{p}<.001$.

$2 X^{2}=10.24, \underline{d f}=2, \underline{p}<.001$.

$3 . X^{2}=2.55, \underline{d f}=2, n . s$.

The time durations between the project entry hearing and recidivist actions extending probation (i.e., probation extension, and suspension of the driving 
privilege), as well as revocations, was also of interest. The proportions of probation violators within each hearing format remaining free of increases in probation, or revocation of the driving privilege (project entry action excluded), were tested at three points in time using survival analysis techniques. The results indicated that the standard hearing format had a significantly greater ( $\mathrm{p}<.05)$ proportion of probation violators receiving at least one such action than did either of the restriction hearing formats. This was due, of course, to the greater use of license extensions in the standard hearing format. The restriction hearing formats did not differ significantly from each other. These results are described in detail in the survival analyses section of the report, and are compared there to the traffic safety impact related survival analyses.

Terminating probation. The differences between the hearing formats in recidivist actions have al ready been discussed. As part of the process analysis, it is also worthwhile to ask how these actions relate to the volume of drivers completing probation within 12 months. Percentages of drivers remaining free of licensing actions (other than the project entry action and driver requested changes) were 59.56, 64.85, and 63.59 for the standard hearing, fixed restriction hearing, and sequential restriction hearing, respectively. Warning letters were not defined as recidivist actions in this analysis, since they did not affect the duration of probation. It is interesting to contrast these percentages with the percentage of drivers within each hearing format who were not actually removed from probation within $131 / 2$ to $141 / 2$ months. The latter percentages were 51.82, 61.40, and 60.90 for the three hearing formats, as above. All statistical tests of the differences in the number of drivers receiving licensing actions and those whose license still retained the probation flag were significant at $p<$ .05 for all hearing formats, as shown in Table 8. Since the magnitude of $x^{2}$ is dependent on sample size, these tests may not be compared directly across hearing formats. The $x^{2}$ were therefore converted to phi-squared. The phi-squared scores indicated that the disparity between the number of drivers receiving licensing actions due to recidivism and the number of drivers retained on probation beyond 12 months was clearly greater in the standard hearing format. 
Table 8

Statistical Tests of the Differences Between Nimber of Drivers Recelving Llcensing Actions and Those Retained on Probation for 14 Months, by Hearling Format

\begin{tabular}{c|c|c|c}
\hline \multirow{2}{*}{ Statistlc } & \multicolumn{3}{|c}{ Hearing format } \\
\cline { 2 - 4 } & $\begin{array}{l}\text { Standard } \\
\text { hearing }\end{array}$ & $\begin{array}{c}\text { Fixed } \\
\text { restriction }\end{array}$ & $\begin{array}{c}\text { Sequential } \\
\text { restriction }\end{array}$ \\
\hline Chi-squared........ & $25.43^{* *}$ & $6.49^{*}$ & $4.54^{*}$ \\
.009 & .003 & .002 \\
\hline
\end{tabular}

$$
{ }^{*} p<0.05 .001 .
$$

Traffic Safety Impact

Two tests of traffic safety impact were conducted. First, accident impact alone was tested. This was followed up by tests of accidents and convictions combined. This report section begins with the tests of biases in the data, describes the covariate selection process and explores the relationship of covariates, the traffic safety impact variables, and the hearing format.

Bias. Testing. Drivers were assigned to a hearing format on the basis of the terminal digit (TD) of the drivers license number. The number of drivers entering each hearing format and the expected group sizes (based on the planned proportions of 40-30-30) are shown in Table 9. The statistical test $\left.\left\langle x^{2}=4.16, \underline{d f}=2, \underline{p}\right\rangle .10\right)$ indicates that the proportions of drivers obtained in each hearing format are consistent with expectations based on the driver assignment: procedures.

Drivers who did not receive the randomly assigned hearing format were excluded from the project data base. The decision to exclude drivers who did not receive the randomly assigned treatment was made a priori. Such a strategy served to maintain the distinctions between treatments in the data analyses. It was recognized that such exclusions could introduce biases in the analyses. Testing for biases indicated, however, that inclusion of those cases not used because of incomplete or incorrect treatments would not have significantly changed the outcome of the analyses $(p>.50)$. The number of drivers who did not appear for a hearing was proportional to the group size 
of usable cases for all hearing formats. There is no reason to suspect that deletion of the no shows biased the comparisons. Since no shows did not receive the treatment, their inclusion in the data would bias the ability to detect real treatment differences. Data deletion is further discussed in Appendix 0 .

Table 9

Number of Drivers by Treatment

\begin{tabular}{l|c|c|c}
\hline \multirow{2}{*}{ Results } & \multicolumn{3}{|c}{ Hearing format } \\
\cline { 2 - 4 } & $\begin{array}{c}\text { Standard } \\
\text { hearing }\end{array}$ & $\begin{array}{c}\text { Fixed } \\
\text { restriction }\end{array}$ & $\begin{array}{c}\text { Sequential } \\
\text { restriction }\end{array}$ \\
\hline Expected...... & 1,318 & 988.5 & 988.5 \\
Obtained...... & 1,375 & 956 & 964 \\
\hline$\chi^{2}=4.16, d f=2, \underline{p}>.10$.
\end{tabular}

The data were thoroughly screened for differences in prior histories across treatments (biases) prior to testing the relative traffic safety impact of the three hearing formats. The statistical tests employed to detect bias included both discriminant analysis and contingency table analysis. The results of these analyses are described in detail in Appendix $D$.

Differences were found across hearing formats in the numbers of drivers with prior participation in probation-by-mail. These differences were anticipated, however, in that the license terminal digit (TD) was also used for driver assignment in the prior study. While proportionally more probation-by-mail subjects entered the fixed restriction group, these differences were not significantly different from those anticipated based on TDs. Furthermore, this variable did not create unique effects across hearing formats on either subsequent conviction or accident means.

The PLCRES control subjects in each of the hearing formats were proportional to the sample sizes obtained. Neither accident nor conviction means were influenced significantly by this prior condition. Furthermore, there was no evidence of any bias induced by a prior "no action" treatment. Although drivers who received this prior treatment were unevenly distributed across the hearing formats, $\mathrm{p}=.09$, there were only 34 total cases and no evidence 
of differential impact on convictions or accidents across hearing formats was found.

Prior driving incident means (e.g., accidents, convictions) and legal actions (e.g., hearings, suspensions and revocations) were compared across hearing formats using stepwise discriminant analysis. The criteria was assigned hearing format. Based on this analysis, four prior history variables were found to be disproportionally distributed across the hearing formats. The variables were prior total discretionary suspensions, prior total hearings attended, duration of probation, and prior hearings not attended (driver did not appear). These prior history differences had the potential, despite the procedures used for random assignment of drivers to hearing formats, to bias the tests of treatment impact. Any differences found between the impact of the hearing formats could be ascribed to the pre-existing differences rather than the hearing formats unless these differences were removed from the data prior to testing differences between groups. Such statisitical adjustments were made by using covariates in the data analysis, i.e., by using MANCOVA rather than MANOVA.

Covariate selection. Use of covariates in the analyses served two purposes. This technique increases the precision of the statistical test and, to some degree, reduces biases in the measures of traffic safety impact which are due to pre-existing differences between treatment groups rather than the effects of the different hearing formats.

Two separate discriminant analyses were conducted to identify differences in prior histories for drivers with differing patterns of behavior subsequent to entering the project. The criteria used in these analyses were subsequent accidents (drivers accident-free, drivers accident-involved), and convictions (drivers with no convictions, drivers with 1-2 convictions, and drivers with 3 or more convictions). The prior history variables which best separated these criteria groups are contained in Table 10.

Note that during this analyses, drivers were not separated by treatment. Thus, the possibility existed that the relationship of prior driving incidents and legal history variables to subsequent measures of the same 
Table 10

Prior Driving Record Varlables Discriminating Between Drivers with Varying Subsequent Records of Accidents and Convictions

\begin{tabular}{c|l}
\hline $\begin{array}{c}\text { Subsequent record } \\
\text { critera }\end{array}$ & \multicolumn{1}{c}{ Discriminating variables } \\
\hline Accidents $\ldots . .$. & $\begin{array}{l}\text { Prior total convictions } \\
\text { Prior DUI accidents } \\
\text { Prior FTA }\end{array}$ \\
Convictions $2 \ldots .$. & $\begin{array}{l}\text { Prior total convictions } \\
\text { Time from last violation to } \\
\text { hearing } \\
\text { Prior DUI accidents }\end{array}$ \\
\hline
\end{tabular}

IGroups are none, one or more.

2 Groups are none, one or two, three or more.

variables might differ across treatment groups. Such circumstances violate an important assumption of the MANCOVA test. The test of such relationships between variables is commonly referred to as a slope test.

Slope tests. Multivariate analysis of variance was used to test the between group differences in the regression slope of prior history and post-treatment data. In running these analyses, it was discovered that the computer core memory available for the program placed limits on the number of variables which could be run simultaneously. Therefore, the number of variables to be tested (both dependent variables and covariates) was reduced to include only the variables contained in Table 11. The prior history variables selected as covariates were those evidencing the greatest correlation with the criteria and those for which prior history differences were the best predictor of assigned hearing formats.

Significant slope differences were found for the subsequent accident variables (Roy's largest root criteria $=.00487, \underline{p}<.05$ ). Only marginally significant slope differences were found for the subsequent conviction variables (Roy's largest root criteria $=.00702, p=.10)$. The slope differences indicate that the relationship between the covariates and accidents (as well as convictions) varied across hearing formats. Under such circumstances, using covariates in the analysis usually results in underadjustment of the means. In addition, the actual probability levels for the significance tests tend to be more conservative than the nominal levels which we state (Glass, Peckham, \& Sanders, 1972). In other words, violation of the common slope assumption 
more likely leads to underestimation of the treatment effects than to overstating them.

Table 11

Variables Tested for Homogeneity of Regression

\begin{tabular}{l|l|l}
\hline Analysis & Dependent variables & Covariates \\
\hline Accidents.... & $\begin{array}{l}\text { - Fatal or injury } \\
\text { accidents } \\
\text { - Property damage } \\
\text { accidents }\end{array}$ & $\begin{array}{l}\text { - Prior total } \\
\text { convictions } \\
\text { - Prior discre- } \\
\text { tionary S\&R } \\
\text { actions }\end{array}$ \\
\hline Convictions... & $\begin{array}{l}\text { Convictions } \\
\text { One-point } \\
\text { convictions } \\
\text { Zero-polint } \\
\text { convictions }\end{array}$ & $\begin{array}{l}\text { - Prior total } \\
\text { convictions } \\
\text { - Time since last } \\
\text { prior violation } \\
\text { Prior discre- } \\
\text { tionary S\&R } \\
\text { actions }\end{array}$ \\
\hline
\end{tabular}

Adjustments to accident and conviction means were examined to determine the impact of slope differences on the means. The adjusted and unadjusted means for fatal and injury accidents are shown in Table 12. Note that the unadjusted means and the adjusted means (using the common slope) are nearly identical. The adjustments based on the individual slopes are virtually the same, except in the fixed restriction hearing format. No matter which adjustment method is used, however, the magnitude of the treatment differences is roughly 10 times as great as the differences between adjusted and unadjusted means, and 100 times as great as the differences in adjusted means resulting from different methods of adjustment. The authors therefore chose to proceed with the MANCOVA as originally planned; i.e., to use covariates to increase the precision of the statistical tests and to reduce bias. The adjusted means for all subsequent accident and conviction variables (using the common regression equations) are contained in Appendix $E$. The unadjusted means and standard deviations for the traffic safety impact variables are shown in Table 13. The analyses which follow are the tests of the differences contained in the data. 
Table 12

Comparison of DIfferences in Unadjusted and Adjusted Fatal and Injury Accident Means, by Hearling Format and Regression Assumption

\begin{tabular}{|c|c|c|c|}
\hline \multirow{3}{*}{$\begin{array}{l}\text { Hearling } \\
\text { format }\end{array}$} & \multirow{3}{*}{$\begin{array}{l}\text { Unad justed } \\
\text { mean }\end{array}$} & \multicolumn{2}{|c|}{$\begin{array}{l}\text { Adjusted } \\
\text { mean }\end{array}$} \\
\hline & & \multicolumn{2}{|c|}{ Regression assumption } \\
\hline & & $\begin{array}{l}\text { Common } \\
\text { slope }\end{array}$ & $\begin{array}{c}\text { Individual } \\
\text { slope }\end{array}$ \\
\hline $\begin{array}{c}\text { Standard } \\
\text { hearling...... }\end{array}$ & .064 & .065 & .065 \\
\hline $\begin{array}{l}\text { Fixed } \\
\text { restriction. }\end{array}$ & .085 & .084 & .077 \\
\hline $\begin{array}{l}\text { Sequential } \\
\text { restriction. }\end{array}$ & .105 & .104 & .104 \\
\hline
\end{tabular}

Table 13

Subsequent One-year Traffic Accldent and Convlction Means, and Standard Deviations, by Hearing Format

\begin{tabular}{|c|c|c|c|c|c|c|}
\hline \multirow{3}{*}{ Variable } & \multicolumn{6}{|c|}{ Hearing Format } \\
\hline & \multicolumn{2}{|c|}{$\begin{array}{l}\text { Standard } \\
\text { hearling }\end{array}$} & \multicolumn{2}{|c|}{$\begin{array}{c}\text { Fixed } \\
\text { restriction }\end{array}$} & \multicolumn{2}{|c|}{$\begin{array}{l}\text { Sequential } \\
\text { restriction }\end{array}$} \\
\hline & $\bar{x}$ & SD & $\bar{x}$ & SD & $x$ & SD \\
\hline $\begin{array}{l}\text { Fatal and injury } \\
\text { accidents....... }\end{array}$ & .064 & .265 & .085 & .297 & .105 & .356 \\
\hline $\begin{array}{l}\text { Property damage } \\
\text { accidents..... }\end{array}$ & .117 & .356 & .109 & .334 & .133 & .369 \\
\hline $\begin{array}{l}\text { Two-point } \\
\text { convictlons... }\end{array}$ & .080 & .311 & .093 & .318 & .101 & .343 \\
\hline $\begin{array}{l}\text { One-point } \\
\text { convictions... }\end{array}$ & .881 & 1.196 & .967 & 1.258 & .939 & 1.283 \\
\hline $\begin{array}{l}\text { Zerompoint } \\
\text { convictions... }\end{array}$ & .273 & .647 & .219 & .523 & .284 & .703 \\
\hline
\end{tabular}


Accidents. The impact of hearing format on traffic accidents was tested using MANCOVA. This analysis was a simultaneous test of fatal and injury accidents combined, as well as property damage accidents. Roy's largest root statistic $(.00322)$ was significant, $p<.10$. This indicated that the three hearing formats had different accident patterns. The log-linear analyses also tend to support this interpretation. These results, described in detail in the Appendix D, were conducted primarily to assess biases in the traffic safety impact evaluation. They also model the traffic safety impact of the hearing formats on total accidents subsequent to project entry. Log-linear analysis does not adjust out prior history influences and interactions in the same manner as analysis of covariance; thus, some conditions which may limit the interpretability of MANCOVA results (e.g., lack of homogeneity in the covariate by treatment regression slopes) do not distort the log-linear analysis results. The significance levels for the effect of hearing format on accidents ranged from .09 to .13 , mean $=.099$.

The standard hearing format had the lowest mean number of fatal and injury accidents, while the fixed restriction format had the lowest mean for property damage accidents. The sequential restriction format had the highest accident means on both measures. The fatal and injury accident means were significantly different, $F(2,3290)=4.96, \underline{p}<.01$. Pairwise $\underline{t}$ tests revealed that fatal and injury accidents were significantly lower for the standard hearing format when compared to the sequential restriction format, but not when compared to the fixed restriction format. Fatal and injury accidents were essentially the same for the two restriction formats (see Table 14). A negative $t$ value merely indicates that the second group mean in the comparison was the larger value. The mean differences for property damage accidents were not significantly different, $F(2,3290)=1.17$.

Table 14

Pairwise Comparisons of Hearling Formats on Fatal and Injury Accident Adjusted Means

\begin{tabular}{l|c|c|c}
\hline \multirow{2}{*}{ Statistic } & \multicolumn{2}{|c}{ Comparison } \\
\cline { 2 - 4 } & $\begin{array}{c}\text { Standard hearing vs. } \\
\text { fixed restriction }\end{array}$ & $\begin{array}{c}\text { Standard hearing vs. } \\
\text { sequential restriction }\end{array}$ & $\begin{array}{c}\text { Fixed restriction vs. } \\
\text { sequential restriction }\end{array}$ \\
\hline \pm value....... & -1.623 & $-3.159 *$ & -.990 \\
\hline${ }^{\prime} \ldots \ldots . . . . .$. & 2,329 & 2,337 & 1,918 \\
\hline${ }^{*}{ }_{p}<.01$ & & &
\end{tabular}


A discriminant analysis of the accident data produced a single discriminant function. The variables were input to the analysis concurrently, rather than sequentially as in step-wise discriminant analysis. The group centroids for the weighted canonical variable, shown in figure 3 , are evenly distributed along this dimension. The standardized discriminant function weights which produced these centroids are shown in Table 15 . The canonical variable clearly is heavily influenced by the accidents. The structure matrix also demonstrates the relationships of the two accident variables to the canonical variable.

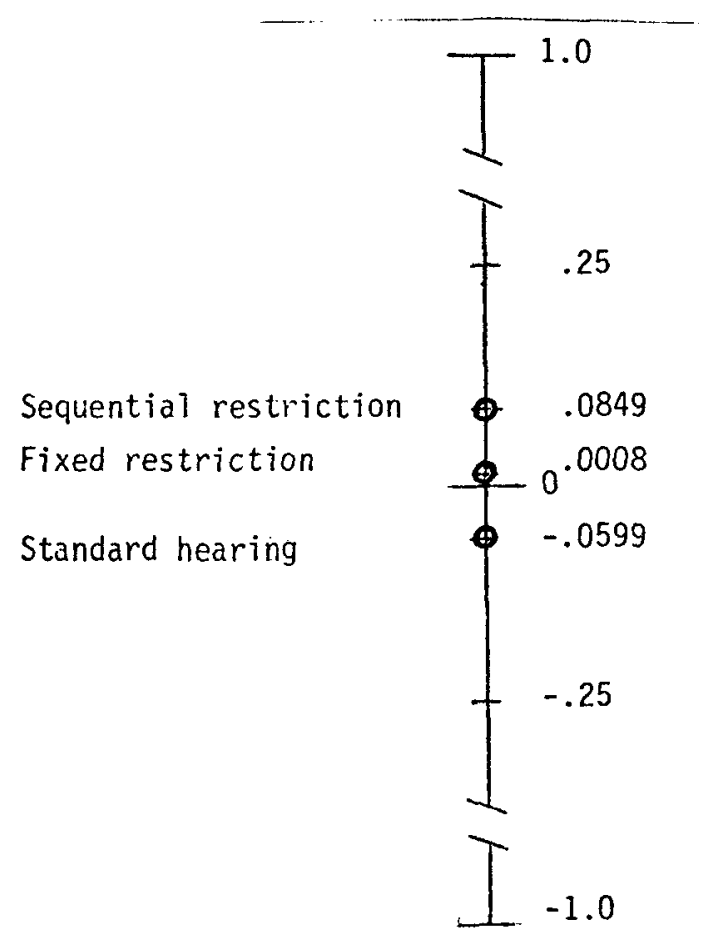

Figure 3. Canonical variable centroids by hearing format-accident discrininant analys is.

Table 15

Standardized Discriminant Function Welghts and Correlations Between the Canonical Variable and Accident Variables, by Accident Type

\begin{tabular}{|c|c|c}
\hline Accident type & $\begin{array}{c}\text { Standardized } \\
\text { weights }\end{array}$ & $\begin{array}{c}\text { Structure } \\
\text { matrix }\end{array}$ \\
\hline Fatal and injury accidents.. & .9628 & .9591 \\
Property damage accidents... & .2832 & .2706 \\
\hline
\end{tabular}


In summary, the multivariate test of accident variables was significant, the most important variable being fatal and injury accidents. The standard hearing format had significantly less fatal and injury accidents than the sequential restriction format.

Accidents and convictions. This is a simultaneous test of fatal and injury accidents, property damage accidents, two-point convictions, one-point convictions, and zero-point convictions. The multivariate test was significant, Wilk's Lambda $=.99265, \underline{F}(10,6570)=2.43, \underline{p}<.007$. The first root accounted for $55 \%$ of the explained variance. The second root accounted for $45 \%$ of the explained variance and was also significant, Wilk's Lambda = .99667 , $F(4,3285)=2.74, \underline{p}<.02$. Thus, the patterns of dependent variables across groups were multidimensional, and the dimensions were of nearly equal importance.

The univariate tests of accident variables across hearing formats have already been discussed. The standard hearing format had the lowest means for both two-point and one-point convictions, but the differences between hearing formats were not significantly different for these variables, $F(2,3289)=$ 1.1816 and 0.5929 , respectively, both $\mathrm{p}>.10$ (see Table 9). The univariate test of zero-point convictions was significant, $\underline{F}(2,3289)=4.29, \underline{p}=.014$. Pairwise comparisons revealed that the mean number of zero-point convictions for the fixed restriction format was significantly lower than either of the other formats (see Table 16). The standard hearing format and sequential restriction format were not significantly different on zero-point convictions.

The centroids for each group are plotted in Figure 4 and shown in Table 17. It is apparent that one dimension separates the standard hearing format from the others, while the second dimension separates the sequential restriction format from the others. Fatal and injury accidents combined and zeropoint convictions were the predominant variables on both dimensions. The group with the lowest fatal and injury accident mean had the highest centroid on the first dimension. The group lowest in no-point convictions had the highest centroid on the second function. 
Table 16

Pairwise Comparisons of Hearing Formats on Zero-Point Conviction Adjusted Means

\begin{tabular}{l|c|c|c}
\hline \multirow{2}{*}{ Statistic } & \begin{tabular}{c} 
Comparison \\
Standard hearing vs. \\
\cline { 2 - 4 }
\end{tabular} & $\begin{array}{c}\text { Standard hearling vs. } \\
\text { sequential restriction }\end{array}$ & $\begin{array}{c}\text { Fixed restriction vs. } \\
\text { sequential restriction }\end{array}$ \\
\hline df value......... & $2.77^{* *}$ & -.007 & $-2.48^{*}$ \\
\hline
\end{tabular}

$*_{p}<.02$.

$* *_{p}<.01$.

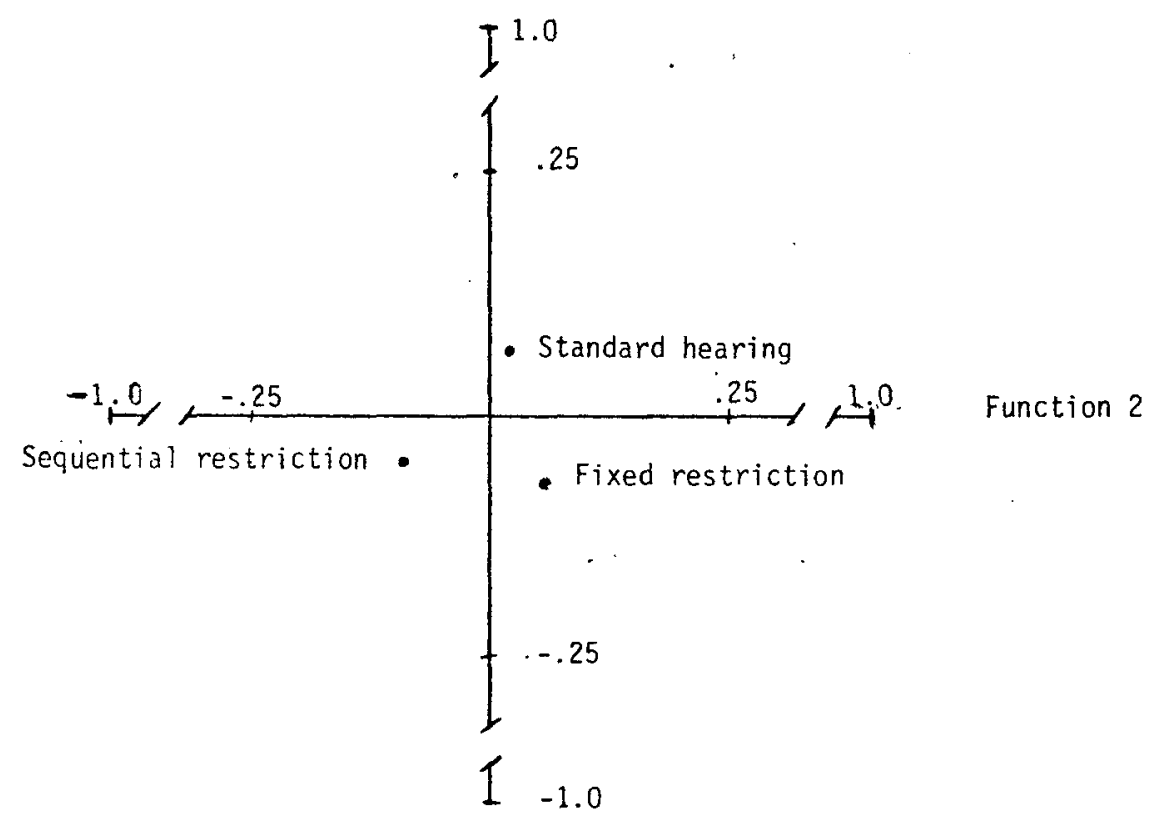

Function 1

Figure 4. Canonical variable centroids by hearing format-accident and conviction discriminant analysis.

\section{Table 17}

Canonical Variable Centroids for Accidents and Convictions, by Hearing Format

\begin{tabular}{l|c|c|c}
\hline \multirow{2}{*}{$\begin{array}{c}\text { Data } \\
\text { dimension }\end{array}$} & \multicolumn{3}{|c}{ Hearing Format } \\
\cline { 2 - 4 } & $\begin{array}{l}\text { Standard } \\
\text { hearing }\end{array}$ & $\begin{array}{c}\text { Fixed } \\
\text { restriction }\end{array}$ & $\begin{array}{l}\text { Sequential } \\
\text { restriction }\end{array}$ \\
\hline $\begin{array}{l}\text { Function 1.... } \\
\text { Function 2.... }\end{array}$ & $\begin{array}{l}.073 \\
.020\end{array}$ & $\begin{array}{r}.063 \\
.060\end{array}$ & $\begin{array}{l}-.042 \\
-.086\end{array}$ \\
\hline
\end{tabular}


The standardized discriminant weights and structure matrix are shown in Table 18. Note that while fatal and injury accidents and zero-point convictions have the highest loadings on both discriminant functions, there are reversals in their order as well as changes in sign. The structure matrix (which portrays the correlation between the dependent variables and the canonical variable) shows only minor differences from the discriminant function weights.

Table 18

Standardized Discriminant Function Weights and

Correlations Between the Canonlcal Varlables and

Accident and Conviction Varlables, by Type

\begin{tabular}{|c|c|c|c|c|}
\hline \multirow{3}{*}{$\begin{array}{l}\text { Dependent } \\
\text { varlable }\end{array}$} & \multicolumn{4}{|c|}{ Function } \\
\hline & \multicolumn{2}{|c|}{$\begin{array}{c}\text { Standardized } \\
\text { welghts }\end{array}$} & \multicolumn{2}{|c|}{$\begin{array}{l}\text { Structure } \\
\text { matrix }\end{array}$} \\
\hline & 1 & 2 & 1 & 2 \\
\hline $\begin{array}{l}\text { Accident type } \\
\text { Fatal and injury... } \\
\text { Property damage... }\end{array}$ & $\begin{array}{r}-.6658 \\
.0792\end{array}$ & $\begin{array}{l}-.5541 \\
-.4468\end{array}$ & $\begin{array}{r}-.6943 \\
.0580\end{array}$ & $\begin{array}{l}-.5652 \\
-.4595\end{array}$ \\
\hline $\begin{array}{l}\text { Conviction type } \\
\text { Two-point......... } \\
\text { One-point........ } \\
\text { Zero-point........ }\end{array}$ & $\begin{array}{r}-.3395 \\
-.3327 \\
.5866\end{array}$ & $\begin{array}{r}. .1290 \\
.2014 \\
-.6612\end{array}$ & $\begin{array}{r}-.3740 \\
-.2930 \\
.5264\end{array}$ & $\begin{array}{r}. .2135 \\
.0625 \\
. .6676\end{array}$ \\
\hline
\end{tabular}

The discriminant analysis shows that traffic accidents and traffic convictions are complex, interrelated variables. The data are not sufficiently clear to allow one to adequately label the two dimensions which were identified. The three most substantial differences between the dimensions relate to the loading of one-count, zero-count and property damage accidents, which suggests a complex interaction of traffic violator pattern and exposure as mediating factors. The inability to label these dimensions, while disconcerting, does not invalidate the analysis. It merely makes it difficult to explain the mathematical results in an intuitively plausible form.

In summary, the test of traffic accidents and convictions combined was significant and revealed complex relationships between these variables. Fatal and injury accidents and zero-point convictions were the predominant sources of the significant statistical results. There was no significant differences between hearing formats or property damage accidents, two-point convictions or one-point convictions. 
Survival analyses. Survival analyses are used to measure the duration of treatment effects over time. These techniques originated in medical research, where the term survival could actually be interpreted as "still living." In traffic safety research, the more common usage is "free of $\underline{x}, "$ where $\underline{x}$ is a measure such as traffic accidents or convictions. Three criteria were used in the probation violator evaluation: traffic accidents, traffic convictions and licensing actions which increased the duration of the probation period. It should be noted that the third criteria perhaps relates more closely to the process analysis than to the traffic safety impact of the hearing formats. The criteria were not adjusted for prior history.

In the first analysis, survival was defined as the absence of any traffic accident. The proportion of subjects remaining free of these incidents was tested at 4-month intervals. The intervals used reflect the most common restriction durations for the fixed restriction and sequential restriction hearing formats.

The proportions of drivers surviving are shown in Table 19 and Figure 5. The standard hearing group had the largest proportion of accident-free drivers and the statistical test was significant $\left(x^{2}=5.097, \underline{d f}=2, \underline{p}=.078\right)$. Additional pairwise tests revealed that only the standard hearing and sequential restriction formats were significantly different (see Table 20).

Table 19

Proportions of Drlvers Free of Accldents by Foll low-up Interval by Hearing Format

\begin{tabular}{l|c|c|c}
\hline \multirow{2}{*}{ Interval } & \multicolumn{3}{|c}{ Hearing format } \\
\cline { 2 - 4 } & $\begin{array}{c}\text { Standard } \\
\text { hearing }\end{array}$ & $\begin{array}{c}\text { Fixed } \\
\text { restriction }\end{array}$ & $\begin{array}{c}\text { Sequential } \\
\text { restriction }\end{array}$ \\
\hline 122 days..... & .9331 & .9310 & .9191 \\
344 days..... & .8742 & .8776 & .8527 \\
366 days..... & .8356 & .8243 & .7988 \\
\hline
\end{tabular}

It appears from inspection of Figure 5 that the last time period accounts for the overall difference between the standard hearing and the sequential restriction formats. The parallel slopes of the lines for these groups between days 122 and 244 suggest that an initial treatment impact on accidents dissi- 


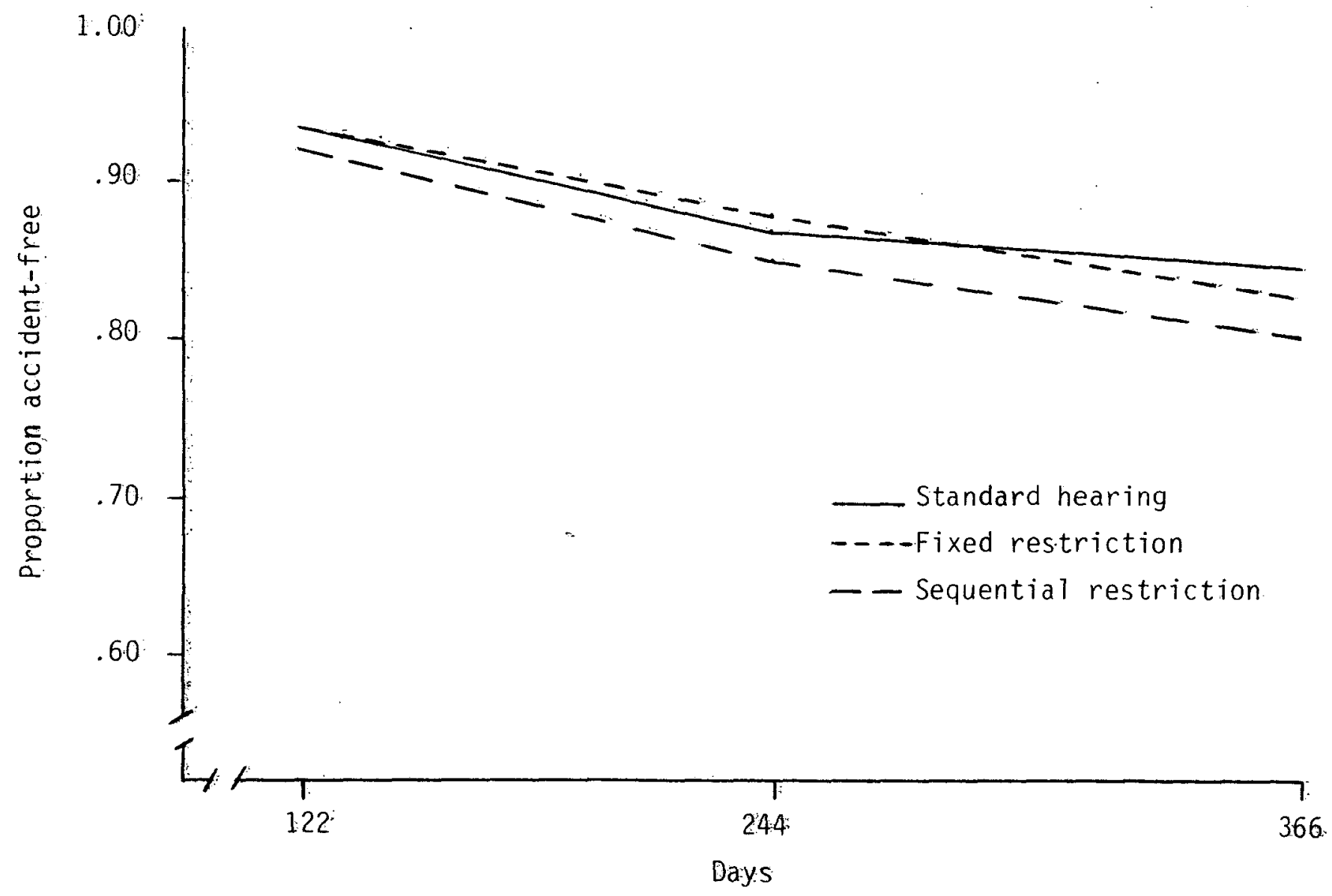

Figure 5: Proportion of drivers remaining accident-free by hearing format--1-year follow-up. 
Table 20

Pairwise Group Comparisons of Accident Survival Patterns over One Year

\begin{tabular}{|c|c|c|c|}
\hline \multirow{2}{*}{ stat Istic } & \multicolumn{3}{|c|}{ Comparison } \\
\hline & $\begin{array}{l}\text { Standard hearling vs. } \\
\text { flxed restriction }\end{array}$ & $\begin{array}{l}\text { Standard hearling vs. } \\
\text { sequential restriction }\end{array}$ & $\begin{array}{l}\text { Fixed restriction vs. } \\
\text { sequential restriction }\end{array}$ \\
\hline Desu score.. & 12,834 & 47,641 & 24,612 \\
\hline$x^{2} \cdots \cdots \cdots$ & .38 & $4.9 *$ & 2.2 \\
\hline$d f \ldots \ldots \ldots$ & 1 & 1 & 1 \\
\hline
\end{tabular}

pated by month four. Given the results contained in the other survival analyses, it seems most likely that the change in slope for the standard hearing format after the 244th day reflects the impact of additional licensing actions, including extensions of probation suspensions and revocations.

The proportions of drivers in each hearing format remaining conviction-free are documented in Table 21 and Figure 6 . While there were crossovers which might be interpreted in terms of restriction durations, the proportions of drivers remaining conviction-free were not significantly different across hearing formats $\left(x^{2}=1.6044\right.$, $\left.d f=2\right)$. The proportion of drivers remaining conviction-free was directionally higher at the end of 12 months in the standard hearing format.

Table 21

Proportion of Drivers Free of Accidents by

Follow-up Interval by Hearing Format

\begin{tabular}{l|l|l|l}
\hline \multirow{2}{*}{ Interval } &. & \multicolumn{3}{|c}{ Hearing format } \\
\cline { 2 - 4 } & $\begin{array}{c}\text { Standard } \\
\text { hearing }\end{array}$ & $\begin{array}{c}\text { Fixed } \\
\text { restriction }\end{array}$ & $\begin{array}{c}\text { Sequential } \\
\text { restriction }\end{array}$ \\
\hline 122 days..... & .6516 & .6590 & .6359 \\
\hline 364 days..... & .4924 & .4644 & .4720 \\
\hline
\end{tabular}




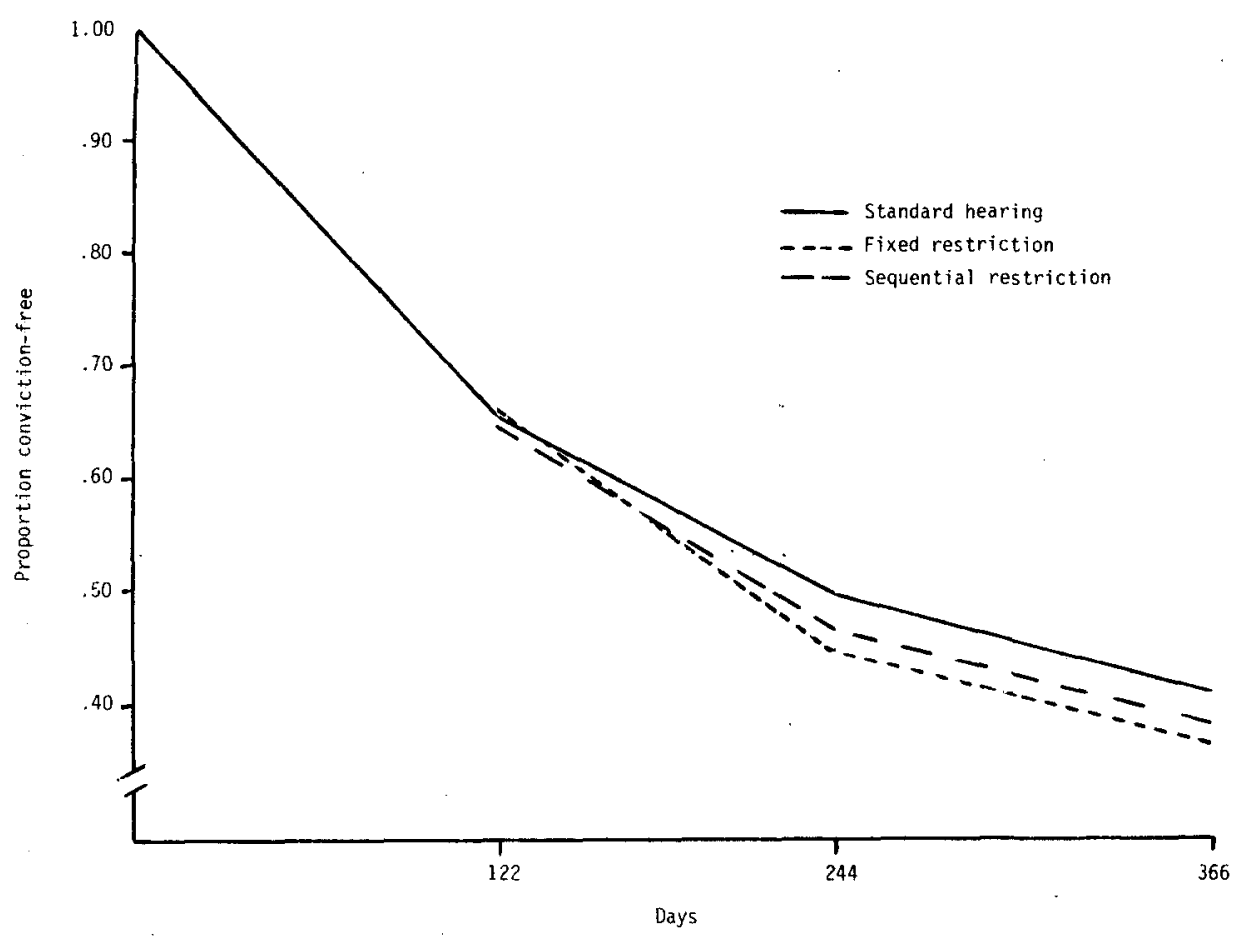

Figure 5. Proportion of drivers remaining free of convictions by hearing format--

The third probation survival criterion used was the absence of any increased or repeated restriction, any extension of probation, or any suspension or revocation other than the project entry action. Changes in restrictions which were due to driver requests rather than recidivism were excluded, as were warning letters. Drivers were deemed survivors until such time as a DIA ordered an extension of probation, or more severe action, in response to driver recidivism. The proportions surviving are shown in Table 22 and Figure 7 .

The statistical test of these differences was statistically significant $\left(x^{2}\right.$ $=8.88$, $\underline{d f}=2, \underline{p}=.012$ ). The pairwise comparisons indicated that a greater proportion of drivers in the standard hearing format received legal sanctions than either the fixed or sequential restriction formats. The latter did not differ from each other (see Table 23).

A collective overview of the survival analyses indicates that while the standard hearing format had a significantly greater proportion of drivers remaining accident-free (and a directionally greater proportion conviction-free), this very group also had a greater proportion with some additional licensing sanction (probation extension, and suspension or revocation of the driving privilege). This phenomenon was of interest, and was studied through 
Table 22

Proportions of Drivers Free of Licensing Actions by TIme Interval by Hearing Format

\begin{tabular}{c|c|c|c}
\hline \multirow{2}{*}{ Interval } & \multicolumn{3}{|c}{ Hearing format } \\
\cline { 2 - 4 } & $\begin{array}{c}\text { Standard } \\
\text { hearing }\end{array}$ & $\begin{array}{c}\text { Fixed } \\
\text { restriction }\end{array}$ & $\begin{array}{l}\text { Sequential } \\
\text { restriction }\end{array}$ \\
\hline 122 days..... & .9636 & .9571 & .9616 \\
244 days..... & .7884 & .8232 & .8288 \\
366 days...... & .5956 & .6485 & .6359 \\
\hline
\end{tabular}

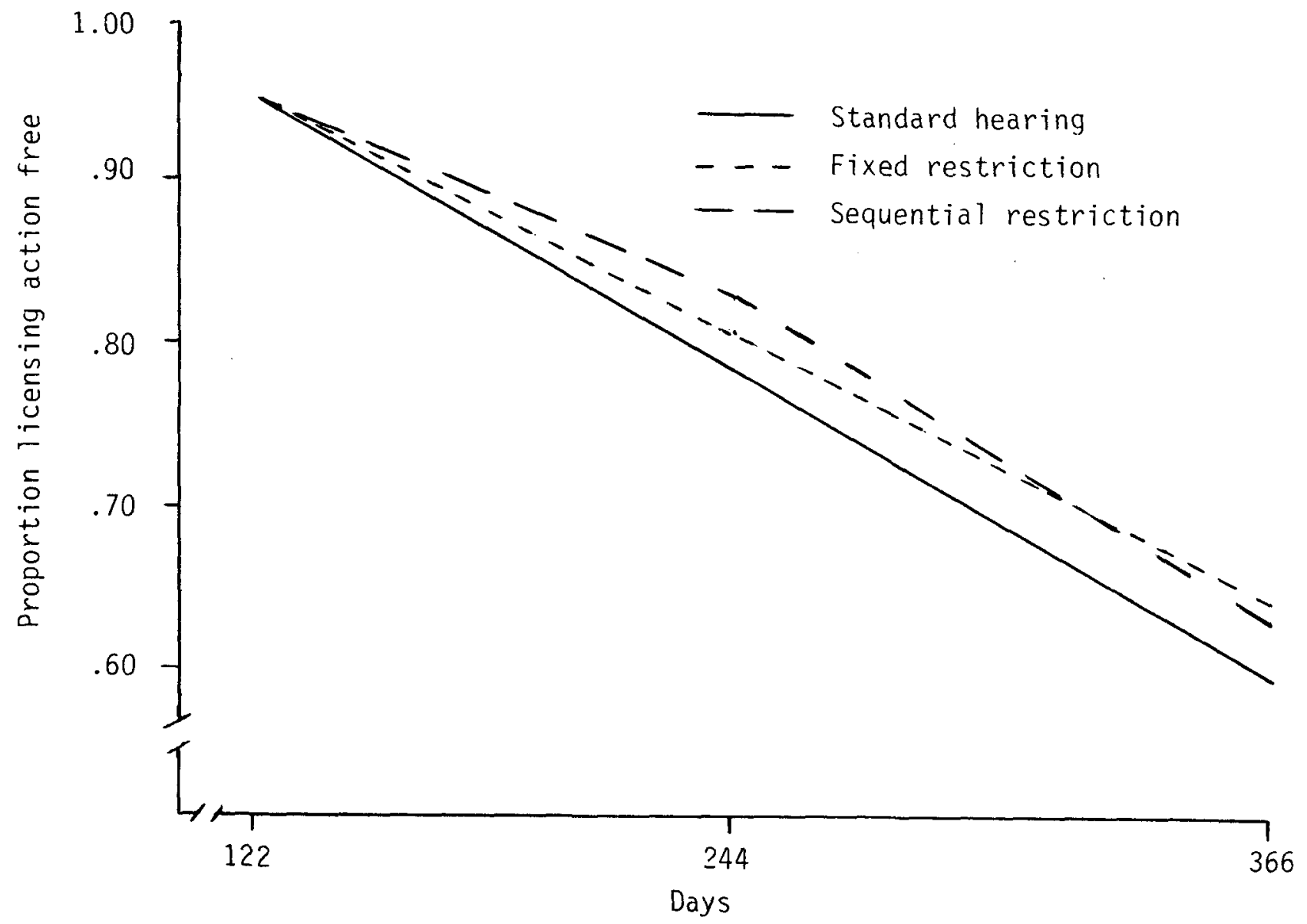

Figure 7. Proportion of drivers remaining free of 1 icensing actions, by hearing format--1-year follow-up. 
Table 23

Pairwise Comparisons of Legal Action

Survival During the One Year Follow-up

\begin{tabular}{l|c|c|c}
\hline \multirow{2}{*}{ Statistic } & \multicolumn{3}{|c}{ Comparison } \\
\cline { 2 - 4 } & $\begin{array}{c}\text { Standard hearing vs. } \\
\text { fixed restriction }\end{array}$ & $\begin{array}{c}\text { Standard hearing vs. } \\
\text { sequential restriction }\end{array}$ & $\begin{array}{c}\text { Fixed restriction vs. } \\
\text { sequential restriction }\end{array}$ \\
\hline Desu score.. & 71,105 & 68,433 & 4,934 \\
$\chi^{2} \ldots \ldots . .$. & $6.47^{*}$ & $5.88 * *$ & .06 \\
df........ & 1 & 1 & 1 \\
\hline$*_{p}^{*}=.011$. & & & \\
$* *_{0}^{*}=.015$. & & &
\end{tabular}

additional survival analyses. Drivers within the standard hearing format were categorized according to the duration of the licensing action they recejved at project entry. Since changes in risk exposure were of interest, particularly during the first few months, survival proportions were measured at 2-week intervals.

The conviction survival data for the standard hearing format are displayed in Figure 8 and in Appendix E. Groups were defined as no-action, 30 day suspension, 60 day suspension and 90+ day suspension (including revocations). The statistical test of the conviction survival differences within the standard hearing format was significant $\left(x^{2}=11.72, \underline{d f}=3, \underline{p}=.008\right)$. A similar test of accident survival differences was not significant $\left(\chi^{2}=2.12\right.$, df $=$ $3, p=.548)$. There was no evidence of marked changes in survival rate coinciding with the end of suspensions. Visual inspection of Figure 8 suggests two patterns of subsequent survival, and this impression is borne out by the pairwise statistical tests shown in Table 24 . The group receiving no suspenTable 24

Pairwise Test of Conviction Survival by Project Entry Action--Standard Hearing

\begin{tabular}{|c|c|c|c|c|c|c|}
\hline \multirow[b]{2}{*}{ Statistic } & \multicolumn{6}{|c|}{ S\&R action group } \\
\hline & $\begin{array}{c}\text { No action } \\
\text { vs. } \\
30 \text { day }\end{array}$ & $\begin{array}{c}\text { No action } \\
\text { vs. } \\
60 \text { day }\end{array}$ & $\begin{array}{c}\text { No action } \\
\text { vs. } \\
90+\text { day }\end{array}$ & $\begin{array}{l}30 \text { day } \\
\text { vs. } \\
60 \text { day }\end{array}$ & $\begin{array}{l}30 \text { day } \\
\text { vs. } \\
90+\text { day }\end{array}$ & $\begin{array}{l}60 \text { day } \\
\text { vs. } \\
90+\text { day }\end{array}$ \\
\hline Desu score... & 2,972 & 17,516 & 16,081 & 6,648 & 6,029 & 192 \\
\hline$x^{2} \ldots \ldots \ldots$ & .25 & $6.23^{*}$ & $5.56^{*}$ & $5.88 *$ & $5.19 * *$ & 0.00 \\
\hline$d+\ldots . . . . . .$. & 1 & 1 & 1 & 1 & 1 & 1 \\
\hline
\end{tabular}




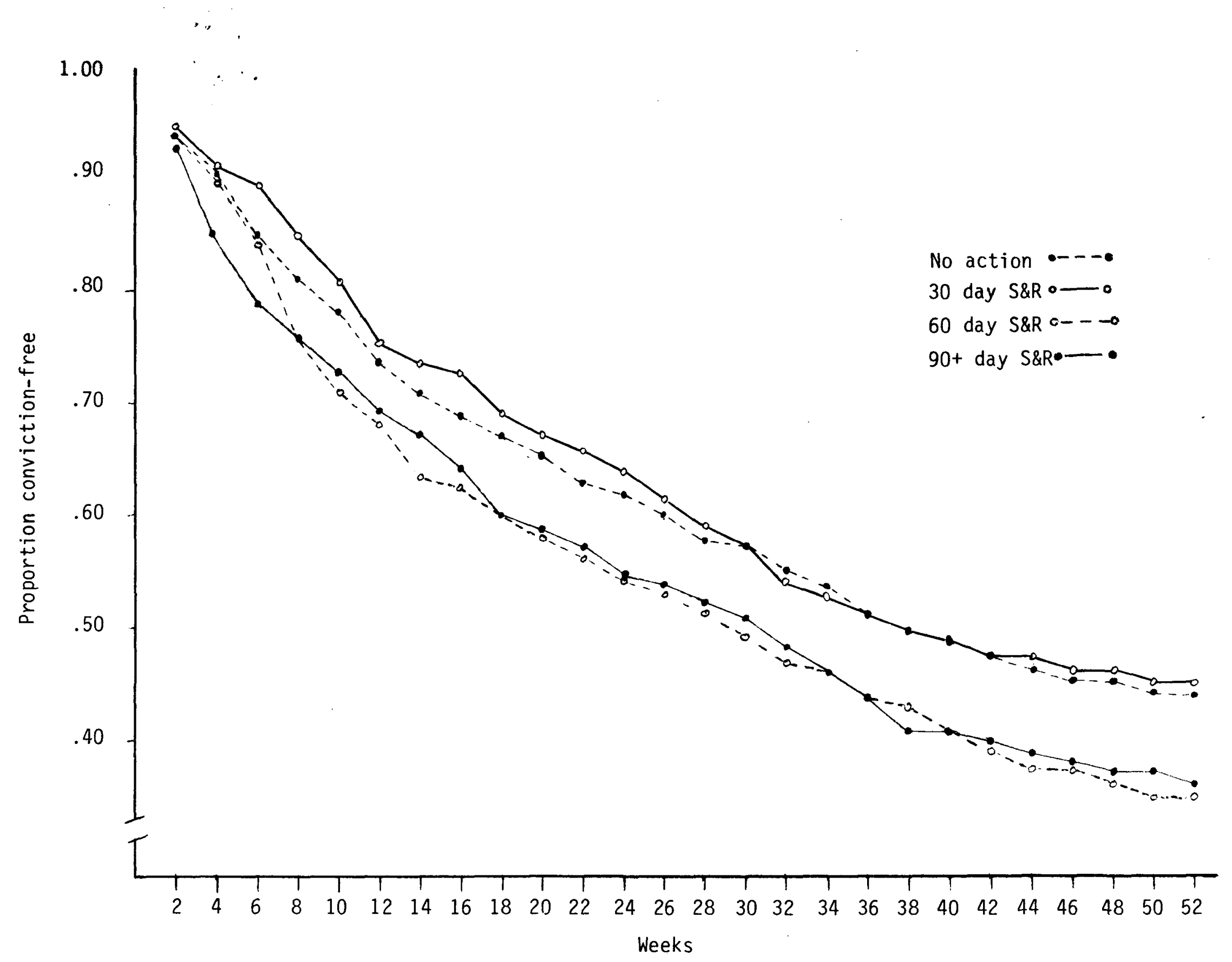

Figure 8. Proportion of drivers in standard hearing format remaining convictionfree, by project entry licensing action--1-year follow-up. 
sion or revocation did not differ significantly in survival rate from the group receiving a 30-day suspension. Similarly, the group receiving a 60 day suspension did not differ significantly from the group receiving a more severe suspension (90-180 days) or a revocation. The groups receiving the most severe licensing actions experienced the greater proportion of drivers receiving at least one conviction.

There are at least two plausible explanations for these conviction survival patterns. First, one may assume that DIAs are screening low risk and high risk drivers at project entry and applying more severe sanctions to the latter. Nonetheless, greater proportion of the driver who received the most severe licensing actions continue to accrue convictions. The alternative explanation ignores prior history and posits that those who continued to drive while suspended or revoked were more likely to be cited for moving violations whether they also incurred VC 14601 convictions or not. In either case, it is clear that the most severe licensing actions are not reducing the risk level of the recipients to the overall group average.

No significant differences in the effects of restriction duration were found on either convictions or accidents. Restriction stages were 4 months in duration for $95 \%$ of all drivers. It is possible that these conditions resulted in tests that were insensitive to actual differences in conviction and accident survival rates.

\section{Probation Success}

In the previous section, the duration of treatment effects on traffic convictions, traffic accidents, and licensing actions was measured. The proportions of drivers in each hearing format remaining free of these incidents were tested at various intervals throughout the follow-up period. No attempt was made in the analysis to examine influences on survival. The intent of the probation success analysis was to examine the influence of prior driving record variables and demographic variables (age, sex) on driver success or failure to comply with the terms of probation. Each hearing format was analyzed separately. 
Traffic convictions, accidents and failures to appear in court (FTA) were combined to form a composite measure of success. This criterion reflects the most stringent measure of probation success. Recall that drivers were told that the conditions of probation included both remaining conviction-free and not being responsible for traffic accidents for 12 months. Most DIAs (and the automated review criteria) do not apply such severe standards of success, but rather recognize that drivers who remain accident and conviction free for several months should be considered as having succeeded to some degree in meeting the conditions of probation.

The statistical technique used was stepwise discriminant analysis. Prior convictions (measured variously as prior abstracts, points, or total vehicle code sections violated), along with the time between the hearing date and the last prior violation, proved to be the predominant variables in the classification equation. Drivers who accrued accidents, convictions and/or FTAs had higher prior conviction means and more recent convictions than drivers with no accidents, convictions or FTAs. The prior history variable means, discriminant function weights and the correlation between the prior variables and the canonical variable created by the discriminant function are shown in Table 25.

\section{Cost-Benefit Analyses}

The costs associated with the three hearing formats are contained in Table 26. The hearing cost figures were developed jointly by the Management and Operations Analysis Section, the Division of Drivers Licenses, and the Research and Development office. Reducible costs are defined as direct costs plus 55\% of indirect costs. Fixed costs and the remaining portion of indirect costs are considered nonreducible.

Both experimental programs were substantially more costly than the standard program. The fact that the fixed restriction program and the sequential program resulted in almost identical costs cannot be explained because the more complex sequential program was considered to be slightly more costly because of more planned driver contacts. 
Table 25

Varlables Predictive of Driver Accldents, Canvictlons and Fallures to Appear Following Probation Violator Hearlings, by Order of Entry In the Discriminant Function Equatlons and Hearling Format

\begin{tabular}{|c|c|c|c|c|}
\hline \multirow[b]{2}{*}{ Varlable } & \multicolumn{2}{|c|}{ Mean } & \multirow[b]{2}{*}{$\begin{array}{l}\text { Standardized } \\
\text { diser Iminent } \\
\text { function welght }\end{array}$} & \multirow[b]{2}{*}{$\begin{array}{l}\text { Correlation to } \\
\text { canonlcal varlable }\end{array}$} \\
\hline & $\begin{array}{l}\text { Had accldents } \\
\text { convictions and/or } \\
\text { fal lures to appear }\end{array}$ & $\begin{array}{c}\text { No acclidents } \\
\text { convlctions or } \\
\text { tall lures to appear }\end{array}$ & & \\
\hline \multicolumn{4}{|c|}{ STANDARO HEARING } & \\
\hline Prior convictions.................... & 7.97 & 6.30 & .456 & .785 \\
\hline Prior drunk drlving accidents........... & .05 & .11 & -.382 & -.333 \\
\hline Days from last ticket to entry hearing.. & 91.84 & 108.59 & -.270 & -.473 \\
\hline $\begin{array}{l}\text { Prior accidents reported by law } \\
\text { enfor cement............................ }\end{array}$ & .57 & .48 & .234 & .182 \\
\hline Prior scheduled hearings unattended...... & .18 & .12 & .158 & .245 \\
\hline Duration of probation (months)........... & 15.62 & 15.26 & .251 & .045 \\
\hline Age............................... & 26.64 & 28.32 & -.175 & -.300 \\
\hline Prior negligent operator polnts.......... & 7.21 & 6.09 & .259 & .698 \\
\hline $\begin{array}{l}\text { Duration of all prlor discretionary } \\
\text { suspensions or revocations............... }\end{array}$ & 35.42 & 26.85 & .162 & .166 \\
\hline Prior Implled consent suspension......... & .02 & .02 & .125 & .042 \\
\hline Prior control group assignment (PLCRES). & 1.92 & 1.92 & .125 & .010 \\
\hline Drunk orlving suspenslons and & & & & \\
\hline 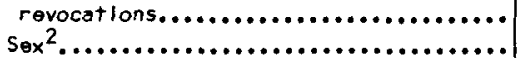 & .00 & .00 & $\begin{array}{r}.117 \\
-.103\end{array}$ & $\begin{array}{r}.112 \\
-.144\end{array}$ \\
\hline \multicolumn{5}{|c|}{ FIXED RESTRICTION HEARING } \\
\hline Prior vehicle code sectlons clted........ & 11.10 & 8.48 & .578 & .725 \\
\hline Days trom last ticket to entry hearing.. & 90.54 & 106.03 & -.301 & -.445 \\
\hline Prior drunk drlving accidents........... & .05 & .10 &.- .258 & -.271 \\
\hline Prior conviction--violation of & 10 & 03 & 234 & \\
\hline $\begin{array}{l}\text { suspension or ravocation................. } \\
\text { Prior control group assignment (PLCRES). }\end{array}$ & .10 & .03 & $\begin{array}{r}.234 \\
-.234\end{array}$ & $\begin{array}{r}.294 \\
-.261\end{array}$ \\
\hline Prlor injury accidents.................. & .25 & .18 & .425 & .217 \\
\hline Prior accldents reported by law & & & & \\
\hline 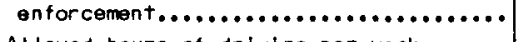 & .53 & .50 & -.315 & .049 \\
\hline 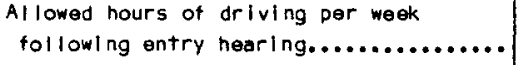 & 91.60 & 86.50 & .217 & .183 \\
\hline Age, $\ldots \ldots \ldots \ldots \ldots \ldots \ldots \ldots \ldots \ldots \ldots$ & 26.02 & 27.73 &. .167 & -.304 \\
\hline Prlor scheduled hearings unattended...... & .16 & .11 & .134 & .221 \\
\hline $\operatorname{Sex}^{2} \ldots \ldots \ldots \ldots \ldots \ldots \ldots \ldots \ldots \ldots \ldots \ldots$ & 1.02 & 1.04 & -.135 & -.217 \\
\hline $\begin{array}{l}\text { Prlor accidents reported under } \\
\text { tinanclal responslblilty laws............ }\end{array}$ & .08 & .09 & -.141 & -.027 \\
\hline Prior fatal accidents.................... & .00 & - & .132 & .129 \\
\hline \multicolumn{5}{|c|}{ SEQUENTIAL RESTRICTION HEARING } \\
\hline Prior convictions...................... & 8.19 & 6.45 & .933 & .738 \\
\hline Days from last ticket to entry hearlng.. & 90.14 & 110.50 & -.346 & -.484 \\
\hline Age $\ldots \ldots \ldots \ldots \ldots \ldots \ldots \ldots \ldots \ldots \ldots \ldots \ldots$ & 25.44 & 27.92 & -.276 & -.417 \\
\hline Prlor negllgent operator points.......... & 7.32 & 6.35 & -.376 & .486 \\
\hline $\begin{array}{l}\text { Duration of all prlor discretionary } \\
\text { suspensions or revocations............... }\end{array}$ & 39.14 & 24.01 & .190 & .258 \\
\hline Geographic or purpose restriction........ & - & - & -.166 & -.250 \\
\hline $\begin{array}{l}\text { Prior drunk driving suspensions or } \\
\text { revocations } \ldots \ldots \ldots \ldots \ldots \ldots\end{array}$ & .006 & - & .139 & .131 \\
\hline 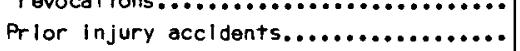 & .218 & .250 & -.197 & -.091 \\
\hline Prior nlght accldents $(1800-0600) . . . .$. & .199 & .158 & .206 & .125 \\
\hline 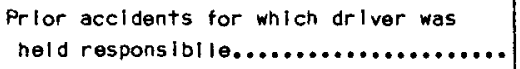 & .125 & .147 & -.152 & -.081 \\
\hline Duration of all prlor mandatory & 17.59 & 12.80 & -118 & 094 \\
\hline Vehicle restrictions..................... & 11.39 & $\begin{array}{l}12.80 \\
-\end{array}$ & .0118 & $\begin{array}{r}.094 \\
-.182\end{array}$ \\
\hline
\end{tabular}

$l_{1}=$ yes, 2 = no

21. $=$ male, $2=$ female

${ }^{3}$ Categorlcal variable 
Table 26

Hearing Unit Cost Estimates

1979 - 1980

\begin{tabular}{l|c|c|c}
\hline \multirow{2}{*}{ Hearing format } & \multicolumn{3}{|c}{ Cost breakdown } \\
\cline { 2 - 4 } & Reduclble & Nonreduclble & Total \\
\hline Standard............... & $\$ 65.77$ & $\$ 38.98$ & $\$ 104.75$ \\
Fixed restriction........ & $\$ 90.19$ & $\$ 38.98$ & $\$ 129.17$ \\
Sequential restriction.. & $\$ 89.02$ & $\$ 38.98$ & $\$ 128.00$ \\
\hline
\end{tabular}

Accident costs used in this analysis (shown in Table 27) are based on estimates provided by the NHTSA and the National Safety Council, adjusted for negligent operator accident proportions and updated to 1979-1980. These accident cost estimates are revisions of those contained in PLCRES Status Report \#5 (DMV, 1980).

Table 27

Estimated Accident Costs and Proportions, by Accldent Type and Cost Data Source

\begin{tabular}{l|r|r|r}
\hline \multirow{2}{*}{ Accidents } & \multicolumn{2}{|c|}{ Source } & \multirow{2}{*}{ Proportion } \\
\cline { 2 - 4 } & NSC & NHTSA & \\
\hline Weighted average... & $\$ 4,357$ & 8,655 & \\
Fatal and injury... & 3,759 & 7,785 & .3429 \\
Property damege.... & 598 & 870 & .6571 \\
\hline
\end{tabular}

A review of the accident traffic safety impact analysis is in order prior to discussing the outcome of the benefit-cost analysis. Recall that it was determined that the pattern of combined fatal and injury accidents and pro- 
perty damage accidents was significantly different across hearing formats. In addition, it was determined that fatal and injury accidents were the primary source of these differences. Nonetheless, the difference between adjusted fatal and injury accident means was not significantly different for the standard hearing and the fixed restriction hearing $(\underline{t}=-1.623$, $\underline{d f}=2329, \underline{p}>$ $.10)$. The latter group had the higher mean of the two groups. The test of the unadjusted means indicated that the fixed restriction hearing format had significantly more fatal and injury accidents than did the standard hearing format $(\underline{t}=-1.771$, df $=2329, \underline{p}<.10)$.

The tallies of fatal and injury accidents and property damage accidents obtained for the standard hearing format did not differ, however, from those expected, based on the ratio of fatal and injury accidents to total accidents in the PLCRES data $\left(x^{2}=.12, \underline{d f}=1, N S\right)$. Both the fixed restriction hearing format and the sequential restriction hearing format did exhibit such differences $\left(x^{2}=7.42\right.$ and 10.29 , respectively, both $\left.\underline{d f}=1, \underline{p}<.01\right)$. Visual inspection of the data suggests that fatal and injury accidents were higher for these hearing formats than would have been expected from the proportion of fatal and injury accidents in PLCRES data. These results tend to corroborate the earlier conclusion that the experimental hearing formats (at least the sequential restriction format) had a negative impact on serious accidents. Since the sequential restriction format had the greatest potential for increasing serious accidents, no cost benefit calculations were made for this hearing format.

It is conservatively estimated that one additional fatal accident and an additional 54.72 injury accidents per year would result from statewide implementation of the fixed restriction format in probation violator hearings. These estimates were derived using the proportions of fatal, injury and property damage accidents for negligent operators derived from PLCRES data. Use of the actual proportion of fatal and injury accidents obtained with the project sample, rather than the more stable PLCRES estimates, would have resulted in even higher estimates of future fatal and injury accidents combined (proportions are .3429,.3534, and .4378 for PLCRES, standard hearing, and fixed restriction samples, respectively). 
Furthermore, differences in property damage accidents across the three treatment groups cannot be attributed to the self-reporting instructions issued in the caseload hearing formats. The proportions of property damage accidents reported under financial responsibility statutes and those reported by law enforcement (mutually exclusive in the project data coding) are shown in Table 28. The statistical test revealed no significant differences across hearing formats $\left(X^{2}=.19\right.$, df $\left.=1, N S\right)$.

Table 28

Numbers and Percentages of PDO Accidents by Reporting Source and Hearing Format

\begin{tabular}{|c|c|c|c|}
\hline \multirow{2}{*}{ Reporting source } & \multicolumn{3}{|c|}{ Hearing format } \\
\hline & $\begin{array}{l}\text { Standard } \\
\text { hearing }\end{array}$ & $\begin{array}{c}\text { Fixed } \\
\text { restriction }\end{array}$ & $\begin{array}{l}\text { Sequential } \\
\text { restriction }\end{array}$ \\
\hline Law enfor cement... & $\begin{array}{l}51 \\
(31.688)\end{array}$ & $\begin{array}{c}33 \\
(31.73 \%)\end{array}$ & $\begin{array}{c}45 \\
(35.15 \%)\end{array}$ \\
\hline $\begin{array}{l}\text { Financial } \\
\text { responsibility... }\end{array}$ & $\begin{array}{l}110 \\
(68.32 \%)\end{array}$ & $\begin{array}{c}71 \\
(67.26 \%)\end{array}$ & $\begin{array}{c}83 \\
(64.848)\end{array}$ \\
\hline Total.............. & 161 & 104 & 128 \\
\hline $\begin{array}{l}\text { Expected FR } \\
\text { reported accldents } \\
\text { (based on standard } \\
\text { hearling proportions }\end{array}$ & .51 & 33.28 & 40.96 \\
\hline
\end{tabular}

The financial impact of instituting the fixed restriction hearing format is shown in Table 29. The probability of a net loss was determined by finding the standardized score $(\underline{z})$ of the break-even point and then looking up the associated probability. Note that the probability of a net loss is at least .80 using both the low and high accident cost estimates. The expected loss is estimated to be in excess of $\$ 800,000$. While the $90 \%$ confidence intervals include a region of possible accident reduction (and dollar savings), they also include the possibility of losses over $\$ 1,000,000$.

\section{Procedure and Forms Survey}

A survey of all DIAs who had attended the project training sessions was conducted near the end of the project operational phase. Those surveyed 
Table 29

Annual Financlal Impact Estimates

for Fixed Restriction Hearings

\begin{tabular}{|c|c|c|c|}
\hline $\begin{array}{l}\text { Financlal Impact } \\
\text { estimate source }\end{array}$ & $\begin{array}{c}\text { Expected } \\
\text { financial } \\
\text { Impact }\end{array}$ & $\begin{array}{l}\text { Potential } \\
\text { range (90\$ } \\
\text { conf idence } \\
\text { (nterval) }\end{array}$ & $\begin{array}{l}\text { Probabllity } \\
\text { of net loss }\end{array}$ \\
\hline $\begin{array}{l}\text { NHTSA (high cost } \\
\text { estimate) } \ldots \ldots \ldots\end{array}$ & $-\$ 1,402,102$ & $\begin{array}{c}-4,174,797 \\
\text { to } \\
1,370,527\end{array}$ & .80 \\
\hline $\begin{array}{l}\text { NSC (l ow cost } \\
\text { estimate)........ }\end{array}$ & $-\$ 834,895$ & $\begin{array}{c}-2,230,704 \\
\text { to } \\
560,870\end{array}$ & .84 \\
\hline
\end{tabular}

included both DIAs and their managers. The project duties of those surveyed included scheduling probation violator hearings, conducting hearings and completing associated paperwork, as well as reviewing, monitoring and managing all activities relating to probation violators. A complete listing of the survey questions and DIA responses, as well as general comments, is contained in Appendix $F$. The interpretation of these data is contained in the Discussion section of the project report. The DIA responses are more meaningful as aids in interpreting the project outcomes than as independent information. 


\section{DISCUSSION}

The analysis of descriptive data received from questionnaires and driver records provided information regarding both the personal and driver record characteristics of the probation violator. Drivers who violate negligent operator probation are predominantly young, single males who are employed in blue collar jobs. This profile is consistent with prior DMV descriptions of drivers with high conviction rates (Harrington \& McBride, 1970) and of biographical factors predictive of high accident liability (Harano, McBride, \& Peck, 1973).

The mileage estimates provided by drivers indicate a high annual mileage for probation violators. These estimates may be inflated, since the department allows high mileage drivers two additional points on the driver record prior to classifying them as negligent operators (VC \$12810.5). The majority of drivers needed primarily to drive to and from work between 0600-1800, Monday through Friday. It proved difficult to describe the transportation needs of those driving during their course of employment when such drivers were also on call, worked rotating shifts, or had destinations which differed from trip to trip.

Examination of official driving records revealed that probation violators, on the average, had numerous previous traffic convictions and had been on probation more than one year. Many drivers in the standard treatment hearing format received no license suspension or revocation at project entry. This finding is consistent with an earlier assessment of PV licensing actions (Finkelstein \& MCGuire 1971). It appears that the use of suspension or revocation prior to the PV project was most common for drivers who did not appear for the scheduled hearing. The driving restrictions negotiated in the caseload hearing formats were, for the most part, more lenient than anticipated. Perhaps these results emerged from the project emphasis on a mutually satisfactory agreement between the probation violator and the DIA. It is likely that the restriction patterns used mostly reflect transportation needs related to employment.

Operational differences between the hearing formats resulted in more drivers being retained on probation in the standard hearing, despite the fact that 
this group had the highest proportion of accident- and conviction-free drivers.

Differences in the tallies of drivers receiving licensing actions and the tally of drivers retained on probation more than 12 months might be explained in several ways. First, the required time for review to end probation may exceed 45-75 days for some cases. Project data-gathering procedures allowed 45-75 days to elapse beyond the 12 month follow-up period before driver records were pulled. Nonetheless, records were found which had generated for review to end probation (i.e., the 01 suspense was no longer present) where there were no additions to the record, and yet the p-flag was still present. It should be noted that the caseload treatment groups had the most involved review process during the probation violator project, yet the standard hearing format had the greater difference in proportion of drivers with licensing actions and drivers with p-flags. It is likely that the standard review currently conducted to determine whether probation can be ended results in retaining drivers on probation when they have not qualified for treatment at the time a conviction or accident abstract was posted on the driver record.

If the department truly wishes to take action against all probationary drivers who fail to maintain a clean record for 12 months, such action should be taken at the time the conviction abstract is posted on the driver record. Both the timeliness and perceived fairness of licensing actions taken at the end of the 12-month probation period are suspect.

Differences in probation completion rate have implications for the driver improvement program in any comparison of hearing alternatives. The department has recently considered the feasibility of adopting a single hearing strategy under which drivers would receive a revocation, but the action would be stayed. Reimposition of the stayed action would be contingent upon subsequent failure, defined as receipt of traffic convictions or accidents. If the effectiveness of the "single hearing" for probation violators approximates that of the standard hearing, one would expect the number of revocations to increase over the current number of legal actions by $140 \%-170 \%$; i.e., to perhaps 6,200 per year. Revocation would replace warning letters, extensions of probation, and suspension of the driving privilege which are currently the more common licensing actions. 
Were the single hearing concept implemented at the individual hearing level, drivers receiving revocations due to violation of probation would include not only those currently defined as entry level probation violators and probation violator recidivists, but also all drivers who receive convictions while on probation, but fall short of the current PV hearing scheduling criteria. The volume of revocations would be fairly large during the first year of the single hearing process, perhaps as high as 8,000-10,000 drivers. The current probation violator level of the post licensing control program would essentially be eliminated after one year since all drivers at that level would either successfully complete probation or be revoked. The volume of revocations thereafter would be approximately $35 \%$ of all drivers at the individual hearing or probation-by-mail level, assuming treatment effectiveness comparable to the current conviction survival rate for the individual hearing (Carpenter, 1980).

The traffic safety impact analyses offer little support for the new hearing formats. The standard hearing group had the lowest average number of subsequent fatal and injury accidents. Discriminant analysis revealed that the combination of fatal and injury accidents was largely responsible for the statistically significant multivariate test of traffic safety impact on accidents. Little additional information was gained in the discriminant analysis by including property damage accidents as a variable (once fatal and injury accidents entered the discriminant functions equation), even though roughiy $2 / 3$ of all reported subsequent accidents were in this category.

The accident survival analyses indicated significant differences between the standard hearing and the sequential restriction hearing formats. These differences apparently occurred during months 1-4 and 9-12 of the follow-up period. The fact that survival lines during months 5-8 were parallel suggests that the initial treatment effects had dissipated by the fourth month. Changes during months 9-12 may have been due to actions levied against recidivists in the standard hearing format.

The simultaneous test of accidents and convictions demonstrated that significant differences existed between hearing formats, and that the pattern of accidents and convictions was complex. This pattern was dominated by fatal and injury accidents and zero-point convictions. No significant univariate 
differences for two-point or one-point convictions were found, although the trends on both favored the standard group. It is unclear why this was so. It may be that the initial licensing actions actually used in the three hearing formats did little to differentially reduce driving exposure across hearing formats. Recall that nearly $50 \%$ of the drivers in the standard hearing format received no suspension or revocation at project entry. Likewise, the restrictions used in the new hearing formats tended to be liberal.

Differences in zero-point conviction means across hearing formats are difficult to explain from the available project data. Violation of a suspension (CVC \$14601) receives no point count, although it is a misdemeanor, while violation of a restriction receives one point (CVC \$14603). Furthermore, an examination of several hundred driver record printouts indicates that more often than not, the CVC $\$ 14601$ conviction abstract does not contain evidence of a moving violation. It seems likely that the moving violation is often dropped from the charges against the driver as part of the plea-bargaining process. Given these conditions, it is possible that violations of project entry actions (suspension or revocation in the standard hearing, restrictions in the other hearing formats), when they occurred, may have produced a point count differential on the conviction abstracts received by project participants. This interpretation is largely conjecture, however, and other unknown factors may have influenced conviction abstract point counts.

The survival patterns for convictions demonstrated no differences in traffic safety impact duration between treatment groups. Comparisons of drivers with different licensing action durations within the standard hearing were more revealing. These results suggest that driver improvement analysts were effectively screening high risk and low risk drivers--if one assumes that those receiving more severe sanctions were perceived as high risk--but the licensing actions used did not counteract their increased risk level. Prior total abstracts were the best discriminating variable in the discriminant function analysis of convictions and accidents. There is some evidence that recidivism can be predicted to a statistically significant degree. Marsh and Hubert, (1974) found that DIAs can predict recidivism to a modest degree. Such patterns also appear in research on drunk drivers. Homel (1980) states that drinking drivers may be classified as responsive or nonresponsive to licensing actions, and that such a classification is supported by recidivism 
data. Sufficient evidence was not obtained for probation violators to interpret changes in conviction survival curve slopes in terms of licensing action duration, i.e., changes in slope directions for either convictions or accidents did not noticeably coincide with the end of a license suspension. It may well be that differences in conviction likelihood vary simultaneously with both licensing action and driver related variables (e.g., risk taking, defiance of authority).

Some readers may wish to know how the standard hearing format compares with the effectiveness of probation violator treatment as reported previously by the department (e.g., PLCRES Status Report \#4). A direct comparison of the data in the two reports is open to a number of logical and statistical errors. It is very possible, for example, that changes in accident and conviction means for probation violators are due to some unknown factor (rather than the probation violator hearing) that has changed over time. It is also possible that the current cohort of probation violators differs from the 1976-77 cohort. With these cautions in mind, and realizing that any causeand-effect conclusions may be invalid, we will nonetheless discuss the trends in accident means over time.

No 12-month accident means were reported for probation violators in PLCRES Status Report \#4. The reported 12-month survival proportions may be converted to accident means by multiplying the proportion failing by 1.09 . This calculation results in accident means of .187 and .202 for drivers receiving the PV hearing through 1977 and the comparable hands-off control group, respectively. The total accident means for the three treatments analyzed in the probation violator project were .1796, .1904, and .2365 for the standard hearing, fixed restriction hearing and sequential hearing formats, respectively. While statistical tests of these differences are meaningless, one may make some cautious observations predicated--without proof--on the assumption that drivers defined as probation violators in the various studies are members of the same population. The accident mean for the standard hearing was lower than the former PLCRES treatment mean. Had such a difference been found in a scientifically controlled study, and had it been found to be statistically significant, it would be attributed to differences in treatment impact. The specific differences known to exist between the previous PV hearing and the standard hearing were: (1) stamping "PROBATION" on the 
license and (2) specifically defining accident responsibility as a violation of probation. The available evidence thus suggests the possibility that these differences in procedure may be producing a slight additional accident reduction. A controlled evaluation would be required to demonstrate a logically sound conclusion on this issue.

Comparison of the fixed restriction hearing format accident mean to the earlier data shows that the fixed restriction group accident mean was midway between the hands-off condition and the former PV hearing. The sequential restriction hearing mean is higher than the hands-off control group. Clearly, the latter results, if obtained in a controlled study, would be interpreted as negative treatment impact. Such results could not possibly produce desirable benefit cost ratios. Again, the reader is cautioned that a logically sound conclusion regarding the efficacy of the various hearing formats (compared to doing nothing) would require further evaluation.

One must finally raise the issue of whether any driver improvement strategy based upon behavior modification learning principles can reduce accidents or convictions to a significantly greater degree than conventional punitive sanctions. Results to date--including the present project and Kleinknecht (1969)--have failed to demonstrate the applicability of such strategies with probation violators. Likewise, studies with other problem drivers (Harano \& Hubert, 1974; Marsh, 1978) have yielded only equivocal results. One of the basic precepts of learning theory is that reinforcement should occur immediately after the desired behavior in order to be maximally effective. Given a lag of 96 days between a traffic violation and a PV hearing, this simply is not occurring. Finkelstein \& McGuire (1971) also expressed their concern with the lag times between violation date and DMV hearing. Lag time appears to have decreased from the 152 day average they reported to a mean of 96.3 days. Secondly, many drivers who signed probation agreements may have considered the contract an avoidance agreement rather than an escape agreement. Under these conditions, a license suspension or revocation would be perceived of by the driver as punishment. As such, the licensing action would tend to decrease undesirable driving behavior. The reduction in unsafe driving would be most likely to take place, however, only in the presence of some cue that the possibility of punishment was increasing; e.g, when a police officer was present. 
An escape contract, on the other hand, is structured to increase good driving behavior by removing an ongoing adversive condition. Technically, the removal of the adversive situation under these conditions is negative reinforcement rather than punishment. No external cue other than the adversive situation itself is necessary to produce the desired behavior. Driver perception of licensing actions as punishment and the probation agreement as an avoidance contract could well lead to an ineffective treatment.

Although the above problems raise questions about the efficacy of behavior modification in improving negligent driving, it would be precipitous to recommend that attempts to develop an effective operational model be abandoned. Rather, any future application of behavior modification techniques within the post-licensing control program should be made with the knowledge that due process requirements may place limitations on actual application of those models, and that the specific formats evaluated here are not likely to be effective.

There are also a number of reasons, at the operational level, which might explain the general lack of success of the new hearing formats. Some drivers may not have "bought into" the contracting process. Under the latter circumstances, they would have had little incentive to improve their driving. Secondly, some drivers may not have understood the probation agreement. The complexity of the sequential hearing format may have led to confusion in some drivers as to the department's plans and expectations. Comments by some DIAs indicated that this complexity was sometimes burdensome to them. Other DIAs, however, preferred the sequential format because of the greater span of control over the driver.

The evidence obtained in evaluating the two restriction hearing formats should not be taken to mean that restricting the driving privilege is an ineffective driver control action. No evaluation of restrictions per se was possible, since this sanction was confounded with the contingency contracting strategy and caseload assignment procedures. The possibility that restrictions were too lenient, or not enforcible as written, can neither be supported or rejected using the project data. An intensive effort was made during the project training and pilot phases to secure clearly worded, enforcible restrictions. Likewise, the driver-monitoring procedures designed as part of 
the caseload assignment process may have broken down. Thirty out of 57 DIAs who were originally trained to conduct project hearings were either transferred, promoted or retired during the course of the project.

Driver improvement analysts who had received project training were surveyed near the end of the project regarding the strengths and weaknesses of the operational procedures and the forms used in the various hearing formats. It was recognized that the experience gained through day-to-day use of the procedures might prove valuable in interpreting the outcome of the data analyses, and in making recommendations for the probation violator hearing component of the negligent operator program. A listing of the survey questions and the most common responses is contained in Appendix $F$. General comments by those surveyed are also contained therein.

Responses indicated that most DIAs felt that the fixed restriction hearing required 45-60 minutes, while the sequential hearing required a full 60 minutes. Those conducting hearings most commonly reported a weekly volume of 1-3 P.V hearings. Favorable comments regarding the pre-hearing questionnaire indicated that it focused on the specific information gathering tasks for which it was intended. Negative comments and suggestions for improvement indicated it was too complicated and time consuming. It appears from the responses of DIAs that there were difficulties with the pre-hearing questionnaire that should be evaluated before such an information gathering strategy is attempted again.

Responses regarding the negotiated probation agreement showed more acceptance of this document and its associated procedures than of the questionnaire. The most common responses indicated that the document led to a mutually binding agreement that encouraged joint decision-making by the DIA and the driver. Negative comments, however, indicated that driver refusal to cooperate in the process was at times a problem. It appears that although most drivers ultimately signed the probation agreement, some were reluctant participants in the negotiation process. Suggestions for improving the probation agreement form itself focused on minor changes in wording.

The majority of the respondents indicated that the caseload approach did improve DIA knowledge of the driver and provide some feedback regarding DIA 
performance. The most commonly indicated shortcoming of the approach was the potential for bias by the DIA against the driver, or the potentially better response by the driver to a different DIA.

DIA preferences between the hearing formats were divided. Among those stating a preference, the standard hearing format was the most popular with the fixed restriction hearing a close second. Only a few DIAs preferred the sequential hearing format. It was most commonly felt that traffic safety impact should be the criteria for any choice between the hearing formats. The flexibility of operational personnel was ranked second, and cost effectiveness (which, of course, considers program impact and program costs jointly) was ranked third in importance by DIAs.

General comments were also solicited regarding the alternative probation violator hearing procedures. The tone of these comments ranged from enthusiasm for the caseload approach and use of contingency contracts to complete rejection of these alternatives. It appears that the majority of DIAs felt that the alternative hearing formats were workable, but suggested that forms and procedures be simplified, that some additional time be allowed for follow-up activities, and that constraints on DIA discretion which were required by evaluational rather than operational needs be removed. Although requesting a louder voice in the processes by which procedures and policies are made and managed, most DIAs recognized that traffic safety impact and cost effectiveness are the yardstick against which procedures must be measured. Some of the general comments addressed the same personnel, procedure, and work climate issues raised in the project interim report (Hagen \& Williams, 1979).

Some operational personnel objected to working with new procedures during pilot trials or evaluations. Likewise, working DIAs and managers (like many practitioners) at times regard program evaluation as a necessary evil at best. It is probably true in general that practitioners believe that their efforts in changing behavior are successful. To deny that such success exists is to remove one of the intrinsic rewards of conducting driver improvement hearings. 


\section{RECOMMENDATIONS}

The recommendations of the Research \& Development office regarding the probation violator hearing are as follows. The department should cease using the fixed restriction hearing and sequential restriction hearing formats. The project results suggest that statewide implementation of either of these formats would result in increased program costs, without commensurate traffic safety benefits. The department should continue to conduct probation violator hearings, using license restrictions at the option of the driver improvement analyst. The current practice, whereby many probation violators receive no restriction, suspension or revocation of the driving privilege following a hearing, should be closely examined. It may be possible to further reduce the accident and conviction rates of probation violators by systematically increasing the use of licensing actions at the first PV hearing. Such a change in practice, if implemented, should, of course, be closely monitored and evaluated.

Concerns raised regarding the probation violator hearing in past years have been primarily economic; i.e., the PV hearing was known to reduce traffic accidents, but not sufficiently to offset hearing costs. In light of the reduced review of discretionary actions beginning in 1981 ( $A B 351$ - Montoya), it is suggested that the benefit-cost ratios of the $P V$ hearing may have improved over those previously reported. Should additional cost reductions be necessary or desirable, it is recommended that the department evaluate the feasibility of conducting only one PV hearing per driver (the single hearing concept). Additional convictions or FTAs during the following year would result in suspension or revocation of the driving privilege. Likewise, responsible accidents should be considered grounds for licensing action. While the reaction of the driving public to such procedures must be considered, it is likely that eliminating the hearing costs (except in cases where the conviction or accident may have been posted on the driver record in error) could result in cost savings to the department. If the department chooses to implement the single hearing concept, it is recommended that such a program be subjected to a rigorously controlled traffic safety evaluation.

The department should continue to restrict the driving privilege of the negligent operator in cases where such an action is determined by the DIA to 
be appropriate. Likewise, the department should explore the feasibility of employing restrictions for other drivers who demonstrate elevated accident risk, but who currently receive no licensing action. For example, license restriction in addition to participation in an approved alcohol treatment program may serve to reduce accident risk until such time as treatment produces changes in drinking and driving practices. Another example is the large percentage of probation violators who currently receive no licensing action following their initial PV hearing. Considering the extreme deviancy and accident risk level of any driver who advances to PV status, a license restriction is the minimal outcome that should be considered. 


\section{REFERENCES}

Ames, W. A., \& Micas, S. L. Programs and problems in rehabilitation of the high risk driver. Charlottesville, VA: Highway Research Council, 1972. Bandura, A. Principles of behavior modification. New York, NY: Holt, Rinehart, and Winston, Inc., 1969.

Bishop, Y. M. Multidimensional contingency tables: Cell estimates. (Doctoral Dissertation, Harvard University, 1967) University Microfilms No. 74-9261.

Bock, R. D. Multivariate statistical methods in behavioral research. New

York: McGraw-Hill, 1975.

Borgen, F. H., \& Seling, M. J. Uses of discriminant analysis following MANOVA: Multivariate statistics for multivariate purposes. Journal of Applied Psychology, 1978, 63(6), 689-697.

Boudin, H. M. Contingency contracting as a therapeutic tool in the deceleration of amphetamine use. Behavior Therapy, 1972, 3, 604-608.

California Department of Motor Vehicles The California Driver Fact Book. 5th Edition, Sacramento, CA: Author, Report 29, 1981.

Callner, D. A. Behavioral treatment approaches to drug abuse: A critical review of the research. Psychological Bulletin, 1975, 82(2), 143-164.

Carmer, S. G. \& Swanson, M. R. An evaluation of ten pairwise multiple comparison procedures by Monte Carlo methods. Journal of the American Statistical Association. 1973 68,66-74.

Carpenter, D. W. \& Peck, R. C. Post licensing control reporting and evaluation system: Negligent operator program costs and effectiveness. Periodic Status Report No. 6. Sacramento, CA: Department of Motor Vehicles, 1980.

Coppin, R. S. \& Samuels, I. Control of the negligent driver, Sacramento, CA: Department of Motor Vehicles, (NTIS No. PB-177647) 1961.

Coppin, R. S., \& van 01 denbeek, G. Driving under suspension and revocation. Sacramento, CA: Department of Motor Vehicles, (NTIS No. PB-218850) 1965. Davidson, W. S., II, \& Seidman, E. Studies of behavior modification and juvenile delinquency: A review, methodological critique, and social perspective. Psychological Bulletin, 1974, 81(12) 998-1011. 
Finkelstein, R., \& McGuire, J. An optimum system for traffic enforcement/ driver control volumes I through III. Sacramento, CA: Department of Motor Vehicles, October, 1971. (NTIS No. PB-217952, Part I), (NTIS No. PB-217953, Part II), and (NTIS No. PB-217954, Part III).

Franks, C. M. Behavior therapy: Appraisal and status. New York, NY: McGraw-Hi11, Inc., 1969.

Garretson, M. E., \& Peck, R. C. The effect of "no action" negligent operator hearings as an alternative to hearings resulting in probation. Sacramento, CA: Department of Motor Vehicles, (NTIS No. PB-80-101686) 1979.

Glass, G., Peckham, P., \& Sanders, J. Consequences of failure to meet assumptions underlying the fixed effects analyses of variance and covariance. Review of Educational Research, 42 (1972). American Education Research Associates, Washington D.C., 1972.

Goldiamond, I. Toward a constructional approach to social problems. Behavjorism, 2(1), 1974, 1-84.

Hagen, R. E., McConnel1, E. J., \& Williams, R. L. Suspension and revocation effects on the DUI offender. Sacramento, CA: Department of Motor Vehicles, 1980.

Hagen, R. E., \& Williams, R. L. Driver improvement: A survey of personnel, procedures, and work climate--An interim report prepared in support of a project titled "Optimization of the probation violator hearing format." Sacramento, CA: Department of Motor Vehicles, 1979.

Harano, R. M., McBride, R. S., \& Peck, R. C. The prediction of accident liability through biographical data and psychometric tests. Sacramento, CA: Department of Motor Vehicles, March, 1973. (NTIS No. PB-220369). Harano, R. M., \& Hubert, D. M. An evaluation of California's "good driver" incentive program. Sacramento, CA: Department of Motor Vehicles, (NTIS No. PB-235032/AS) 1974.

Harrington, D. M., \& McBride, R. S. Traffic violations by type, age, sex, and marital status. Sacramento, CA: Department of Motor Vehicles, June, 1970. (NTIS No. PB-218851).

Harris, R. J. A primer of multivariate statistics. New York: Academic Press, 1975.

Homel, R. Penalties and the drink/driver: A study of one thousand offenders. Volume 1 - Main Report. School of Behavioural Sciences: Macquarie University, 1980. 
Kadel1, D. J., Peck, R. C., Fong, S., \& Marsh, W. C. Post licensing control reporting and evaluation system: Negligent operator program costs and effectiveness. Periodic Status Report \#5. Sacramento, CA: Department of Motor Vehicles, (NTIS No. PB-81-154262) 1980.

Kadell, D., \& Peck, R. C. Post licensing control reporting and evaluation system: Negligent operator program costs and effectiveness. Periodic Status Report No. 4, Sacramento, CA: Department of Motor Vehicles, (NTIS No. PB-295082/AS) 1979.

Kade 11, D., Peck, R. C., \& Howe, W. Post licensing control reporting and evaluation system: Negligent operator program costs and effectiveness. Periodic Status Report No. 3, Sacramento, CA: Department of Motor Vehicles, 1978.

Kade11, D., Peck, R., Howe, W., \& Epperson, W. Post licensing control reporting and evaluation system: Negligent operator program costs and effectiveness. Periodic Status Report No. 2, Sacramento, CA: Department of Motor Vehicles, 1977.

Keselman, H. J., Games, P. A. \& Rogan, J. C. Protecting the overall rate of Type I errors for pairwise comparisons with an omnibus test statistic. Psychological Bulletin. 1979, 86, 884-888.

Kleinknecht, R. A. Behavior modification of problem drivers. Olympia, WA: Department of Motor Vehicles, 1969.

Kazdin, A. E. Behavior modification in applied settings. Homewood, IL: The Dorsey Press, 1975.

Kwong, K. W., Kuan, J., \& Peck, R. C. Longitudinal study of California driver accident frequencies I: An exploratory multivariate analysis. Sacramento, CA: Department of Motor Vehicles, (NTIS No. PB-267435/AS) 1976.

Marsh, W. C. \& Hubert, D. E. The prediction of driving record following driver improvement contacts, Sacramento, CA: Department of Motor Vehicles, (NTIS No. PB-238687/AS) 1974.

Marsh, W. C. Educational approaches to driver improvement: An experimental evaluation with negligent drivers. Sacramento, CA: Department of Motor Vehicles, (NTIS No. PB-285541/AS) 1978.

McGuire, J. P., \& Peck, R. C. Traffic offense sentencing processes and highway safety: Volume II. San Francisco, CA: PRC Public Management Services, Inc., 1977. (DOT-HS-802-327) 
National Highway Traffic Safety Administration. Involvement of suspended/ revoked drivers in traffic crashes--A statement of the problem. In cooperation with the American Association of Motor Vehicle Administrators, Washington, D.C., 1979.

Nie, N. H., Hill, C. H., Jenkins, J. G., Steinbrenner, K., \& Bent, D. H. SPSS: Statistical package for the social sciences (2nd Edition). New York: McGraw-Hill, 1975.

0'Dell, S. Training parents in behavior modification: A review. Psychological Bulletin, 1974, 81(7), 418-433.

01son, C. L. On choosing a test statistic in multivariate analysis of variance. Psychological Bulletin, 83, 4, pp. 579-586, 1976.

0lson, C. L. Practical considerations in choosing a MANOVA test statistic: A rejoinder to Stevens. Psychological Bulletin, $\underline{86}$, 6, pp. 1350-1352, 1979.

Overal1, J. \& Klett, C. J. Applied Multivariate Analysis. San Francisco: McGraw-Hi11, 1972.

Peck, R. C. Toward a dynamic system of driver improvement program evaluation. Human Factors, 18(5), 1976, 493-506.

Peck, R. C., \& Kuan, J. Individual accident prediction models (Chapter V). In Department of Insurance (Eds.), Study of California driving performance (Phase II). Sacramento, CA: November 1979.

Rubin, J. Z., \& Brown, B. R. The social psychology of bargaining and negotiation. New York, NY: Academic Press, Inc., 1975.

Schuster, D. H. The effects of official action taken against problem drivers. Iowa Academy of Science, 1970, 77, 315-321.

Schuster, D. H. A two year follow-up of official action taken against problem drivers. Paper presented at the American Psychological Association Convention, Washington, D.C., 1971.

Sherman, B., \& Ratz, M. An evaluation of probation-by-mail as an alternative to mandatory hearing attendance for negligent operators. Sacramento, CA: Department of Motor Vehicles, (NTIS No. PB-80-101694) 1979.

Sobe11, M. B., \& Sobe11, L. C. Individualized behavior therapy for alcoholics: Rationale, procedures, preliminary results, and appendix. Sacramento, CA: Department of Mental Hygiene, 1972.

Stevens, J. Comment on 0lson: Choosing a test statistic in multivariate analysis of variance. Psychological Bulletin, 86, 2, pp. 355-340, 1979. 
Stuart, R. B. Behavioral contracting within the families of delinquents. Journal of Behavioral Therapy and Experimental Psychiatry, 1971, 2, 1-11.

Tosti, D., Hagen, R. E., \& Williams, R. L. Probation-violator hearing project: Training manual. Sacramento, CA: Department of Motor Vehicles, 1978.

Williams, R. L., \& Hagen, R. E. Operations and administrative procedures manual: Probation-violator hearing project. Sacramento, CA: Department of Motor Vehicles, 1978.

Zeilberger, J., Sampen, S. E., \& Sloane, H. N., Jr. Modification of a child's problem behaviors in the home with the mother as therapist. Journal of Applied Behavior Analysis, 1968, 1(1), 47-53. 


\begin{tabular}{c|c} 
STATE OF CALIFORNIA & DEPARTMENT OF MOTOR VEHICLES \\
DIVISION OF DRIVERS LICENSES & DRIVER'S LICENSE NO. \\
\hline DRDER MODIFYING PROBATION & \begin{tabular}{l} 
VEHICLE CODE AUTHORITY SECTION \\
14105 \\
\hline EFFCTIVE DATE \\
$6 / 13 / 79$
\end{tabular} \\
\hline
\end{tabular}

As a result of your hearing the terms and conditions of your probation are modified to include the following:

YOU MUST REMAIN FREE FROM TRAFFIC ACCIDENT

RESPONSIBILITY

All other terms and conditions of probation remain the same. No other restriction or action which might be in effect is changed by this notice.

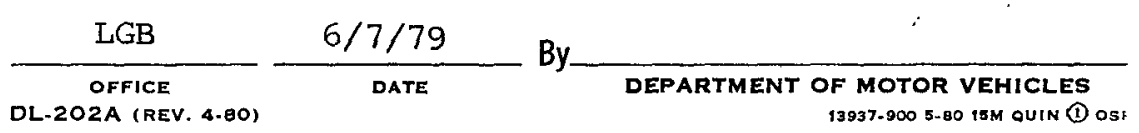




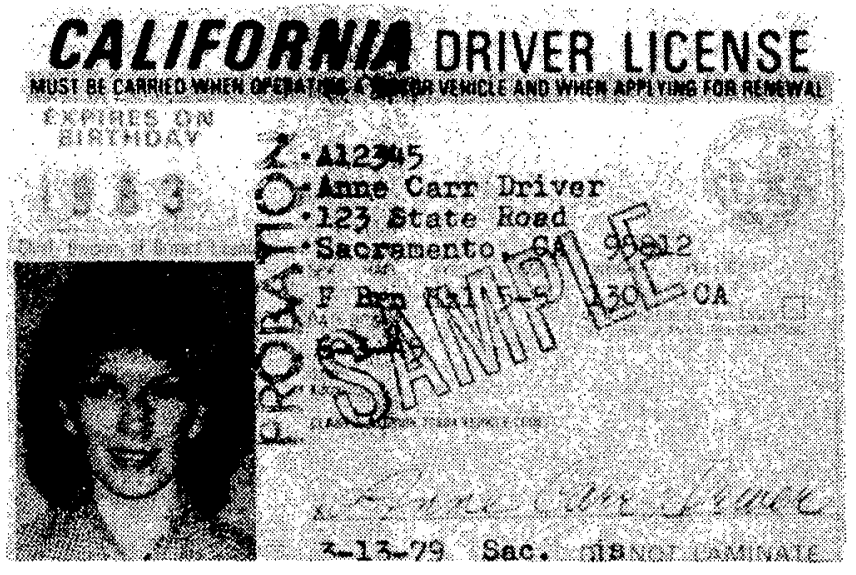

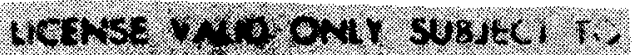

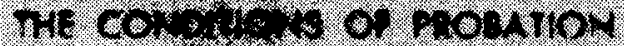

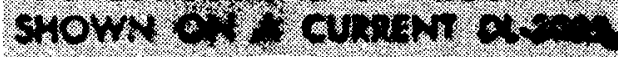




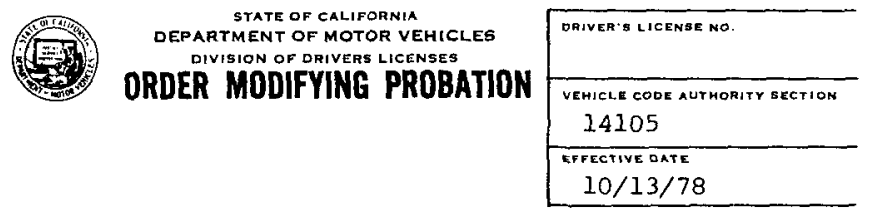

As a result of your hearing the terms and conditions of your probation are modified to include the following: Driving permitted from 5:00 a.m. to 12 midnight Monday through Friday and from 8:00 a.m. to 6:00 p.m. on Saturdays. No Sunday driving permitted.

You must remain free from traffic accident responsibility The above restriction ends at the termination of probation.

All other terms and conditions of probation remain the same. No other restriction or action which might be in effect is changed by this notice.

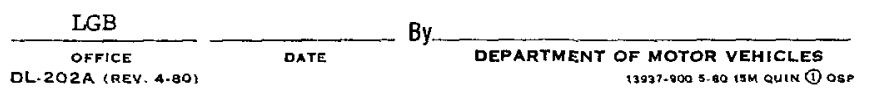

\begin{tabular}{|c|c|c|}
\hline \multirow{3}{*}{ 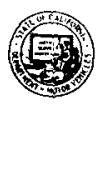 } & \multirow{2}{*}{$\begin{array}{c}\text { STATE OF CALIFORNIA } \\
\text { DEPARTMENT OF MOTOR VEHICLES } \\
\text { DIVISION OF DRIVERS LICENSES } \\
\text { ORDER MODIFYING PROBATION }\end{array}$} & DRIVER B LICENSEE NO. \\
\hline & & $\begin{array}{l}\text { VEHICLE CODE AUTHORITY SECYION } \\
14105\end{array}$ \\
\hline & SECOND STAGE & $\begin{array}{l}\text { EFFECTIVE DATE } \\
2 / 13 / 79\end{array}$ \\
\hline
\end{tabular}

As a result of your hearing the terms and conditions of your probation are modified to include the following: Driving permitted from 5:00 a.m. to midnight Monday through Friday. Unlimited driving permitted on Saturday, but no Sunday driving.

YOU MUST REMAIN FREE FROM TRAFFIC ACCIDENT RESPONSIBILITY

The above restriction ends on termination of probation.

All other terms and conditions of probation remain the same. No other restriction or action which might be in effect is changed by this notice.

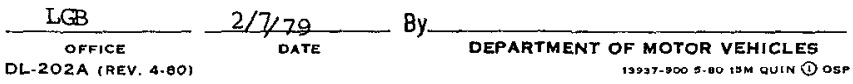

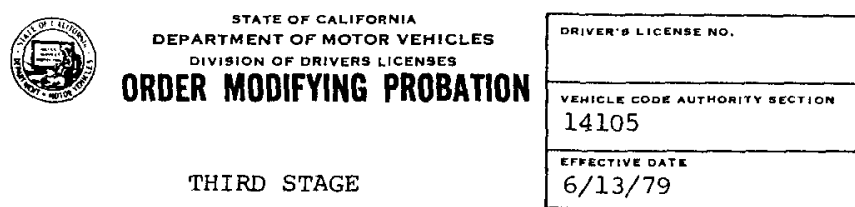

As a result of your hearing the terms and conditions of your probation are modified to include the following:

YOU MUST REMAIN FREE FROM TRAFFIC ACCIDENT RESPONSIBIIITY

The above restriction ends on termation of probation

All other terms and conditions of probation remain the same. No other restriction or action which might be in effect is changed by this notice.

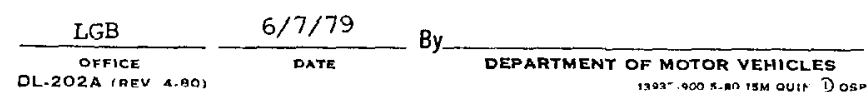


INSTRUCTICNS

11) Please corflete this questionnaire before your hasing starts, you have approxinately-15 minutes.

(2) Please an swer each of the following questions as completely as possible.

NotE: Your answers to chese quescions will be reviewed during your hearing. They will help your analyst know you better and
to understand your driving needs.

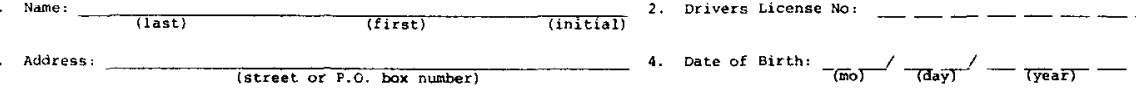

$$
\begin{aligned}
& \text { (city) (zip code) }
\end{aligned}
$$

5. Home Telephone No:

6. Frincipal occupation (If student, specify) oncriel - freelarice what hours do you normally work or attend school? it warbeos

7. Principal employer: Direyer Prodeling Cegency

8. Mari tal scatus (check one only):

$$
\underset{\substack{\text { single (never } \\ \text { married) }}}{\text { Married }} \square \text { separated } \square \text { Divorced } \square \text { widowed How Long? }
$$

4. What vehicles do you normally drive? Include all cars, trucks or notorcycles you may use for work or personal business.
Make vehicle "1 the vehicle you drive most of ten, vehicle *2 second nost often, and so forth

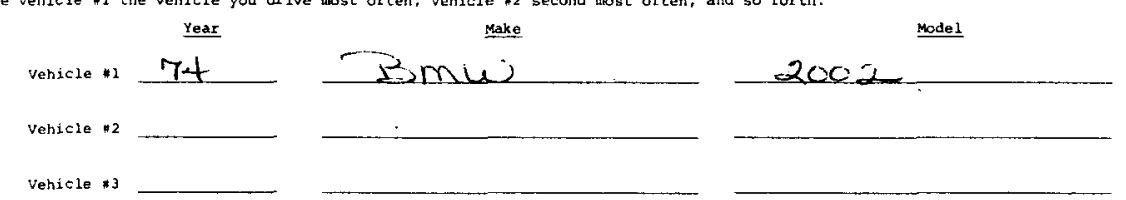

10. Approximately hou nany miles do you usually drive a year 2 (check one)

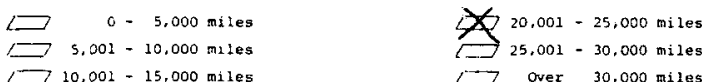

$$
\begin{aligned}
& 7 \text { Over 30,000 miles }
\end{aligned}
$$

\#15,001 - 20,000 miles

\section{How confident are you about this mileage estimate? (check one)}
Very sure
$\square$ pairly sure
$\square$ unsure

11. Approximately hou many years have you been driving? Y_. Y Y

12. In the past month

A. How many hights have you driven after $100^{\circ}$ clock at night? 10

B. Have you driven to "let off steam" or to think out your problems?

c. Have you driven after having three or more drinks? $\square$ yes $\square_{\text {res }}^{\text {nights }}$ 奴o

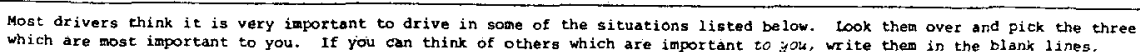
Look over ene 12 ise again and pick the most inportant driving situation for you. Put a one (1) on the short 1ine. Fut a two

13. $X \perp$ to and trow work

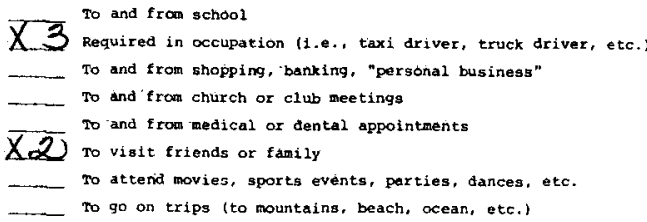

\begin{tabular}{|c|c|c|c|c|c|c|c|}
\hline & sonday & Tuesday & wednesday & Thursday & Friday & Sacurday & Sunday \\
\hline $\begin{array}{l}6: 00 \text { in the morning } \\
\text { to noon }\end{array}$ & $\checkmark$ & $\checkmark$ & $\checkmark$ & $\checkmark$ & $\checkmark$ & & \\
\hline $\begin{array}{l}\text { noon to } 6: 00 \text { at } \\
\text { night }\end{array}$ & $\checkmark$ & & $\checkmark$ & $\checkmark$ & $v^{\prime}$ & $\checkmark$ & \\
\hline 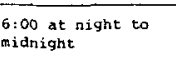 & $\sqrt{ }$ & $\sqrt{ }$ & $\checkmark$ & $v^{\prime}$ & $\checkmark$ & & \\
\hline $\begin{array}{l}\text { midnight to } 6: 00 \text { in } \\
\text { the morning }\end{array}$ & & & & & & & \\
\hline
\end{tabular}

14. In question "13, you indicatad the most important situations for you to drive. Please check ( $V$ ) below inhen you usually do
this type of driving (Your \#1 choice Erom question \#13)

15. How of ten last month did you ride the bus? (check one) $T_{\text {to bus available }}$ 'Eus avallable but never use $\sum_{1-5 \text { times }}$ Yore than 5 times

16. Do you car pool to and from work or school? $\Longrightarrow$ often sometimes

17. could you ride to work or school with someone else? $\square$ of ten $\square$ sometimes

i8. Are there other 1icensed drivers 3iving with your yes $^{\text {yes }}$ 
PROBATION AGREEMENT

$$
\begin{array}{cc}
\text { Beginning } & \text { Ending } \\
\text { Date } & \text { Date }
\end{array}
$$

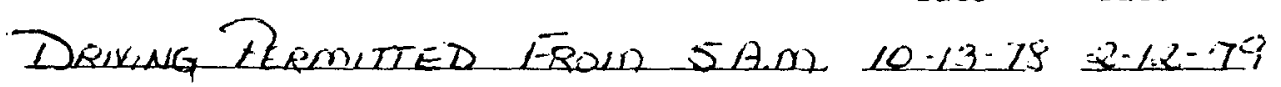
te 12 ONLLNGMT IVONDAY - FRIDAY

AND Feom SAm to GION ON SATLEDAY. No SUADAY DRIVING PERMITTED.

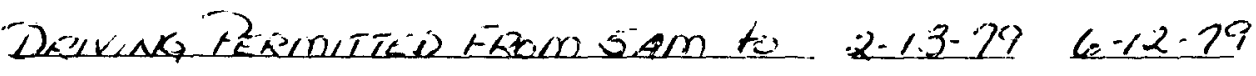

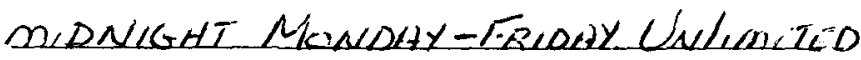

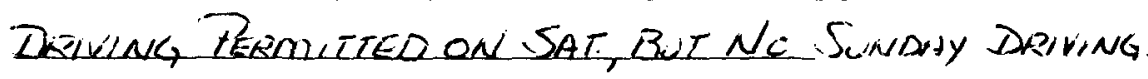
You Mlust coxey All Conditions 10-13-28 10-12-79 of PBOBATION PRNTED BLlowi

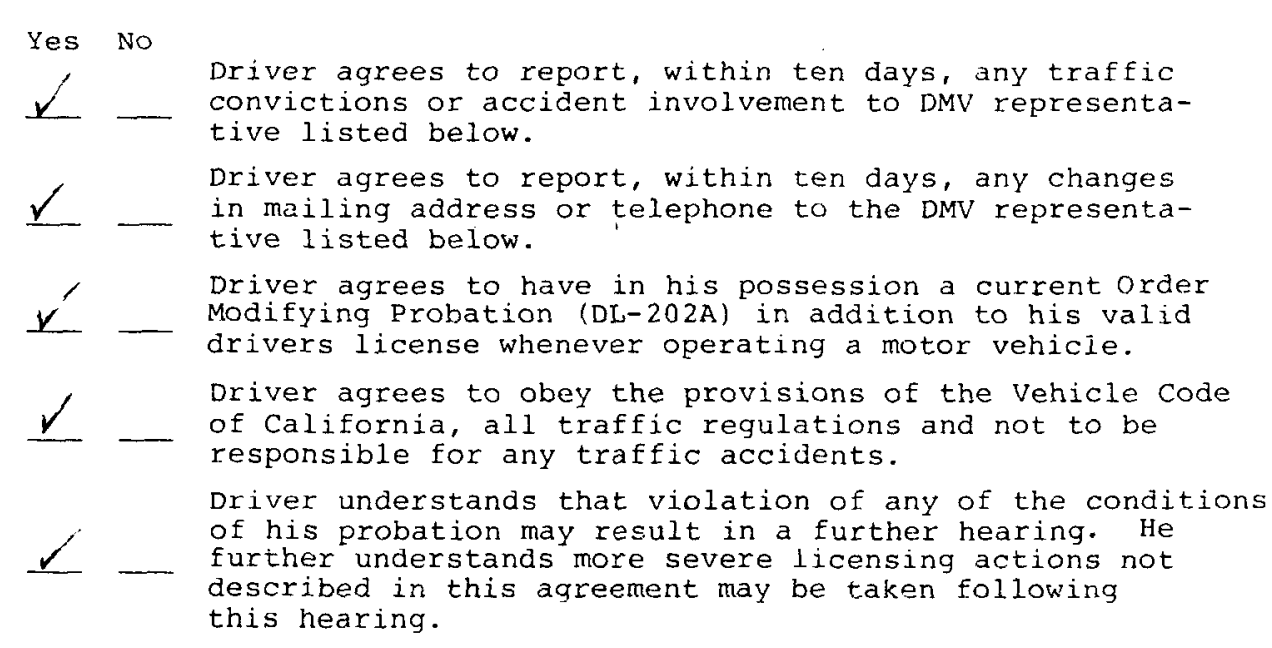

DRIVER

$\longrightarrow$ signature $\quad 1 \frac{1}{\text { Datc }}$

DL number

Mailing

Address

Phone

Number
DMV REPRESENTATIVE

\begin{tabular}{l} 
Name Signature \\
Title \\
Phone \\
Number \\
Dirv \\
Reviewer \\
\hline Signature
\end{tabular}




\section{APPENDIX B \\ Probation Violator Evaluation \\ Data Base}

DRIVER DATA

- Demographic Data
A. Sex
G. High-risk driving during last month
B. Age
1. Letting off steam
C. Marital status
2. After $3+$ drinks
D. Duration of marital status
3. After 2200 hours
E. Occupation
H. Bus or car pool available
F. Yearly milage
I. Bus or car pool used

- Two-Year Prior Driver Record History

A. Abstracts

1. All two point

2. Violation of restrictions

3. All one point

4. All zero point

5. Violation of suspension and/or revocation actions

B. Accidents
1. Fațal
2. Injury
3. Cited or responsible
4. Single vehicle
5. Night time (2000-0600 hours)
6. Aicohol and/or drugs
7. Total law enforcement reported
8. Total financial responsibility
9. All accidents

6. Total countable points

7. Total convictions

8. Total accidents

9. Failure to appear in court 
- DMV post licensing control (PLC) activity

A. Suspensions and/or revocations

1. Total duration of all mandatory suspensions/revocations

2. Number of implied consent (IC) suspensions

3. Number of DUI/drug suspensions/revocations

4. Number of FR suspensions/revocations

5. Total number of discretionary suspension or revocation actions

6. Duration of all negligent operator (discretionary) suspensions and/or revocations (reason codes 300-329, $450-451$, and 854 )

B. DMV hearings, interviews, or reexaminations (reason codes $300-329,450-451,854,857-859$, or $861-864$ )

1. Total number of discretionary S\&R hearings

2. Attended

3. Not attended

C. Unique groups

1. Prior control group status

2. Prior probation-by-mail (reason code 300)

3. Prior "no-action" treatment

- Project entry history

A. Probation

1. Duration of current probation

B. Entry hearing attendance

C. Entry action: May be warning letter, end probation, modify probation, extend probation, restriction, suspension, or. revocation

1. Suspension duration

2. Restrictions
a. Number of restriction stages
d. Vehicle
b. Duration of restrictions
e. Geographic
c. Time--hours/week allowed 
- Follow-up driver record history--12 months

A. Abstracts

1. All two point

2. Violation of restrictions

3. All one point

4. All zero point

5. Violation of suspension and/or revocation actions

B. Accidents

1. Fatal

2. Injury

3. Cited or responsible

4. Single vehicle

5. Night time (2000-0600 hours)
6. Total countable points

7. Total convictions

8. Total abstracts

9. Failures to appear in court
6. Alcohol and/or drugs

7. Total law enforcement reported

8. Total finacial responsibility

9. All accidents

- DMV post licensing control activity

A. Suspensions/revocations

1. Total duration of all mandatory suspensions/revocations

2. Number of IC suspensions

3. Number of DUI/drug suspensions/revocations

4. Number of FR suspensions/revocations

5. Total number of discretionary suspension or revocation actions

6. Duration of all negligent operator (discretionary) suspensions and/or revocations (reason codes 300-32.9, $450-451$, and 854 )

B. DMV hearings/interviews/reexaminations

1. Total number of discretionary S\&R hearings

2. Attended

3. Not attended

C. Reasons for any restriction change

1. Recidivism

2. Driver request 
D. Assigned to new DIA

1. Trained DIA

2. Project office

E. Chronology

1. Time to first violation

2. Time to first accident

3. Time to first probation failure (extension, suspension, revocation) 
APPENDIX C

Driver Descriptive Data

Sample size is indicated in the table titles as follows:

Sex of Probation Violators ${ }^{1}$

\begin{tabular}{l|r|r}
\hline \multirow{2}{*}{ Sex } & \multicolumn{2}{|c}{ Percent of } \\
\hline Males............. & $\begin{array}{c}\text { Drivers } \\
\text { surveyed }\end{array}$ & $\begin{array}{c}\text { Usable } \\
\text { responses }\end{array}$ \\
\hline Females.......... & 97.10 & 97.10 \\
Total............ & 2.90 & 2.90 \\
Total unusable... & 100.00 & 100.00 \\
\hline
\end{tabular}

Age of Probation Violators 1

\begin{tabular}{|c|c|}
\hline Age & Percent surveyed \\
\hline$<20 \ldots \ldots \ldots \ldots \ldots \ldots$ & 7.80 \\
\hline $20-24 \ldots \ldots \ldots \ldots \ldots \ldots \ldots$ & 48.20 \\
\hline $25-29, \ldots \ldots \ldots \ldots \ldots \ldots \ldots$ & 20.60 \\
\hline $30-34 \ldots \ldots \ldots \ldots \ldots \ldots$ & 9.50 \\
\hline $35-39 \ldots \ldots \ldots \ldots \ldots \ldots$ & 5.50 \\
\hline $40-44 . \ldots \ldots \ldots \ldots \ldots \ldots$ & 3.00 \\
\hline $45-49 \ldots \ldots \ldots \ldots \ldots \ldots \ldots$ & 1.80 \\
\hline $50-54 \ldots \ldots \ldots \ldots \ldots \ldots$ & 1.50 \\
\hline $55-59 \ldots \ldots \ldots \ldots \ldots \ldots$ & 1.00 \\
\hline $60-64 \ldots \ldots \ldots \ldots \ldots \ldots$ & .60 \\
\hline $65-69 . \ldots \ldots \ldots \ldots \ldots \ldots$ & .40 \\
\hline $70-74 \ldots \ldots \ldots \ldots \ldots \ldots$ & $<.10$ \\
\hline$>\quad 74 \ldots \ldots \ldots \ldots \ldots \ldots \ldots$ & .20 \\
\hline Total usable............ & 100.00 \\
\hline Total unusable........... & - \\
\hline
\end{tabular}

$I_{N}=3325$

$\bar{X}=26.69$ SD $=8.82$ median $=23.69$ mode $=22$ 
Probation Violator Occupations ${ }^{2}$

\begin{tabular}{|c|c|c|}
\hline \multirow[b]{2}{*}{ Occupation } & \multicolumn{2}{|c|}{ Percent } \\
\hline & $\begin{array}{l}\text { Drivers } \\
\text { surveyed }\end{array}$ & $\begin{array}{c}\text { Usable } \\
\text { responses } \\
\end{array}$ \\
\hline $\begin{array}{l}\text { Craftsman } \\
\text { foreman................... }\end{array}$ & 28.81 & 31.40 \\
\hline $\begin{array}{l}\text { Protessional } \\
\text { drivers................... }\end{array}$ & 12.33 & 13.40 \\
\hline Sales worker................. & 6.94 & 7.60 \\
\hline 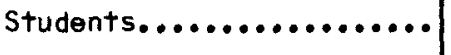 & 6.58 & 7.20 \\
\hline Operatives................. & 6.32 & 6.90 \\
\hline 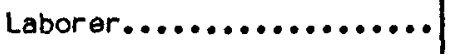 & 6.27 & 6.80 \\
\hline $\begin{array}{l}\text { Managers/ } \\
\text { of ficals................... }\end{array}$ & 3.58 & 3.90 \\
\hline Clerlcal.................. & 4.72 & 5.10 \\
\hline Service workers............ & 5.18 & 5.60 \\
\hline Proprietors............... & 2.54 & 2.80 \\
\hline other..................... & 8.14 & 9.30 \\
\hline Tota1................. & 91.41 & 100.00 \\
\hline Total unusable........... & 8.59 & - \\
\hline
\end{tabular}

Primary Vehicle ${ }^{2}$

\begin{tabular}{|c|c|c|}
\hline \multirow[b]{2}{*}{ Type } & \multicolumn{2}{|c|}{ Percent } \\
\hline & $\begin{array}{l}\text { Dr I vers } \\
\text { surveyed }\end{array}$ & $\begin{array}{c}\text { Usable } \\
\text { responses }\end{array}$ \\
\hline Automoblle................. & 54.35 & 56.83 \\
\hline Plckup/Jeep.................. & 16.99 & 17.77 \\
\hline 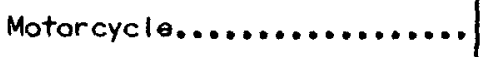 & 7.31 & 7.64 \\
\hline Panel truck................. & 6.63 & 6.93 \\
\hline 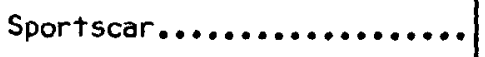 & 5.18 & 5.42 \\
\hline Truck...................... & 5.03 & 5.25 \\
\hline 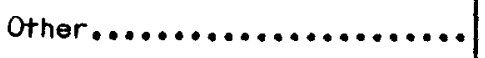 & .16 & .16 \\
\hline 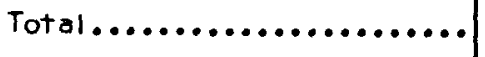 & 95.65 & 100.00 \\
\hline Total unusable.............. & 4.35 & - \\
\hline
\end{tabular}

$2_{N}=1930$ 
Annual Mileage ${ }^{2}$

\begin{tabular}{|c|c|c|}
\hline \multirow[b]{2}{*}{ Miles } & \multicolumn{2}{|c|}{ Percent } \\
\hline & $\begin{array}{l}\text { Drivers } \\
\text { surveyed }\end{array}$ & $\begin{array}{l}\text { Usable } \\
\text { responses }\end{array}$ \\
\hline$<5,001 \ldots \ldots \ldots \ldots \ldots \ldots \ldots$ & 3.68 & 3.75 \\
\hline $5,001-10,000, \ldots \ldots \ldots \ldots \ldots$ & 10.05 & 10.24 \\
\hline $10,000-15,000 \ldots \ldots \ldots \ldots \ldots$ & 14.72 & 14.99 \\
\hline $15,001-20,000, \ldots \ldots \ldots \ldots \ldots$ & 15.13 & 15.41 \\
\hline $20,001-25,000 \ldots \ldots \ldots \ldots \ldots$ & 15.70 & 15.99 \\
\hline $25,001-30,000, \ldots \ldots \ldots \ldots \ldots$ & 11.55 & 11.77 \\
\hline$>30,000 \ldots \ldots \ldots \ldots \ldots \ldots$ & 27.36 & 27.86 \\
\hline Total.................... & 98.19 & 100.01 \\
\hline Total unusable.............. & 1.81 & - \\
\hline
\end{tabular}

Time Perlod of Primary DrIving Need 2

\begin{tabular}{|c|c|c|c|c|}
\hline \multirow{3}{*}{ Day } & \multicolumn{4}{|c|}{ Percent of drivers responding } \\
\hline & \multicolumn{4}{|c|}{ TIme } \\
\hline & $\begin{array}{l}0001- \\
0600\end{array}$ & $\begin{array}{l}0601- \\
1200\end{array}$ & $\begin{array}{l}1201- \\
1800 \\
\end{array}$ & $\begin{array}{l}1801- \\
2400\end{array}$ \\
\hline 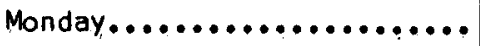 & 7.82 & 73.99 & 65.49 & 31.19 \\
\hline 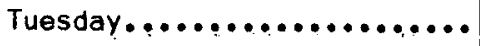 & 12.64 & 73.37 & 65.80 & 31.61 \\
\hline 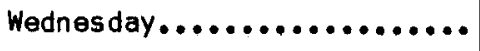 & 12.12 & 73.47 & 65.75 & 30.98 \\
\hline 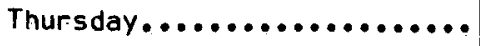 & 12.18 & 73.58 & 65.28 & 31.61 \\
\hline Friday.................. & 12.23 & 73.73 & 64.87 & 33.68 \\
\hline 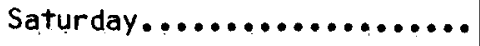 & 13.47 & 43.37 & 39.69 & 27.25 \\
\hline 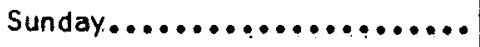 & 10.78 & 21.09 & 22.23 & 19.02 \\
\hline
\end{tabular}

Age of Primary Vehlcle

\begin{tabular}{|c|c|c|}
\hline \multirow[b]{2}{*}{ Years } & \multicolumn{2}{|c|}{ Percent } \\
\hline & $\begin{array}{l}\text { Drivers } \\
\text { surveyed }\end{array}$ & $\begin{array}{l}\text { Usable } \\
\text { responses }\end{array}$ \\
\hline $0-5 \ldots \ldots \ldots \ldots \ldots \ldots \ldots \ldots$ & 30.21 & 31.74 \\
\hline $6-10 \ldots \ldots \ldots \ldots \ldots \ldots \ldots \ldots \ldots$ & 34.87 & 36.64 \\
\hline $11-15 \ldots \ldots \ldots \ldots \ldots \ldots \ldots$ & 20.47 & 21.50 \\
\hline $16-20 \ldots \ldots \ldots \ldots \ldots \ldots \ldots \ldots$ & 6.48 & 6.80 \\
\hline 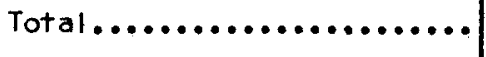 & 95.19 & 100.00 \\
\hline Total unusable............... & 4. 18 & - \\
\hline
\end{tabular}


Driving to "Let off Steam":

Incidents in Last Month ${ }^{2}$

\begin{tabular}{|c|c|c|}
\hline \multirow[b]{2}{*}{ Varlable } & \multicolumn{2}{|c|}{ Percent } \\
\hline & $\begin{array}{l}\text { Drivers } \\
\text { surveyed }\end{array}$ & $\begin{array}{c}\text { Usable } \\
\text { responses }\end{array}$ \\
\hline Yes................... & 8.24 & 8.50 \\
\hline No........................ & 88.39 & 91.50 \\
\hline Total $\ldots \ldots \ldots \ldots \ldots \ldots \ldots$ & 96.63 & 100.00 \\
\hline Total unusable............... & 3.37 & - \\
\hline
\end{tabular}

Driving After Three or More Drinks in Past Month ${ }^{2}$

\begin{tabular}{|c|c|c|}
\hline \multirow[b]{2}{*}{ Variable } & \multicolumn{2}{|c|}{ Percent } \\
\hline & $\begin{array}{l}\text { Drivers } \\
\text { surveyed }\end{array}$ & $\begin{array}{l}\text { Usable } \\
\text { responses }\end{array}$ \\
\hline Yes....................... & 11.30 & 11.50 \\
\hline No....................... & 86.74 & 88.50 \\
\hline 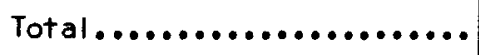 & 98.04 & 100.00 \\
\hline Total unusable.............. & 1.96 & - \\
\hline
\end{tabular}

- ........

Primary Driving Noeds 2

\begin{tabular}{|c|c|c|}
\hline \multirow[b]{2}{*}{ Varlable } & \multicolumn{2}{|c|}{ Percent } \\
\hline & $\begin{array}{l}\text { Drivers } \\
\text { surveyed }\end{array}$ & $\begin{array}{c}\text { Usable } \\
\text { responses }\end{array}$ \\
\hline To/from work.................. & 54.82 & 66.70 \\
\hline Occupation................... & 20.57 & 25.00 \\
\hline To/from school............... & 4.25 & 5.20 \\
\hline 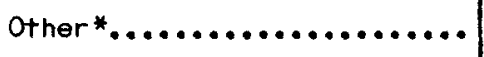 & 2.54 & 3.10 \\
\hline 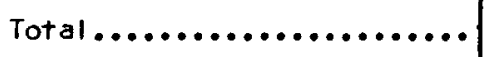 & 82.18 & 100.00 \\
\hline Total unusable.............. & 17.82 & - \\
\hline
\end{tabular}

* Includes personal buslness and pleasure driving.

$2 N=1930$ 
Marital Status of Probation Violators 2

\begin{tabular}{|c|c|c|}
\hline \multirow[b]{2}{*}{ Marltal Status } & \multicolumn{2}{|c|}{ Percent } \\
\hline & $\begin{array}{l}\text { Drivers } \\
\text { surveyed }\end{array}$ & $\begin{array}{l}\text { Usable } \\
\text { responses }\end{array}$ \\
\hline 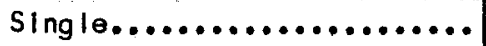 & 58.70 & 59.10 \\
\hline Marrled..................... & 27.51 & 27.70 \\
\hline 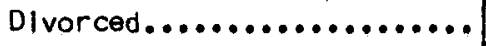 & 9.33 & 9.40 \\
\hline 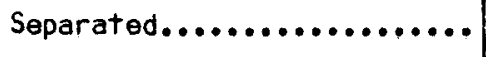 & 3.52 & 3.50 \\
\hline WI dowed...................... & .31 & .30 \\
\hline 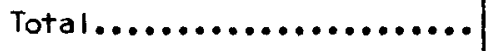 & 99.37 & 100.00 \\
\hline Total unusable.............. & .62 & - \\
\hline
\end{tabular}

Number of Nights Driven In Past Month ${ }^{2}$

\begin{tabular}{|c|c|c|}
\hline \multirow[b]{2}{*}{ Number } & \multicolumn{2}{|c|}{ Percent } \\
\hline & $\begin{array}{l}\text { Dr I vers } \\
\text { surveyed }\end{array}$ & $\begin{array}{l}\text { Usable } \\
\text { responses }\end{array}$ \\
\hline $0 \ldots \ldots \ldots \ldots \ldots \ldots \ldots$ & 9.07 & 10.09 \\
\hline $1-5, \ldots \ldots \ldots \ldots \ldots \ldots$ & 18.19 & 20.23 \\
\hline $6-10 \ldots \ldots \ldots \ldots \ldots \ldots \ldots$ & 19.64 & 21.84 \\
\hline $11-15 \ldots \ldots \ldots \ldots \ldots \ldots \ldots \ldots \ldots$ & 12.33 & 13.72 \\
\hline $16-20 \ldots \ldots \ldots \ldots \ldots \ldots \ldots$ & 12.02 & 13.37 \\
\hline $21-25 . \ldots \ldots \ldots \ldots \ldots \ldots \ldots$ & 6.84 & 7.61 \\
\hline $26-31 \ldots \ldots \ldots \ldots \ldots \ldots$ & 11.81 & 13.14 \\
\hline Total $\ldots \ldots \ldots \ldots \ldots \ldots \ldots$ & 89.90 & 100.00 \\
\hline Total unusable............. & 10.00 & - \\
\hline
\end{tabular}

$2 N=1930$ 
APPENDIX D

Bias Tests

The purpose of bias tests is to insure that drivers were not assigned to the hearing formats in such a way as to influence the outcome of the project. Implicit in such testing is: (1) a comparison of the distribution of preexisting conditions across treatment groups and (2) verification that any nonrandom distribution of priors did not moderate or amplify the effect of any hearing format.

Driver prior history.

Two statistical techniques were used to identify differences in the distributions of prior history variables across hearing formats which might indicate bias in the random assignment process. First, the obtained and expected distributions of three prior treatments (probation by mail, no-action hearings, and PLCRES hands-off control group assignment) were tested using the chi-square goodness-of-fit statistic. Expected values were based.on the distribution of terminal digits across prior treatments and PV hearing formats. Continuous variables from the driver record (e.g., prior convictions, prior suspensions, durations of time between events) were tested using discriminant analysis, with the assigned hearing format as the criterion.

The data contained in Table $A$ indicates that the three unique negligent operator treatments in driver prior histories (probation by mail, assignment to a hands-off control group for the PLCRES evaluation, or receipt of a no action hearing) were unevenly distributed across hearing formats. In the case of probation-by-mail, four license TDs were used, and it was not possible to distribute four TDs evenly across three PV treatments also assigned by TD. The statistical test indicates that the distribution of probation-by-mail subjects was not statistically different from that expected on the basis of TD $\left(x^{2}=4.16, \underline{d f}=2, p<.20\right)$. 
Table A

Observed Distributions of Three Unique Treatments in Driver Prior Histories, by Hearing Format

\begin{tabular}{l|c|c|c}
\hline \multirow{2}{*}{ Hearing format } & \multicolumn{3}{|c|}{ Treatment } \\
\cline { 2 - 4 } & $\begin{array}{c}\text { Probation } \\
\text { by maifl }\end{array}$ & $\begin{array}{c}\text { PLCRES control } \\
\text { group }\end{array}$ & $\begin{array}{c}\text { No action } \\
\text { hearing }\end{array}$ \\
\hline Standard hearing.... & 75 & 109 & 17 \\
Fixed restriction... & 123 & $9 ?$ & 4 \\
Sequential \\
restriction....... & 81 & 72 & 13 \\
Total............... & 279 & 273 & 34 \\
\hline
\end{tabular}

$x^{2}=4.16, \underline{d f}=2, p<.20$

$2 X^{2}=2.44, \underline{d f}=2, p<.30$

$3 x^{2}=4.77, \underline{d f}=2, p<.10$

There was no evidence that drivers who had served as PLCRES control groups subjects were unevenly distributed across hearing formats $x^{2}=2.44$, df $=$ 2, $p<.30$. Finally, while 2,604 drivers had received a no-action hearing between September, 1976 and February, 1977, only 34 of these drivers entered the PV project evaluation. This small number is not surprising, given the time lag between the two projects and the aggravated subsequent record that would be required for such drivers to receive a subsequent hearing and then violate the probation status resulting from that hearing. Drivers with prior no-action hearings were unevenly distributed across hearing formats, even when license TD distributions are taken into account, $x^{2}=4.77, \underline{d f}=2, p$ $<.10$.

Differences among drivers on age, prior convictions, prior accidents, prior suspensions and revocations, and prior hearings were also examined across hearing formats. One-way ANOVA tests indicated that the hearing formats differed significantly $(\mathrm{P}<.10)$ on at least 10 of these variables. Since these variables were highly intercorrelated, however, the ANOVA results were insufficient to identify those prior history variables likely to result in bias. The data were therefore examined using stepwise discriminant analysis.

Four variables emerged from this analysis as potential sources of bias in the traffic safety impact analysis. These were the number of prior hearings attended, prior hearings scheduled (but not attended), prior discretionary 
suspensions, and the duration of probation. The means on these variables for each hearing format are shown in Table B. Note that no consistent pattern exists in the four variables. There does appear, however, to be a direct positive relationship between the total number of hearings scheduled and the duration of probation. Differences between hearing formats on these variables were of sufficient magnitude for these variables to predominate in the discriminant function equation. The pre-existing group differences appeared to have little potential, however, for creating biases in the treatment impact analyses. The variance accounted for by hearing format in the discriminant function equations was less than $3 \%$. Only $39 \%$ of the drivers were correctly classified by hearing format using these equations.

Table B

Two-year Prior History Means by Variable and Hearing Format

\begin{tabular}{l|c|c|c}
\hline \hline \multirow{2}{*}{$\begin{array}{c}\text { Prior history } \\
\text { variable }\end{array}$} & $\begin{array}{c}\text { Standard } \\
\text { hearing }\end{array}$ & $\begin{array}{c}\text { Fixed } \\
\text { restriction }\end{array}$ & $\begin{array}{c}\text { Sequential } \\
\text { restriction }\end{array}$ \\
\hline $\begin{array}{c}\text { Total hearings } \\
\text { scheduled.......... }\end{array}$ & .96 & .91 & .95 \\
Attended......... & .81 & .76 & .75 \\
Unattended...... & .16 & .15 & .20 \\
$\begin{array}{c}\text { Discretionary } \\
\text { Suspensions or } \\
\text { revocations....... }\end{array}$ & .24 & .27 & .28 \\
$\begin{array}{c}\text { Duration of } \\
\text { probation (months) }\end{array}$ & 15.50 & .14 .00 & 14.78 \\
\hline
\end{tabular}


Four additional variables were also of interest, based on prior traffic safety research. These were prior total accidents, prior accidents with alcohol involvement, prior total convictions and prior major convictions. While none of these four variables entered the discriminant function equation, the later two were significantly different between groups. All were correlated $(p<.001)$ with at least one variable in the discriminant function.

Concerns regarding potential bias in the data analysis thus focused on several history variables. Although there were differences across the hearing formats on these variables, such differences alone do not constitute bias. Bias comes into existence only when mean differences across treatments exert an influence on subsequent accidents or convictions. The exploration of such influences was undertaken using contingency table analysis, specifically log-linear analysis.

Log-linear analysis and analysis of variance are related techniques in that both may be explained in terms of the general linear hypothesis model (Bishop, 1967). While all variables in a log-linear analysis are stated as discrete categories, the analysis of variance requires that dependent variables be continuous. In either technique, main effects and interactions may be isolated and tested. In analysis of variance these effects would include treatments (factors), covariates, and the dependent measures. Higher order effects in the log-linear analysis appear as interactions between background, factor treatment category, and dependent variable. These 3-way interactions are analogous to the previously mentioned MANCOVA slope differences. If significant, each provides evidence that the effect of treatment is not constant across all levels of the background factor or covariate. The results of the log-linear analyses are summarized in Table $C$. 
Table C

Significance of Chi-square Tests in the Log-linear Analysis for Total Accidents 1

\begin{tabular}{|c|c|c|c|}
\hline \multirow{2}{*}{\multicolumn{2}{|c|}{ Prior history variable }} & \multicolumn{2}{|c|}{ Significance } \\
\hline & & \multirow{3}{*}{$\begin{array}{c}\begin{array}{c}\text { Effect of } \\
\text { hearing format }\end{array} \\
.09\end{array}$} & $\begin{array}{l}\text { Interaction of } \\
\text { hearing format } \\
\text { and prior history }\end{array}$ \\
\hline Name & Categories & & \\
\hline Total accidents & None/one/two or more & & .06 \\
\hline DUI accidents & None/one or more & .09 & .12 \\
\hline Total convictions & $0-5 / 6-8 / 9$ or more & .09 & .55 \\
\hline Major convictions & None/one or more & .10 & .32 \\
\hline Probation-by-mail & Yes/no & .09 & .15 \\
\hline No action hearing & Yes/no & .09 & .15 \\
\hline PLC control group & Yes/no & .09 & .31 \\
\hline Hearings attended & None/one or more & .09 & .70 \\
\hline Hearings not attended & None/one or more & .13 & .05 \\
\hline Suspension \& revocation & None/one or more & .12 & .90 \\
\hline
\end{tabular}

1Categorized as none/one or more.

2 Main effect of hearing format on total accidents independent of prior history $x$ treatment interaction. 
The results indicate none of the prior treatments (probation by mail, PLCRES hands-off control group, no-action hearing) interaction with hearing format $(p>.10)$. Likewise, subsequent measures of tota1 convictions (not shown) were not influenced by any interaction between hearing and prior history variables or driver characteristics.

While prior total accidents were not differentially distributed across hearing formats $(\underline{p}=.75)$, this variable did interact with hearing format, on subsequent accident totals $(\mathrm{p}=.06)$. Thus, differences in subsequent accidents must be interpreted in light of both prior accidents and hearing format; i.e., there is a bias on these variables.

The variable, number of prior hearings not attended, was not eventy distributed across hearing formats $(p=.03)$. One possible explanation of this phenomenon was that drivers assigned to a hands-off control group at the PLCRES individual hearing level, as well as drivers who received probation by mail, would not be scheduled for a hearing, and thus would never fail to attend one during a portion of their prior driving history. Prior number of hearings not attended interacted with hearing format and influenced subsequent total accidents $(\underline{p}=.05)$.

It should be noted in closing that a relationship between prior and subsequent history variables was anticipated, and in fact was one basis for the use of covariates in the traffic saftey analyses. When prior history variables have different correlations with the dependent variables (e.g., accidents) in different hearing formats, however, the possibility exists that certain assumptions of MANCOVA are being violated. Thus, prior accidents or prior hearings not attended were not appropriate covariates and they were not used as such in the MANCOVA. Further use of the log-linear analyses to validate the MANCOVA results is discussed in the body of the report.

Data exclusion

Exclusion of drivers from the traffic safety analysis because of incomplete treatment or incorrect hearing formats had certain advantages in 
that it served to maintain the distinctions between treatments. In al1, 213 excluded cases were identified. Prior to completion of the report, it was recognized that such exclusion (to the extent that it was nonrandom) could have influenced the outcome of the traffic safety analyses.

A sample of 144 driver record printouts of excluded drivers was located in the project archives. The follow-up accident histories were coded for these drivers, and they were assigned to a hearing format on the basis of license $T D$, rather than the treatment actually received. Inclusion of these data had negligible impact on the accident means of the hearing formats as shown in Table D. These means may be compared to Table 12 in the body of the report, which shows the unadjusted accident means without the excluded cases.

Table D

One Year Unadjusted Means, Subsequent Traffic Accidents by Hearing Format, With Wrong or Incomplete Treatments Included

\begin{tabular}{c|c|c|c}
\hline \multirow{2}{*}{ Variable } & $\begin{array}{c}\text { Hearing format } \\
\text { Hearing }\end{array}$ & $\begin{array}{c}\text { Fixed } \\
\text { Restriction }\end{array}$ & $\begin{array}{c}\text { Sequential } \\
\text { Restriction }\end{array}$ \\
\hline $\begin{array}{c}\text { Fatal and injury } \\
\text { accidents........ }\end{array}$ & .057 & .084 & .103 \\
$\begin{array}{c}\text { Property damage } \\
\text { accidents........ }\end{array}$ & .122 & .111 & .131 \\
\hline
\end{tabular}

Statistical tests indicated that inclusion of the additional accidents in the hearing format totals did not cause the tallies to vary from those expected. The expected values were calculated by multiplying the number of drivers (including deleted cases) by the accident means shown in Table 9 in the body of the report. The results were not significant for either fatal and injury accidents $\left(x^{2}=.055\right.$, df $\left.=2\right)$ or for property damage only accidents $\left(x^{2}=\right.$ .054 , $d f=2)$. The authors concluded that the exclusion of drivers who did not receive their randomly assigned treatment did not bias the project results. 
APPENDIX E

MISCELLANEOUS TABLES

Table E

Proportions of Drivers in Standard Hearing Format Remaining Conviction-Free, by Project Licensing Action

(1 year follow-up)

\begin{tabular}{|c|c|c|c|c|}
\hline \multirow[b]{2}{*}{ Week } & \multicolumn{4}{|c|}{ Licensing Action } \\
\hline & No action & 30 day S\&R & 60 day S\&R & $90+$ day S\&R \\
\hline 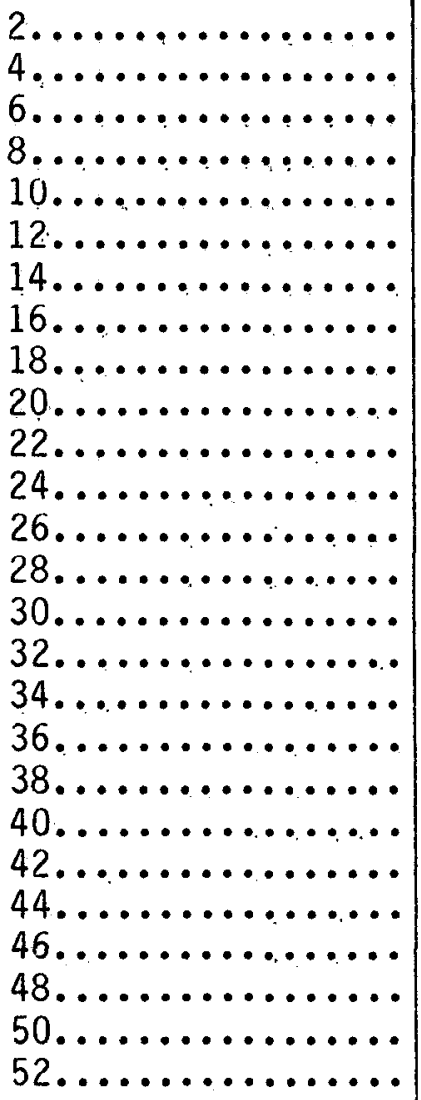 & $\begin{array}{l}.9447 \\
.9028 \\
.8490 \\
.8161 \\
.7818 \\
.7414 \\
.7130 \\
.6936 \\
.6682 \\
.6532 \\
.6323 \\
.6203 \\
.6039 \\
.5815 \\
.5695 \\
.5546 \\
.5277 \\
.5082 \\
.5007 \\
.4918 \\
.4783 \\
.4709 \\
.4634 \\
.4574 \\
.4514 \\
.4454\end{array}$ & $\begin{array}{l}.9458 \\
.9064 \\
.8867 \\
.8571 \\
.8079 \\
.7635 \\
.7438 \\
.7291 \\
.6946 \\
.6650 \\
.6552 \\
.6355 \\
.6059 \\
.5862 \\
.5665 \\
.5419 \\
.5222 \\
.5123 \\
.5025 \\
.4926 \\
.4828 \\
.4778 \\
.4680 \\
.4680 \\
.4631 \\
.4581\end{array}$ & $\begin{array}{l}.9377 \\
.8949 \\
.8444 \\
.7626 \\
.7121 \\
.6770 \\
.6342 \\
.6226 \\
.5992 \\
.5798 \\
.5564 \\
.5447 \\
.5331 \\
.5136 \\
.4942 \\
.4708 \\
.4553 \\
.4397 \\
.4280 \\
.4125 \\
.3852 \\
.3735 \\
.3696 \\
.3619 \\
.3541 \\
.3502\end{array}$ & $\begin{array}{l}.9268 \\
.8496 \\
.7886 \\
.7602 \\
.7276 \\
.6870 \\
.6667 \\
.6423 \\
.6016 \\
.5854 \\
.5732 \\
.5488 \\
.5407 \\
.5163 \\
.5081 \\
.4797 \\
.4553 \\
.4431 \\
.4146 \\
.4146 \\
.4024 \\
.3943 \\
.3821 \\
.3740 \\
.3659 \\
.3577\end{array}$ \\
\hline
\end{tabular}


Table F

Subsequent One-Ýear Traffic Accident and Conviction Adjusted Means

\begin{tabular}{c|c|c|c}
\hline \multicolumn{1}{c|}{ Variable } & \multicolumn{3}{|c}{ Hearing format } \\
\cline { 2 - 4 } & $\begin{array}{c}\text { Standard } \\
\text { hearing }\end{array}$ & $\begin{array}{c}\text { Fixed } \\
\text { restriction }\end{array}$ & $\begin{array}{c}\text { Sequential } \\
\text { restriction }\end{array}$ \\
\hline $\begin{array}{c}\text { Fatal and injury } \\
\text { accidents......... }\end{array}$ & .065 & .084 & .104 \\
$\begin{array}{c}\text { Property damage } \\
\text { accidents......... }\end{array}$ & .119 & .107 & .132 \\
$\begin{array}{c}\text { Two-point } \\
\text { convictions........ }\end{array}$ & .081 & .092 & .101 \\
$\begin{array}{c}\text { One-point } \\
\text { convictions....... }\end{array}$ & .900 & .945 & .934 \\
$\begin{array}{c}\text { Zero-point } \\
\text { convictions........ }\end{array}$ & .281 & .211 & .281 \\
\hline
\end{tabular}


Ilsted below are each of the questions included in the pV project survey. The responses are ranked according to the frequency with which they occurred in the survey. Ties are noted by identical ranks being assigned to different responses. The frequency of the most common responses is shown in parenthesis. ONLY responses occurring at least three times are included in the overview. Finally, all of the genexal comments are reported verbatim. A total of 83 questionnaires were malled to DIAs who had recelved the special PV training. The surveyed group included management and supervisorial personnel as well as DIAs actualiy conducting hearing. Sixty-three percent of the surveyed population returned their questionnaire.

Question 1. Estimate the amount of time required to have the ariver complete the prehearing questionnaire and to conduct the hearing:

Fixed Sequential

Responses 1. 60 minutes (12)

1. 60 minutes

(17)
2. 45 minutes (10)
2. 45 minutes
3. 15 minutes (5)
3. 15 minutes

question 2. List two things that made the prehearing questionnaire useful: Responses 1. Driving needs (hours of work, etc.). (18)

2. Personal history and job identification. (7)

3. Current address and telephone number. (5)

4. Did not find useful. (3)

Question 3. List two things that made using the prehearing questionnaire difficult.

Responses 1. Drivers did not understand how to complete (e.g., driving needs). (18)

2. Too much paper work and time being used. (9)

3. Size is too large. (5)

4. None--considered useful as is. (3) 
Question 4. List two things that could be done to improve the prehearing questionnaire:

Responses 1. Shorten, condense, and clarify instructions. (14)

2. Elininate 1t. (7)

3. No improvement needed.

(6)

Question 5. On the average, how many PV hearings would you estimate you conduct each week?

Responses 1. 1-3 (12)

2. 0 (6)

3. 4-6 (5)

4. $7-9$ (3)

Question 6. List two things that made the negotiated probation agreement useful:

Responses 1. Agreement makes it legal and binding. (9);

2. Driver felt part of decision-making process. (8)

3. Driver able to understand restriction wher negotiated with DIA. (3)

3. Document for subsequent reference. (3)

3. Able to tailor restriction to driver's needs. (3)

3. None. (3)

Question 7. List two things that made using the negotiated probation agreement difficult:

Responses 1. Driver refusing to sign or to help develw an appropriate restriction. (8)

2. Not difficult. (4)

2. Odd working hours or rotating work schedule. (4)

2. Not effective--driver will drive anyway. (i4)

3. DIAs must specify restriction to dictate then they feel driver should be off the road. (3) 
guestion 8. Ifst two things that could be done to improve the probation agreement.

Responses 1. No improvement necessary. (7)

2. Change wording (5)

-require reporting of violation within 10 days -conviction to read citation or violation

-more emphasis on "self-reporting"

3. Make optional or permit more flexibility in using restrictions or specifying length. (3)

3. Shorten or require less writing.

4. Eliminate.

(3)

Question 9. Iist two things that could be done to improve the current mode of driver follow-up:

Responses 1. None. (5)

2. Status card file maintained by clerk rather than DIA.

2. Eliminate phone call prior to next stage. (3)

2. Increase phone or mail contacts. (3)

Question 10. List two things you like most about having a probation violator referred back to you for a recidivist action:

Responses 1. Increased rapport and knowledge of drivers and their records. (18)

2. Enhanced DIA performance by providing feedback. (6)

3. Increased leverage to motivate driver improvement. (5)

4. None. (3)

Question 11. List two things you like least about having a probation violator referred back to you for a recidivist action: $\therefore$

Responses 1. Seeing same DIA may permit driver to claim bias or driver may respond to a different DIA personality or approach. (8)

2. None. (4)

3. Inclination to take more severe action since they saw driver before. (3)

3. Limitation on available licensing action (e.g., revocation). (3) 
Question 12. Iist two things that could be done to improve the current method of referring a probation violator back to you for a recidivist action:

Responses 1. None. (12)

2. Modify or improve office procedures concerning rescheduling.

3. Headquarters handle scheduling. (3)

Question 13. Iist things you feel could be done to improve the review of the hearing report and associated documents after a fixed or sequential hearing:

Responses 1. None. (13)

2. Properly train reviewer. (3)

3. Eliminate prehearing questionnaire and probation agreement. (3)

Question 14. Based upon your experience to date, which hearing format is the most effective?

Responses 1. Blank (10)

--each case different

2. Standard (9)

- others not effective since leaves dangerous drivers on the road

3. Fixed (8)

--sequential too complicated and tended to confuse driver

4. Sequential (5)

Question 15. What should be the principal factors considered when deciding wich type of hearing format to implement statewide?

Responses 1. Which hearing format produces positive traffic safety impact. (16)

2. Flexibility of DIA. (10)

3. Cost effectiveness. (9)

4. Simplicity and time. (6)

5. Acceptance by DIAs. (4)

5. No comment. (4) 
Question 16. List two additional types of training you feel would make you more effective in conducting PV hearings.

Responses 1. No comment or none. (15)

2. Regional DIA meetings to discuss their approaches or with headquarters representative to discuss procedural updates. (9)

3. Effective listening and interviewing.

4. Psychological training (personality theory, motivation, behavior modification)

5. Procedural duties (form completion, filing systems, typing, etc.). (3)

Question 17. If a task force is created to guide statewide implementation of either the fixed or sequential hearing formats, would you be wlling to participate?

Responses 1. No. (18)
2. Yes. (13)
2. No comment. (13)
3. Maybe. (8)

\section{GENERAL COMMENTS}

I like the P/N program, even with the paperwork "boon-doggle." I would like changes suggested in this questionnaire considered--and the referees encouraged to act, look, and behave more like social workers, helping the subject with a problem--not a judge, or high-handed politician, using the "authority" image. Also I would like a follow-up look at our individual effectiveness as a guide for future changes (stats, etc.).

This program could be effective on hard core chronic traffic violators. Should not be used generally because of the time consuming nature. Analysts are like "judges" and judges have probation officers to follow-up subjects. Analysts don't have any assistance in follow-up.

Surely there are times when a restriction is appropriate. In other instances a withdrawal is necessary. Let's not go one way or the other. The better approach is to permit the DIA to choose which treatment applies best in a given situation.

I feel that the fixed and sequential formats have definite advantages over the standard. They are more time consuming, but the following elements are 
worth considering: (1) when a person helps to create the agreement, he is more desirous of keeping it than when it is imposed; (2) it appeals to the "adult" (TA) more than fear, (parent [TA]) e.g., penalty of suspension; (3) it is more personal--and strengthened by a sense of partnership and cooperation; (4) it takes advantage of positive reinforcement.

It appeared that most caseload $P / V$ hearings were effective at the time of hearing. Possibly shorter follow up periods would be more effective. However. some persons could be identified immediately as poor candidates for the fixed and sequential treatment. Therefore, I believe the analyst should be trained and given more latitude in using his judgment to go with standard where maximum action could be taken.

I still firmly believe that the PV concept is excellent and should remain ongoing. Changes should be made, if warranted, to improve the structure or policy/procedure for handling each individual case.

Each type of format has good and bad points. Drivers are all different in their needs, causes for poor records, and excuses. It is hard to have one center line to try and hold all of them to. Or maybe I should say it is impossible to use the same rope to hold drivers to the center line.

Time: To dictate, assemble case, run H-6's, write probation phase, and warning and extension letters. Plus ending probation administration, should be allowed. The one hour on the schedule is not sufficient.

We need to return to reason, common sense, and actions that can be both understood and felt.

This could be a good program, but not with double standards. Field supv. do not follow the formats set forth. Headquarters assistance promised was never forthcoming. It was just a case of the blind leading the blind. Even headquarters didn't know what headquarters was doing.

The entire program is a waste of time insofar as results obtained. A large amount of clerical time is involved. The training given for the program was not well-planned and grossly inadequate. Furthermore, the approach to the probation violator gives the impression that no matter how many violations occur there will always be some kind of driving allowed. It is a waste of tax payer's money that could be better used by giving all analysts better training in holding hearings.

Overall, this task/job has been challenging and a change of pace. Many drivers have been grateful and cooperative. Many others, however, don't care 
at all, and simply go along with our "games." Unfortunately the DMV and myself are beating our heads against a wall in the interest of traffic safety. We should have the option open in some cases, of providing restricted licenses, but withdrawal is a bigger stick over the driver's head.

The overall concept of the probation violator (PV) program is excellent. Dr: Roger E. Hagen and DMV staff put on an outstanding traiaing program. The training program was one of the best I have attended in my DMV career; better than most of my university courses of instruction. Chief Brown's support was noted in the entire study period. The support of the administration was also evident in the support Dr. Hagen received. The PV program should be adopted with modifications as needed.

I would not expect my comments to gain an ear. The past has taught me that those who do not "go along with the program" always meet violent opposition. suffice to say: the prob. violator study is the worst example of mountainous, ineffective, red tape I have seen. I would like to see what the TV program "60 Minutes" could do with this turkey.

The program, in general, appears a moderate success. First time contacts--as in 311 short form hearings should sometimes be given a sterner approach. The "fixed" sequence of PV cases leaves too few options.

The $P / V$ hearings when properly conducted consumes more of the analysts time, however it appears that the extra effort and time is well worth the time and effort in bringing about a safer driver. The hearings must be monitored frequently to keep analysts alert to their responsibilities and follow prescribed procedures. After awhile they tend to get into a rut and start cutting the hearings short.

Depending on the outcome of the statistical analysis, it would seem to be time to combine all treatment alternatives and give analysts greater flexibility in available actions. This would encourage DIA entiousiasm and allow a better-tailored action for a given situation.

Due to an extended illness, my participation in the $P /$ program was shortened and I did very little follow-up work. However I found that most subjects were very enthusiastic and I feel that proper and timely follow-up would be effective in controls sought.

After having dealt with the program since its inception $I$ find it involves much too much repetitive paper work, which is very costly, as well as not effective from personal observation. If a person's attitude is cooperative give him an opportunity to demonstrate his ability to improve, but keep a large club over his head. If he continues to acquire vilolations don't be 
afrald to lower the club. Merely extending probation is a waste of time and actually encourages the subject to continue to drive in an unlawful manner. If he knows that severe action WILL BE TAKEN, he will think twice about taking a chance with traffic laws.

Regarding the cost factor I wonder if the following have been considered:

1. Time required to get the file and make notations whenever either the subject or Sacramento calls regarding additions to the record.

2. Time required to return a subject's call and get the file so that his questions can be answered.

3. KSR time when modifying restrictions or ending probation. A complete record must be obtained whenever any change of status is contemplated.

4. Additional clerk-typist and review time for each set.

5. Filing and refiling time.

6. Reading and trying to implement the great volume of memos coming out of sacramento for this one program alone. This makes it very difficult to recall if you should forget the old procedure or remember a new one. This, in turn, requires consulting the updated manual frequently to comply with the latest memos.

The overall program to me seemed a step in the right direction. Obviously errors/oversights/incomplete preparation lead to processing difficulties. Simplification of types to fixed only would better suit all as far as handling and timeliness is concerned. As to effectiveness for highway safety is concerned program evaluation is the only accurate decision. Would not voluntarily (enthusiastically) offer to do or participate in the program as it was outlined.

Shows promise in many cases--but initial and follow-up contacts are very time consuming.

The analyst should be allowed flexibility in applying restrictions and actions, as the analyst is in the best position to evaluate the driver's basic needs as related to traffic safety.

W1 th few exceptions, the program appears to be effective in driver safety Improvement as there have been more "graduates" than recidivists. 
CAL DMV RSS 12/81 425 REPRODUCED BY DMV, SACRAMENTO 